Published in final edited form as:

J Org Chem. 2016 November 18; 81(22): 10809-10824. doi:10.1021/acs.joc.6b01905.

\title{
Sequential One-Pot Multienzyme (OPME) Chemoenzymatic Synthesis of Glycosphingolipid Glycans
}

\author{
Hai Yu, ${ }^{a, b,}{ }^{*}$, Yanhong Li ${ }^{a, b}$, Jie Zeng ${ }^{b, c}$, Vireak Thon ${ }^{b, \dagger}$, Dung M. Nguyen ${ }^{b, \ddagger}$, Thao Ly ${ }^{b}$, Hui Yu \\ Kuang $^{\mathrm{b}, \pm}$, Alice $\mathrm{Ngo}^{\mathrm{b}}$, and Xi Chen ${ }^{\mathrm{b},{ }^{*}}$ \\ aGlycohub, Inc., 4070 Truxel Road, Sacramento, CA 95834, USA \\ bDepartment of Chemistry, University of California, One Shields Avenue, Davis, CA 95616, USA \\ 'School of Food Science, Henan Institute of Science and Technology, Xinxiang, Henan 453003, \\ China
}

\section{Abstract}

Glycosphingolipids are a diverse family of biologically important glycolipids. In addition to variations on the lipid component, more than 300 glycosphingolipid glycans have been characterized. These glycans are directly involved in various molecular recognition events. Several naturally occurring sialic acid forms have been found in sialic acid-containing glycosphingolipids, namely gangliosides. However, ganglioside glycans containing less common sialic acid forms are currently not available. Herein, highly effective one-pot multienzyme (OPME) systems are used in sequential for high-yield and cost-effective production of glycosphingolipid glycans, including those containing different sialic acid forms such as $\mathrm{N}$-acetylneuraminic acid (Neu5Ac), $\mathrm{N}$ glycolylneuraminic acid (Neu5Gc), 2-keto-3-deoxy-D-glycero-D-galacto-nononic acid (Kdn), and 8- $O$-methyl- $\mathrm{N}$-acetylneuraminic acid (Neu5Ac8OMe). A library of 64 structurally distinct glycosphingolipid glycans belonging to ganglio-series, lacto-/neolacto-series, and globo-/isogloboseries glycosphingolipid glycans is constructed. These glycans are essential standards and invaluable probes for bioassays and biomedical studies.

\section{TOC image}

\footnotetext{
*Corresponding Author: hyu@glycohubusa.com, xiichen@ucdavis.edu.

$\dagger$ Current address: Laboratory of Bacterial Polysaccharides, Food and Drug Administration, Bethesda, MD 20892, USA

\$Current address: Center for Neuroscience, University of California, Davis, CA 95616, USA

${ }^{ \pm}$Current address: College of Pharmacy, Touro University, Vallejo, CA 94592, USA

Supporting Information. ${ }^{1} \mathrm{H}$ and ${ }^{13} \mathrm{C}$ NMR spectra as well as HRMS chromatographs of synthesized glycans. This material is available free of charge via the Internet at http://pubs.acs.org.

Notes

HY, YL, and XC are co-founders of Glycohub, Inc., a company focused on the development of carbohydrate-based reagents, diagnostics, and therapeutics.
} 


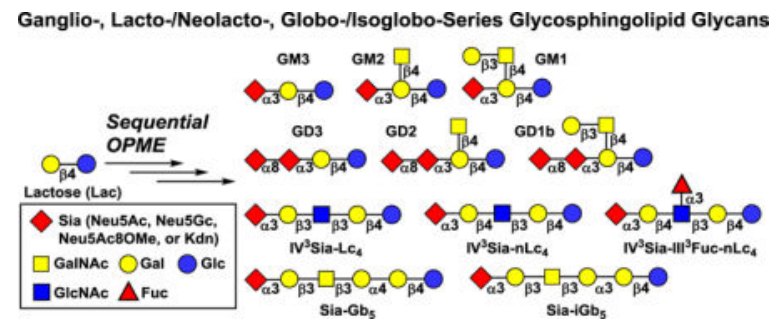

\section{Keywords}

carbohydrate; ganglioside; glycosphingolipid; one-pot multienzyme (OPME); oligosaccharide

\section{INTRODUCTION}

Glycosphingolipids are essential components of human plasma membrane. They are believed to be clustered in "lipid rafts" which are spatial mammalian cell membrane microdomains important for various biological processes including protein sorting, signal transduction, membrane trafficking, viral and bacterial infection, and cell-cell communications. ${ }^{1}$ Aberrant expression of glycosphingolipids has been found to be associated with glycosphingolipid storage diseases and cancer progression. ${ }^{2,3}$ For example, increased expression of GD3 and GM2 in melanoma, elevated levels of sialyl Lewis a and sialyl Lewis $\times$ in gastrointestinal cancers have been reported. ${ }^{4}$ In addition, a non-human sialic acid form, $\mathrm{N}$-glycolylneuraminic acid (Neu5Gc), is overexpressed on several types of human tumor cells. ${ }^{5-7}$ Some cancer-associated gangliosides have been developed as potential cancer markers, cancer vaccine candidates, ${ }^{8,9}$ and immunosuppressants. ${ }^{10}$

Glycosphingolipids exhibit a large structural heterogeneity with more than 300 different glycans characterized to date. They are divided into several subfamilies including ganglio-, lacto-, neolacto-, globo-, and isoglobo-series. ${ }^{11}$ The diverse glycan structures on glycosphingolipids have been found to be important for molecular recognition. Viruses and pathogenic bacteria adhesins use glycosphingolipids on the host cell surface to bind and invade epithelial cells, ${ }^{12}$ and the binding is microbe-specific for the glycan structure. ${ }^{13,14}$ For example, norovirus binds ganglioside GM1, but not other glycolipids. ${ }^{12}$ Cholera toxin also binds to GM1 on the cell surface. ${ }^{15,16}$ Botulinum toxin binds to GT1b and GQ1b. ${ }^{17}$ In addition, the binding of bacteria and viruses to gangliosides is specific to sialic acid forms. For example, Escherichia coli K99 fimbrial adhesin binds to GM3 containing Neu5Gc, but not $\mathrm{N}$-acetylneuraminic acid (Neu5Ac). ${ }^{18} \mathrm{Neu} 5 \mathrm{Gc}$-containing GM1 is a better ligand than Neu5Ac-containing GM1 for simian virus 40 (SV40). ${ }^{19}$ In addition to being key components in cell recognition, structurally diverse glycosphingolipids with different glycan structures are involved in cell signaling. ${ }^{20}$ Therefore, obtaining pure glycosphingolipid oligosaccharides will facilitate structure- activity studies of the glycan components of glycosphingolipids at the molecular level.

Glycosphingolipids for functional studies have been traditionally purified from animal tissues by extraction. ${ }^{21,22}$ Heterogeneity inherited from these purification processes generates complications in data analysis and identifying the ligand that is responsible for 
protein/antibody/cell-binding. Releasing glycans from glycosphingolipids purified from natural sources chemically ${ }^{21,23}$ or enzymatically ${ }^{24}$ suffers similarly from potential contaminations. Additional challenges are limited access to the structures that are less abundant in nature and the loss of labile groups during purification and glycan cleavage processes. ${ }^{25}$ Recently, significant progresses have been made on the synthesis of glycosphingolipids and their glycans. Several complex gangliosides have been synthesized by sophisticated chemical approaches. ${ }^{26}$ Chemically synthesized stage-specific embryonic antigen (SSEA-3 or $\mathrm{Gb}_{5}$ ) by pre-activation-based one-pot approach followed by enzymatic fucosylation and sialylation produced Globo-H and SSEA-4 (or V ${ }^{3} \mathrm{Sia}_{-} \mathrm{Gb}_{5}$ ) successfully. ${ }^{27}$ Globo-H has also been synthesized by total chemical synthesis, ${ }^{28}$ programmable reactivitybased one-pot strategy, ${ }^{29}$ and an enzymatic approach. ${ }^{30}$ Chemoenzymatic synthesis of Neu5Ac-containing GD3, GT3, GM2, GD2, GT2, GM1, and GD1a ganglioside glycans with a 2-azidoethyl linker has also reported. ${ }^{31}$ All of these glycans obtained by chemical and enzymatic approaches either have a lipid aglycon or are tagged with a non-cleavable linker. More recently, free reducing glycans have been released from glycosphingolipids after treatment with ozone followed by heating in neutral aqueous buffer ${ }^{23}$ but the types of the glycans produced by this method are limited as it relies on glycosphingolipids purified from natural sources. Despite the progresses in chemical and enzymatic synthesis, sialic acidcontaining glycosphingolipids and the corresponding glycan head groups containing naturally occurring sialic acid forms other than the most abundant Neu5Ac are not readily available and some have never been synthesized.

Most of the earlier glycosyltransferase-catalyzed synthesis of glycosphingolipid glycans ${ }^{27,29-32}$ relied on the use of expensive and not readily accessible sugar nucleotides as donor substrates. Here we report the use of highly efficient sequential one-pot multienzyme (OPME) systems ${ }^{33}$ for high-yield synthesis of complex glycosphingolipid glycans. In these systems, simple monosaccharides or derivatives can be activated by one or more enzymes to form desired sugar nucleotides for glycosyltransferase-catalyzed formation of target elongated glycans in one pot. Each OPME process adds one monosaccharide or derivative with a desired glycosidic linkage defined by the glycosyltransferase used. Multiple OPME reactions can be carried out to build up more complex glycan targets. As demonstrated here, a library of free oligosaccharides found as the glycan components of glycosphingolipids belonging to ganglio-series, lacto- and neolacto-series, as well as globo- and isoglobo-series are successfully obtained in high yields from lactose (Lac) using sequential OPME approaches (Scheme 1).

The most significant advantage of the OPME strategy is to allow easy introduction of structurally modified monosaccharides including challenging naturally occurring sialic acid forms to the desired glycan structures. As shown here, ganglioside glycans containing one or two sialic acid residues selected from four naturally occurring sialic acid forms, including $\mathrm{N}$-acetylneuraminic acid (Neu5Ac), $\mathrm{N}$-glycolylneuraminic acid (Neu5Gc), 2-keto-3-deoxyD-glycero-D-galacto-nononic acid (Kdn), and 8- $O$-methyl- $N$-acetylneuraminic acid (Neu5Ac8OMe), have been successfully obtained. The access to these structurally defined molecules will help to elucidate the important function of glycosphingolipid glycans including those containing naturally occurring sialic acid diversity which is not currently feasible. 


\section{RESULTS AND DISCUSSION}

\section{Chemoenzymatic synthesis of ganglioside glycans}

Gangliosides are a group of sialylated glycosphingolipids that are presented in all tissues but are particularly abundant in the nervous system ${ }^{34-36}$ where they affect neuronal plasticity during development, adulthood, and aging. ${ }^{37}$ They regulate immunological function. ${ }^{38}$ Some viruses and pathogenic bacteria adhesins use gangliosides on the host cell surface for binding and invasion. ${ }^{12}$ Lack of functional ganglioside metabolic genes leads to rare genetic disorders such as lysosomal glycosphingolipid storage diseases. ${ }^{39}$ Aberrant expressing of gangliosides is associated with cancer progression. ${ }^{2,3}$ Therefore, some cancer-associated gangliosides have been developed as potential cancer markers, cancer vaccine candidates, ${ }^{8,9}$ and immunosuppressants. ${ }^{10}$ Here, four natural occurring sialic acid forms including Neu5Ac, Neu5Gc, Kdn and Neu5Ac8OMe are introduced into the structures of the target ganglioside glycans. Both Neu5Ac (in humans and animals) and Neu5Gc (in animals and small amounts in humans) are common sialic acid forms found in gangliosides. ${ }^{40,41} \mathrm{Kdn}$ containing gangliosides have been found in the sperm, ${ }^{42}$ ovarian fluid, ${ }^{43}$ testis ${ }^{44}$ of rainbow trouts as well as in yak milk ${ }^{45}$ and possibly in porcine milk. ${ }^{46}$ Neu5Ac8OMe has been found in starfish as the components of gangliosides ${ }^{47,48}$ and human erythrocyte membrane. ${ }^{49}$ Its unique property of resistance to sialidases makes the glycans containing Neu5Ac8OMe moiety interesting for biofunctional studies.

\section{Synthesis of GM3 and GD3 glycans containing Neu5Ac, Neu5Gc, Kdn, and} Neu5Ac80Me using OPME sialylation systems-Sialic acid is a key component of gangliosides. Major sialyl linkages in gangliosides are a2-3- and a2-8-linkages although a2-6-sialyl linkage has also been found. ${ }^{50}$ We have developed efficient OPME sialylation approaches for the synthesis of a 2-3/6/8-linked sialosides containing different sialic acid forms and diverse underlying glycans. ${ }^{51-53}$ This approach was tested and applied for the synthesis of GM3 and GD3 glycans containing different sialic acid forms including Neu5Ac, Neu5Gc, Kdn, and Neu5Ac8OMe. For the ones with Neu5Ac form, commercially available inexpensive Neu5Ac was directly used for the synthesis in one-pot two-enzyme systems containing a suitable sialyltransferase and a cytidine $5^{\prime}$-monophosphate sialic acid (CMPSia) biosynthetic enzyme Neisseria meningitidis CMP-sialic acid synthetase (NmCSS) ${ }^{54}$ For the ones with other sialic acid forms including Neu5Gc, Kdn, and Neu5Ac8OMe, onepot three-enzyme systems were used. In these systems, in addition to NmCSS and a sialyltransferase, Pasteurella multocida sialic acid aldolase (PmNanA) was used to form the desired sialic acid forms from their corresponding chemically synthesized precursors and pyruvate.

As shown in Scheme 2, GM3 trisaccharide containing Neu5Ac (Neu5Aca2-3Lac, 1) was readily synthesized in an excellent $98 \%$ yield from lactose as the acceptor substrate and Neu5Ac as the donor precursor using a one-pot two-enzyme system (OPME1) containing NmCSS and Pasteurella multocida a 2-3-sialyltransferase 1 M144D mutant (PmST1 M144D) $)^{55}$ with decreased a2-3-sialidase and donor hydrolysis activity. On the other hand, GM3 trisaccharides containing Neu5Gc, Kdn, and Neu5Ac8OMe (Neu5Gca2-3Lac, 2; Kdna2-3Lac, 3; and Neu5Ac8OMea2-3Lac, 4) were synthesized from lactose and the 
corresponding sialic acid precursors $\mathrm{N}$-glycolylmannosamine (ManNGc), mannose (Man), and 5-O-methyl- $\mathrm{N}$-acetylmannosamine (ManNAc5OMe) ${ }^{56}$ respectively, in excellent yields (93\%, 95\%, and 91\%, respectively) using a one-pot three-enzyme system (OPME2) containing PmNanA, NmCSS, and PmST1 M144D.

Three synthetic GM3 trisaccharides Neu5Ac/Neu5Gc/Kdna2-3Lac (1-3) were further used as acceptor substrates for synthesizing nine GD3 tetrasaccharides using a Campylobacter jejuni a 2-3/8-sialyltransferase (CjCstII) ${ }^{52}$-dependent one-pot two-enzyme (OPME3 when Neu5Ac was used as the sialyltransferase donor precursor) or a one-pot three-enzyme (OPME4 when ManNGc or Man was used as the sialic acid precursor) a2-8-sialylation system. From Neu5Aca2-3Lac (1), OPME3 and OPME4 produced three GD3 glycans Neu5Aca2-8Neu5Aca2-3Lac (5), Neu5Gca2-8Neu5Aca2-3Lac (6), and Kdna28Neu5Aca2-3Lac (7) in good 85\%, 84\%, and 83\% yields, respectively. Similarly, from Neu5Gca2-3Lac (2), three GD3 glycans Neu5Aca2-8Neu5Gca2-3Lac (8), Neu5Gca28Neu5Aca2-3Lac (9), and Kdna2-8Neu5Aca2-3Lac (10) were synthesized in good 86\%, $83 \%$, and $81 \%$ yields, respectively. From Kdna2-3Lac (3), three GD3 glycans Neu5Aca2Kdna2-3Lac (11), Neu5Gca2-Kdna2-3Lac (12), and Kdna2-Kdna2-3Lac (13), were synthesized in $82 \%, 78 \%, 81 \%$ yields, respectively. Neu5Ac8OMea2-3Lac (4) has a $O$ methyl group at C-8 of the terminal sialic acid and cannot be used for adding an additional a2-8-linked sialic acid. In addition, CMP-Neu5Ac8OMe (formed in situ in the OPME4 system) was found as a poor donor substrate for CjCstII. Therefore, the corresponding GD3 glycan containing a terminal Neu5Ac8OMe was not produced.

\section{Synthesis of GM2 and GD2 glycans using an OPME $\beta 1-4-G a I N A c$ transfer} system-The synthesis of GM2 and GD2 glycans involved the use of Campylobacter jejuni $\beta 1-4$ GalNAcT (CjCgtA). The gene sequence of this enzyme was reported before. ${ }^{57} \mathrm{~A}$ recombinant $\mathrm{CjCgtA}$ was used previously for the synthesis of ganglioside oligosaccharides containing an ethyl azido aglycon. ${ }^{31}$ In our attempts to obtain an active CjCgtA and improve its expression level, a customer synthesized synthetic gene based on the Campylobacter jejuni CgtA-II protein sequence (GenBank accession number: AAL05993) was used as a template for polymerase-chain reaction (PCR) for cloning into pET22b(+) vector. In addition, series truncation of $\mathrm{N}$-terminal sequence was carried out. Compared to the full length construct and the constructs with N-terminal 10 amino acid (aa), 20 aa, or 25 aa truncation, the one with the N-terminal 15 aa had a higher expression level $(40 \mathrm{mg} / \mathrm{L}$ culture). Therefore, it was expressed and used for synthesis. The purified CjCgtA samples were not stable for storage at $4{ }^{\circ} \mathrm{C}$. In comparison, purified CjCgtA and lysates could be stored at $-20{ }^{\circ} \mathrm{C}$ for over a year without significant loss of activity. CjCgtA lysate was used directly in the enzymatic synthesis.

As shown in Scheme 3, four GM2 tetrasaccharides Neu5Aca2-3(GalNAc $\beta 1-4) L a c$ (14), Neu5Gca2-3(GalNAc $\beta 1-4) L a c(\mathbf{1 5})$, Kdna2-3(GalNAc $\beta 1-4) L a c ~(\mathbf{1 6})$, and Neu5Ac8OMea2-3(GalNAc $\beta 1-4)$ Lac (17) were readily obtained from four synthetic GM3 (1-4) trisaccharides in extremely high yields (95-99\%) using an OPME $\beta 1-4-G a l N A c$ activation and transfer system (OPME5) containing CjCgtA and uridine $5^{\prime}$-diphosphate $N$ acetylgalactosamine (UDP-GalNAc) biosynthetic enzymes including Bifidobacterium 
longum $N$-acetylhexosamine-1-kinase (BLNahK, NahK_ATCC55813), Pasteurella multocida $\mathrm{N}$-acetylglucosamine uridyltransferase (PmGlmU), Pasteurella multocida inorganic pyrophosphatase (PmPpA). All four enzymes were quite active in Tris- $\mathrm{HCl}$ buffer at $\mathrm{pH} 7.5$.

The same OPME5 system (Scheme 3) was also used for the synthesis of eight GD2 pentasaccharides (18-25) from GD3 tetrasaccharides $(\mathbf{5 - 1 0}, \mathbf{1 2}-\mathbf{1 3})$. Neu5Aca28Neu5Aca2-3(GalNAc $\beta 1-4) L a c$ (18), Neu5Gca2-8Neu5Aca2-3(GalNAc $\beta 1-4) L a c ~(19)$, Kdna2-8Neu5Aca2-3(GalNAcß1-4)Lac (20), Neu5Aca2-8Neu5Gca2-3(GalNAc $\beta 1-$

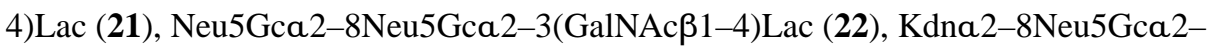
3(GalNAc $\beta 1-4) L a c ~(23)$, Neu5Gca2-8Kdna2-3(GalNAc $\beta 1-4) L a c ~(24)$, and Kdna28Kdna2-3(GalNAc $\beta 1-4)$ Lac (25), were obtained in excellent yields (nearly quantitative conversion).

\section{Synthesis of GM1 and GD1b glycans using an OPME $\beta 1-3$-galactosylation} system-As shown in Scheme 3, the synthesis of GM1 pentasaccharides (26-29) from GM2 tetrasaccharides (14-17) was achieved using a one-pot four-enzyme galactoseactivation and transfer system (OPME6) containing Campylobacter jejuni $\beta 1-3-$ galactosyltransferase $(\mathrm{CjCgtB})$ and uridine $5^{\prime}$-diphosphate galactose (UDP-Gal) biosynthetic enzymes including Escherichia coli galactokinase (EcGalK), ${ }^{58}$ Bifidobacterium longum UDP-sugar pyrophosphorylase (BLUSP), and PmPpA. GD1b hexasaccharides (3034) containing different sialic acid forms from the corresponding GD2 pentasaccharides (18, 19, 22, 23, and 25) were synthesized similarly. Excellent yields were achieved using 1.1 equivalent of galactose $(\mathrm{Gal})$ as the donor precursor by incubating reaction mixtures in Tris$\mathrm{HCl}(100 \mathrm{mM}, \mathrm{pH} 7.5)$ at $37{ }^{\circ} \mathrm{C}$ for 24 hours. It was found important not to add larger equivalents of Gal. Otherwise, an additional Gal would be added to the desired GM1 and GD1b products.

\section{Synthesis of lacto- and neolacto-series glycosphingolipid glycans}

Lacto- and neolacto-series glycosphingolipids differ only by one galactosyl linkage: Gal $\beta 1-$ $3 \mathrm{Lc}_{3}$ for $\mathrm{Lc}_{4}$ in the lacto-series and $\mathrm{Gal} \beta 1-4 \mathrm{Lc}_{3}$ for $\mathrm{nLc}_{4}$ in the neolacto-series. $\mathrm{Lc}_{4}$ is a precursor for fucosyltransferase-catalyzed formation of $\mathrm{Le}^{\mathrm{a}}$ and $\mathrm{Le}^{\mathrm{b}}$. Taking advantage of PmST1 M144D which was shown previously to be able to tolerate fucosylated acceptors with or without further $O$-sulfation, ${ }^{59}$ direct a2-3-sialylation of $\mathrm{Le}^{\mathrm{a}}$ can form sialyl $\mathrm{Le}^{\mathrm{a}}$ $\left(\mathrm{sLe}^{\mathrm{a}}\right)$. While $\mathrm{nLc}_{4}$ is a precursor for fucosyltransferase-catalyzed formation of $\mathrm{Le}^{\mathrm{x}}$ and $\mathrm{Le}^{\mathrm{y}}$, and a 2-3-sialyation of $\mathrm{Le}^{\mathrm{x}}$ using PmST1 M144D can form sialyl Le ${ }^{\mathrm{x}}\left(\mathrm{sLe}^{\mathrm{x}}\right)$. Neolactoseries glycosphingolipids have been found on the surface of human hematopoietic cells and are involved in the differentiation of hematopoietic cells. ${ }^{60} \mathrm{Le}^{\mathrm{a}}, \mathrm{sLe}^{\mathrm{a}}, \mathrm{Le}^{\mathrm{x}}$, and $\mathrm{sLe}^{\mathrm{x}}$ have been found to be overexpressed on some cancer cell surface. ${ }^{61-63}$

As shown in Scheme 4, LNnT Gal $\beta 1-4$ GlcNAc $\beta 1-3 \mathrm{Lac}$ (36) was synthesized from lactose using a sequential two-step $\mathrm{OPME}^{33}$ process similar to that was reported previously. ${ }^{64}$ Briefly, $\mathrm{Lc}_{3}$ trisaccharide GlcNAc $\beta 1-3 \mathrm{Lac} 35$ was synthesized from lactose (Lac) and $N$ acetylglucosamine (GlcNAc) in a 94\% yield using a one-pot four-enzyme GlcNAc activation and transfer system (OPME7) containing Neisseria meningitidis $\beta 1-3-N$ - 
acetylglucosaminyltransferase (NmLgtA) and uridine $5^{\prime}$-diphosphate $\mathrm{N}$-acetylglucosamine (UDP-GlcNAc) biosynthetic enzymes (the same set of enzymes for UDP-GalNAc biosynthesis in OPME5) including BLNahK (NahK_ATCC55813), PmGlmU, PmPpA. Lacto- $N$-neotetraose (LNnT) tetrasaccharide Gal $\beta 1-4 \mathrm{GlcNAc} \beta 1-3 \mathrm{Gal} \beta 1-4 \mathrm{Glc} 36$ was then synthesized from $\mathrm{Lc}_{3}(\mathbf{3 5})$ and galactose in an excellent (99\%) yield using a OPME galactose activation and transfer system (OPME8) ${ }^{64}$ containing Neisseria meningitidis $\beta 1-$ 4-galactosyltransferase (NmLgtB) and UDP-Gal biosynthetic enzyme including EcGalK, BLUSP, and PmPpA (the same set of UDP-Gal biosynthetic enzymes in OPME6).

With LNnT in hand, sialylated LNnT pentasaccharides containing Neu5Ac, Neu5Gc, Kdn, and Neu5Ac8OMe (37-40) were successfully synthesized using OPME1 sialylation system with Neu5Ac as the donor precursor or OPME2 sialylation system with ManNGc, Man, or ManNAc5OMe as the sialic acid precursor.

Similarly, sialylated lacto- $N$-tetraose (LNT) pentasaccharides containing Neu5Ac, Neu5Gc, $\mathrm{Kdn}$, and Neu5Ac8OMe (42-45) were obtained via OPME1 or OPME2 sialylation system using commercial available LNT (41) as the acceptor substrate and Neu5Ac, ManNGc, Man, and ManNAc5OMe, respectively, as donor precursors (Scheme 5).

Although sialylated $\mathrm{Le}^{\mathrm{x}}$ pentasaccharides $\mathbf{4 7 - 5 0}$ can be synthesized by fucosylation of sialylated LNnT 37-40, purification of the product from starting materials in these fucosylation reactions was found difficult due to their similarity in sizes and polarity. To simplify the production and purification processes, fucosylated LNnT 46 was synthesized and used as the acceptor substrate for PmST1 M144D-catalyzed OPME a2-3-sialylation. This was made feasible by a single mutation M144D introduced to PmST1 which made the a2-3-sialylation of fucosylated acceptors efficient by reducing donor hydrolysis and a2-3sialidase activity of PmST1. ${ }^{59}$ As shown in Scheme 6, Le ${ }^{\mathrm{x}}$ pentasaccharide Gal $\beta 1-$ 4(Fuca 1-3)GlcNAc $\beta 1-3 \mathrm{Lac}(\mathbf{4 6})$ was synthesized in a preparative-scale $(500 \mathrm{mg})$ in an excellent $94 \%$ yield from LNnT tetrasaccharide (36), using a one-pot three-enzyme fucose activation and transfer system (OPME9) containing Helicobacter pylori a 1-3fucosyltransferase $(\mathrm{Hp} 1-3 \mathrm{FT})^{55}$ and guanosine $5^{\prime}$-diphosphate fucose (GDP-Fuc) biosynthetic enzymes including a bifunctional Bacteroides fragilis L-fucokinase and guanidine $5^{\prime}$-diphosphate (GDP)-fucose pyrophosphorylase (BfFKP) ${ }^{65}$ and PmPpA. Sialylated $\mathrm{Le}^{\mathrm{x}}$ pentasaccharides $\mathbf{4 7 - 5 0}$ were then synthesized from 46 via OPME1 or OPME2 sialylation system with Neu5Ac, ManNGc, Man, or ManNAc5OMe as the sialyltransferase donor precursor.

\section{Synthesis of globo- and isoglobo-glycosphingolipid glycans}

The globo (Gb) and isoglobo (iGb) series glycosphingolipid glycans are built, respectively, on trisaccharides $\mathrm{Gb}_{3}$ (Gala1-4Lac) and $\mathrm{iGb}_{3}$ (Gala 1-3Lac) that differ by only one terminal Gal linkage. Globo-series glycosphingolipids are used as receptors by Shiga toxin, 66 verotoxins, and HIV adhesin gp120. ${ }^{67}$ They have also attracted much attentions due to their overexpression in cancer ${ }^{68}$ and accumulation in Fabry's disease. ${ }^{69}$ Tumor-associated Globo $\mathrm{H}$ antigen was initially identified from human breast cancer cell line MCF- $7^{70}$ and 
was later found in several human cancers. Globo H-based synthetic vaccines have shown promising results in clinical trials for breast and prostate cancers. ${ }^{71-74}$

As shown in Scheme 7, $\mathrm{Gb}_{3}$ trisaccharide Gala 1-4Lac (51) was readily obtained in an excellent $95 \%$ yield from Lac, Gal, adenosine $5^{\prime}$-triphosphate (ATP), and uridine $5^{\prime}$ triphosphate (UTP) using an OPME a 1-4-galactosylation system (OPME10) containing $N$. meningitidis a 1-4-galactosyltransferase (NmLgtC) ${ }^{75,76}$ and UDP-Gal biosynthetic enzymes including EcGalK, BLUSP, and PmPpA. On the other hand, $\mathrm{iGb}_{3}$ trisaccharide Gala 1-3Lac (52) was synthesized in an outstanding 99\% yield from Lac, Gal, ATP, and UTP using an OPME a 1-3-galactosylation system (OPME11) containing a recombinant bovine a 1-3GalT $(\mathrm{Ba} 1-3 \mathrm{GalT})^{77}$ and UDP-Gal biosynthetic enzymes including EcGalK, BLUSP, and PmPpA.

A bifunctional Haemophilus influenzae $\beta 1-3 \mathrm{GalT} / \beta 1-3 \mathrm{GalNAcT}$ (HiLgtD) ${ }^{78,79}$ was used to catalyze the transfer of GalNAc from in situ generated UDP-GalNAc to $\mathrm{Gb}_{3}(\mathbf{5 1})$ and $\mathrm{iGb}_{3}$ (52) in an OPME $\beta 1-3-G a l N A c$ transfer system (OPME12) containing HiLgtD and UDPGalNAc biosynthetic enzymes NahK, PmGlmU, and PmPpA to produce $\mathrm{Gb}_{4}(\mathbf{5 3}, 92 \%)$ and $\mathrm{iGb}_{4}(\mathbf{5 4}, 91 \%)$ tetrasaccharides, respectively, in excellent yields.

For the synthesis of $\mathrm{Gb}_{5}(\mathbf{5 5})$ and $\mathrm{iGb}_{5}(\mathbf{5 6})$ pentasaccharides by adding a $\beta 1$-3-linked Gal to $\mathrm{Gb}_{4}(\mathbf{5 3})$ and $\mathrm{iGb}_{4}(\mathbf{5 4})$ tetrasaccharides, respectively, the bifunctional HiLgtD (having both $\beta 1-3-G a l$ and $\beta 1-3-G a l N A c$ transferase activities) was initially tested. However, it was found that HiLgtD-catalyzed reaction for forming pentasaccharides was very low. In comparison, $\mathrm{CjCgtB}$ was found to be able to catalyze the transfer of Gal from UDP-Gal to $\mathrm{Gb}_{4}$ to form $\mathrm{Gb}_{5}$ in moderate yields. Therefore, $\mathrm{Gb}_{5}(\mathbf{5 5})$ and $\mathrm{iGb}_{5}(\mathbf{5 6})$ pentasaccharides were synthesized from $\mathrm{Gb}_{4}(\mathbf{5 3})$ and $\mathrm{iGb}_{4}(\mathbf{5 4})$ tetrasaccharides using $\mathrm{CjCgtB}$-containing OPME6 in $61 \%$ and $45 \%$ yields, respectively.

$\mathrm{Gb}_{5}(\mathbf{5 5})$ and $\mathrm{iGb}_{5}(\mathbf{5 6})$ pentasaccharides were then used as the acceptor substrates in PmST1 M144D-containing OPME a2-3-sialylation (OPME1 or OPME2) systems to produce sialylated $\mathrm{Gb}_{5}(\mathbf{5 7 - 6 0}, 78-86 \%)$ and sialylated $\mathrm{iGb}_{5}(\mathbf{6 1 - 6 4}, 71-85 \%)$

hexasaccharides containing Neu5Ac, Neu5Gc, Kdn, and Neu5Ac8OMe sialic acid forms, respectively, with good yields.

\section{Enzymatic reaction conditions and purification processes}

A pH range of 8.0-8.5 was found to be optimal and Tris-HCl buffer (100 mM, pH 8.5) was used in the OPME sialylation systems for the synthesis of desired sialosides. In comparison, a pH range of 7.5-8.0 was found to be more suitable and Tris- $\mathrm{HCl}$ buffer $(100 \mathrm{mM}, \mathrm{pH} 8.0)$ was used in NmLgtB-containing OPME reaction for the synthesis of LNnT (36). On the other hand, Tris-HCl buffer (100 mM, pH 7.5) was used in CjCgtA-containing OPME GalNAc-transfer system for the production of GM2 and GD2, NmLgtA-catalyzed GlcNActransfer system for the synthesis of $\mathrm{Lc}_{3}$ (GlcNAc $\beta 1-3 \mathrm{Lac}$ ), and other OPME galactosylation (including CjCgtB-catalyzed production of GM1, GD1b, Gb 5 , and $\mathrm{iGb}_{5}, \mathrm{Ba} 1-3 \mathrm{GalT} /$ NmLgtC/HiLgtD-catalyzed OPME galactosylation for the production of $\mathrm{Gb}_{3}, \mathrm{iGb}_{3}, \mathrm{~Gb}_{4}$, and $\left.\mathrm{iGb}_{4}\right)$. OPME fucosylation of LNnT was also carried out at Tris-HCl buffer $(100 \mathrm{mM}$, $\mathrm{pH}$ 7.5). Reactions were carried out at $37^{\circ} \mathrm{C}$ or at room temperature and were completed in 
a time frame of $2-48 \mathrm{~h}$. The reaction progress was monitored by thin-layer chromatography (TLC) and mass spectrometry (MS).

The combinations of various columns were used to purify target glycans from OPME reactions. A simple silica gel column followed by a final gel filtration column packed with Bio-gel P2 resin were used to purify $\mathrm{Gb}_{3}, \mathrm{iGb}_{3}, \mathrm{~Gb}_{4}$, and $\mathrm{iGb}_{4}$ glycans (51-54). For purifying GM3 trisaccharides (1-4), $\mathrm{Lc}_{3}$ trisaccharide (35), $\mathrm{nLc}_{4}$ tetrasaccharide (36), and $\mathrm{Le}^{\mathrm{x}}$ pentasaccharide (46), a Bio-gel P2 gel filtration column followed by a silica gel column and a final gel filtration column for desalting were used. For purifying sialylated LNnT, LNT, $\mathrm{Le}^{\mathrm{x}}(\mathbf{3 7 - 5 0})$ as well as $\mathrm{Gb}_{5}(\mathbf{5 5}), \mathrm{iGb}_{5}(\mathbf{5 6})$, and their sialylated glycans (57-64), Biogel P2 gel filtration column followed by high-performance liquid chromatography (HPLC) purification with a reverse-phase C18 column was used. For purifying GD3 tetrasaccharides (5-13), sialyl Le ${ }^{\mathrm{x}}$ hexasaccharides (47-50), Bio-gel P2 gel filtration column followed by silica gel column and HPLC purification with a reverse-phase C18 column was used. For purifying GM2 tetrasaccharides (14-17), GD2 pentasaccharides (18-25), GM1 pentasaccharides (26-29), and GD1 hexasaccharides (30-34), Bio-gel P2 gel filtration column followed by HPLC purification using an XBridge BEH amide column was used. We have also found that the addition of a commercially available alkaline phosphatase from bovine intestinal mucosa to reaction mixture after glycosylation reactions could efficiently break down nucleotides byproducts (e.g. ADP, AMP, UDP, UMP, and GDP) byproducts and make the purification procedures much easier.

\section{CONCLUSIONS}

In conclusion, we have successfully applied sequential one-pot multienzyme (OPME) systems for high-yield and cost-effective production of glycosphingolipid glycans including those belonging to the ganglio-, lacto-, neolacto-, globo-, and isoglobo-series. The OPME approaches allow easy introduction of naturally occurring structurally modified diverse sialic acid forms to glycosphingolipid glycans. These glycans are essential standards for glycan analysis and critical probes for bioassays and biomedical studies for developing novel carbohydrate-based diagnostics and therapeutics.

\section{EXPERIMENTAL SECTION}

\section{Materials and general methods}

All reagents were purchased from commercial sources and used without further purification unless stated otherwise. ${ }^{1} \mathrm{H}$ and ${ }^{13} \mathrm{C}$ spectra were measured in the solvent stated at $800 \mathrm{MHz}$, and $200 \mathrm{MHz}$, respectively. Chemical shifts are quoted in parts per million (ppm) and coupling constants ( $\mathrm{J})$ are given in Hertz (Hz). Multiplicities are abbreviated as br (broad), $\mathrm{s}$ (singlet), d (doublet), t (triplet), q (quartet), and m (multiplet) or combinations thereof. High resonance mass spectrometry samples were analyzed by electrospray ionization mass spectrometry in positive mode or negative mode using flow-injection analysis. Glass-backed TLC plates (Silica Gel 60 with a $254 \mathrm{~nm}$ fluorescent indicator) were used without further manipulation. Developed TLC plates were visualized with anisaldehyde sugar stain and heat provided by a hotplate. Silica gel flash column chromatography was performed using flash silica gel $(40-63 \mu \mathrm{m})$ and employed a solvent polarity correlated with TLC mobility. Gel 
filtration chromatography was performed with a column $(100 \mathrm{~cm} \times 2.5 \mathrm{~cm})$ packed with BioGel P-2 Fine resins.

Cloning of CjCgtA-His ${ }_{6}$ - Synthetic DNA based on Campylobacter jejuni CgtA-II protein sequence (GenBank accession number: AAL05993) and optimized for Escherichia coli was customer synthesized by Biomatik. It was used as a template for target gene amplification of the full-length and $\mathrm{N}$-terminal truncated constructs by polymerase chain reactions (PCRs) for cloning into pET22b(+) vector. The primers used were reverse $5^{\prime}$ CAGCGTCGACTTTGATCTCACCCTGAAACTTC TTCAG-3' (Sall restriction site is underlined); full length CgtA-His ${ }_{6}$ forward $5^{\prime}$ -

GATCCATATGCTGAAAAAGATTATCAGCCTGT ACAAG-3' (Ndel restriction site is underlined); $\triangle 10 \mathrm{CgtA}$-His ${ }_{6}$ forward $5^{\prime}$-GATCCATATGCGCTACAGCATCAGCAAGAAAC TGGTG-3' (NdeI restriction site is underlined); $\triangle 15 \mathrm{CgtA}-\mathrm{His}_{6}$ forward $5^{\prime}$ GATC CATATGAAGAAACTGGTGCTGGACAAC GAGCAC-3' (Ndel restriction site is underlined); $\triangle 20 \mathrm{CgtA}-\mathrm{His}_{6}$ forward $5^{\prime}$ -

GATCCATATGGACAACGAGCACTTTATTAAGG-3' (NdeI restriction site is underlined). PCRs for amplifying the target gene were each performed in a $50 \mu \mathrm{L}$ reaction mixture containing plasmid DNA (10 ng), forward and reverse primers ( $0.2 \mu \mathrm{M}$ each), $1 \times$ Herculase buffer, dNTP mixture $(0.2 \mathrm{mM})$, and $5 \mathrm{U}(1 \mu \mathrm{L})$ of Herculase-enhanced DNA polymerase.

The reaction mixture was subjected to 30 cycles of amplification at an annealing temperature of $55^{\circ} \mathrm{C}$. The resulted PCR product was purified and double digested with $\mathrm{NdeI}$ and $\mathrm{SaI}$ restriction enzymes. The purified and digested PCR product was ligated with the predigested pET22b(+) vector and transformed into E. coli DH5a electrocompetent cells. Selected clones were grown for minipreps and characterized by restriction mapping. Positive construct was transformed into E. coli BL21 (DE3) chemical component cells.

\section{Expression and purification of enzymes involved in the synthesis-This was} carried out similarly to those reported previously. ${ }^{54,55,80}$ Briefly, E. coli BL21 (DE3) strains harboring the recombinant plasmid with target gene was cultured in $50 \mathrm{~mL}$ Luria-Bertani (LB) rich medium $(10 \mathrm{~g} / \mathrm{L}$ tryptone, $5 \mathrm{~g} / \mathrm{L}$ yeast extract, and $10 \mathrm{~g} / \mathrm{L} \mathrm{NaCl})$ containing 0.1 $\mathrm{mg} / \mathrm{mL}$ ampicillin with rapid shaking $(220 \mathrm{rpm})$ at $37^{\circ} \mathrm{C}$ overnight. Then $15 \mathrm{~mL}$ of the overnight cell culture was transferred into $1 \mathrm{~L}$ of LB rich medium with $0.1 \mathrm{mg} / \mathrm{mL}$ ampicillin and incubated at $37^{\circ} \mathrm{C}$. When the $\mathrm{OD}_{600 \mathrm{~nm}}$ of the cell culture reached $0.8-1.0$, isopropyl-1-thio- $\beta$-D-galactopyranoside (IPTG, $0.1 \mathrm{mM}$ ) was added to induce the overexpression of the recombinant enzyme, which was followed by incubation at $20^{\circ} \mathrm{C}$ with shaking (190-250 rpm) for $20 \mathrm{~h}$. Cells were collected by centrifugation at $4000 \mathrm{rpm}$ for $2 \mathrm{~h}$ at $4{ }^{\circ} \mathrm{C}$. Harvested cells were resuspended with lysis buffer $(100 \mathrm{mM}$ Tris- $\mathrm{HCl}$ buffer, $\mathrm{pH}$ 8.0, containing $0.1 \%$ Triton X-100). The cells were broken by sonication to obtain cell lysate which was centrifuged at $12,000 \mathrm{rpm}$ for $15 \mathrm{~min}$ at $4{ }^{\circ} \mathrm{C}$. The supernatant was collected and loaded onto a $\mathrm{Ni}^{2+}$-NTA affinity column pre-equilibrated with a binding buffer $(50 \mathrm{mM}, \mathrm{pH}$ 7.5, Tris- $\mathrm{HCl}$ buffer, $5 \mathrm{mM}$ imidazole, $0.5 \mathrm{M} \mathrm{NaCl}$ ). The column was washed with 10 column volumes of binding buffer and 10 column volumes of washing buffer $(50 \mathrm{mM}$ Tris$\mathrm{HCl}$ buffer, $\mathrm{pH} 7.5,20 \mathrm{mM}$ imidazole, $0.5 \mathrm{M} \mathrm{NaCl}$ ). The target protein was eluted using Tris- $\mathrm{HCl}$ buffer (50 mM, pH 7.5) containing $200 \mathrm{mM}$ of imidazole and $\mathrm{NaCl}(0.5 \mathrm{M})$. 
General procedures for OPME synthesis of GM3 glycans (4 compounds)—Lac (20 mM, 1 eq.), Neu5Ac or a sialic acid precursor (ManNGc, mannose, or ManNAc5OMe, 1.5 eq.) with sodium pyruvate ( 7.5 eq.) were incubated at $37^{\circ} \mathrm{C}$ in a Tris- $\mathrm{HCl}$ buffer (100 $\mathrm{mM}, \mathrm{pH}$ 8.5) containing CTP (1.5 eq.), $\mathrm{MgCl}_{2}(20 \mathrm{mM}), \mathrm{NmCSS}(0.15 \mathrm{mg} / \mathrm{mL}), \mathrm{PmST} 1$ M144D $(0.3 \mathrm{mg} / \mathrm{mL})$, with or without PmNanA $(0.2 \mathrm{mg} / \mathrm{mL}$, omit if Neu5Ac was used). The reaction was monitored by TLC with a developing reagent constituted of $i$ -

PrOH: $\mathrm{H}_{2} \mathrm{O}: \mathrm{NH}_{4} \mathrm{OH}=5: 2: 1$ (by volume) and stained with $p$-anisaldehyde sugar Reactions were typically completed in 12-24 h. Upon completion, to the reaction mixture was added the same volume of ethanol and incubated at $4{ }^{\circ} \mathrm{C}$ for $30 \mathrm{~min}$ before the mixture was centrifuged to remove precipitates. The supernatant was concentrated and passed through a BioGel P-2 gel filtration column and eluted with degassed water. The fractions containing the product were collected, concentrated, and further purified by silica gel column (EtOAc: $\mathrm{MeOH}: \mathrm{H}_{2} \mathrm{O}, 4: 2: 1$ ). The collected fractions were concentrated and passed through the gel filtration column again to obtain the desired GM3 glycans (yield from 91\% to 98\%).

Neu5Aca2-3Lac (1): $2.1 \mathrm{~g}$, yield 98\%; white solid. ${ }^{1} \mathrm{H}$ NMR $\left(800 \mathrm{MHz}, \mathrm{D}_{2} \mathrm{O}\right) \delta 5.21(\mathrm{~d}, J$ $=4.0 \mathrm{~Hz}, 0.4 \mathrm{H}), 4.65(\mathrm{~d}, J=8.0 \mathrm{~Hz}, 0.6 \mathrm{H}), 4.52(\mathrm{~d}, J=8.0 \mathrm{~Hz}, 1 \mathrm{H}), 4.11-3.26(\mathrm{~m}, 19 \mathrm{H})$, $2.74(\mathrm{dd}, J=12.0$ and $4.8 \mathrm{~Hz}, 1 \mathrm{H}), 2.02(\mathrm{~s}, 3 \mathrm{H}), 1.79(\mathrm{t}, J=12.0 \mathrm{~Hz}, 1 \mathrm{H}) ;{ }^{13} \mathrm{C}$ NMR $(200$ $\left.\mathrm{MHz}, \mathrm{D}_{2} \mathrm{O}\right) \delta 174.87,173.77,102.49,99.66,95.65,91.70,78.15,78.01,75.35,75.05$, 74.68, 74.20, 73.67, 72.74, 71.65, 71.26, 71.02, 69.97, 69.24, 68.24, 67.96, 67.33, 62.44, 60.91, 59.93, 59.78, 51.55, 39.51, 21.92. HRMS (ESI) $\mathrm{m} / z$ calcd for $\mathrm{C}_{23} \mathrm{H}_{38} \mathrm{NO}_{19}(\mathrm{M}-\mathrm{H})$ 632.2038, found 632.2036. NMR data were consistent with those reported in the literature. ${ }^{53}$

Neu5Gca2-3Lac (2): $360 \mathrm{mg}$, yield 93\%; white solid. ${ }^{1} \mathrm{H}$ NMR (800 MHz, $\left.\mathrm{D}_{2} \mathrm{O}\right) \delta 5.21$ $(\mathrm{d}, J=4.0 \mathrm{~Hz}, 0.4 \mathrm{H}), 4.64(\mathrm{~d}, J=8.0 \mathrm{~Hz}, 0.6 \mathrm{H}), 4.51(\mathrm{~d}, J=8.0 \mathrm{~Hz}, 1 \mathrm{H}), 4.10(\mathrm{~s}, 2 \mathrm{H}), 4.10$ $3.26(\mathrm{~m}, 19 \mathrm{H}), 2.75$ (dd, $J=12.0$ and $4.8 \mathrm{~Hz}, 1 \mathrm{H}), 2.02(\mathrm{~s}, 3 \mathrm{H}), 1.80(\mathrm{t}, J=12.0 \mathrm{~Hz}, 1 \mathrm{H})$; ${ }^{13} \mathrm{C}$ NMR $\left(200 \mathrm{MHz}, \mathrm{D}_{2} \mathrm{O}\right) \delta 175.65,173.82,102.51,102.49,99.68,95.63,91.72,78.16$, 78.01, 75.34, 75.05, 74.68, 74.20, 73.70, 73.66, 72.46, 71.74, 71.67, 71.02, 69.26, 69.24, $68.00,67.96,67.88,67.37,67.31,62.44,62.38,60.94,60.92,60.86,59.94,59.80,59.19$, 51.29, 51.22, 39.58, 39.55; HRMS (ESI) $\mathrm{m} / \mathrm{z}$ calcd for $\mathrm{C}_{23} \mathrm{H}_{38} \mathrm{NO}_{20}(\mathrm{M}-\mathrm{H}) 648.1987$, found 648.1984. NMR data were consistent with those reported in the literature. ${ }^{81}$

Kdna2-3Lac (3): $82 \mathrm{mg}$, yield 95\%; white solid. ${ }^{1} \mathrm{H}$ NMR (800 MHz, $\left.\mathrm{D}_{2} \mathrm{O}\right) \delta 5.19$ (d, $J=$ $4.0 \mathrm{~Hz}, 0.3 \mathrm{H}), 4.63(\mathrm{~d}, J=8.0 \mathrm{~Hz}, 0.7 \mathrm{H}), 4.50$ (d, $J=8.0 \mathrm{~Hz}, 1 \mathrm{H}), 4.07-3.24(\mathrm{~m}, 19 \mathrm{H}), 2.67$ (dd, $J=12.0$ and $4.8 \mathrm{~Hz}, 1 \mathrm{H}), 1.72(\mathrm{t}, J=12.0 \mathrm{~Hz}, 1 \mathrm{H}) ;{ }^{13} \mathrm{C} \mathrm{NMR}\left(200 \mathrm{MHz}, \mathrm{D}_{2} \mathrm{O}\right) \delta$ 173.93, 170.45, 102.50, 99.65, 95.65, 91.69, 78.13, 77.99, 75.32, 75.05, 74.68, 74.20, 73.78, 73.68, 71.95, 71.25, 71.02, 70.12, 69.97, 69.61, 69.23, 67.58, 67.28, 62.49, 60.91, 59.93, 59.79, 39.16; HRMS (ESI) $\mathrm{m} / \mathrm{z}$ calcd for $\mathrm{C}_{21} \mathrm{H}_{35} \mathrm{O}_{19}$ (M-H) 591.1773, found 591.1782. NMR data were consistent with those reported in the literature..$^{53}$

Neu5Ac80Mea2-3Lac (4): $12 \mathrm{mg}$, yield 91\%; white solid. ${ }^{1} \mathrm{H}$ NMR (800 MHz, $\left.\mathrm{D}_{2} \mathrm{O}\right) \delta$ $5.21(\mathrm{~d}, J=3.2 \mathrm{~Hz}, 0.4 \mathrm{H}), 4.66(\mathrm{~d}, J=8.0 \mathrm{~Hz}, 0.6 \mathrm{H}), 4.49$ (d, $J=8.0 \mathrm{~Hz}, 1 \mathrm{H}), 4.08-3.26$ (m, $19 \mathrm{H}), 3.48$ (s, 3H), 2.67 (dd, $J=12.0$ and $4.8 \mathrm{~Hz}, 1 \mathrm{H}), 2.02(\mathrm{~s}, 3 \mathrm{H}), 1.75(\mathrm{t}, J=12.0 \mathrm{~Hz}$, $1 \mathrm{H}) ;{ }^{13} \mathrm{C}$ NMR $\left(200 \mathrm{MHz}, \mathrm{D}_{2} \mathrm{O}\right) \delta 174.84,173.54,102.65,100.09,95.66,91.72,80.20$, $78.17,78.02,75.64,75.12,74.73,74.17,73.70,72.71,71.23,71.05,70.02,69.27,67.91$, 
67.59, 66.86, 60.92, 59.94, 59.80, 59.23, 57.40, 51.89, 39.70, 21.96; HRMS (ESI) $\mathrm{m} / \mathrm{z}$ calcd for $\mathrm{C}_{24} \mathrm{H}_{40} \mathrm{NO}_{19}(\mathrm{M}-\mathrm{H})$ 646.2195, found 646.2191.

\section{General procedures for OPME synthesis of GD3 glycans (9 compounds)-A}

GM3 glycan (20 mM, 1 eq.) as an acceptor for the a2-8-sialyltransferase activity of CjCstII, Neu5Ac or a sialic acid precursor (ManNGc, mannose, or ManNAc5OMe, 1.2 eq.) with sodium pyruvate (7.5 eq.) were incubated at $37^{\circ} \mathrm{C}$ in Tris- $\mathrm{HCl}$ buffer $(100 \mathrm{mM}, \mathrm{pH} 8.5)$, CTP (1.5 eq.), $\mathrm{MgCl}_{2}(20 \mathrm{mM}), \mathrm{NmCSS}(0.15 \mathrm{mg} / \mathrm{mL}), \mathrm{CjCstII}(0.35 \mathrm{mg} / \mathrm{mL})$ with or without PmNanA $(0.2 \mathrm{mg} / \mathrm{mL}$, omit if Neu5Ac was used). The reaction was carried out by incubating the solution in an incubator shaker at $37^{\circ} \mathrm{C}$ for $2 \mathrm{~h}$ (or at room temperature for overnight) with agitation at $140 \mathrm{rpm}$. The product formation was monitored by LC-MS. When an optimal yield was achieved, the reaction was quenched by adding the same volume of ice-cold ethanol and incubation at $4{ }^{\circ} \mathrm{C}$ for $30 \mathrm{~min}$. The mixture was centrifuged and the precipitates were removed. The supernatant was concentrated, passed through a BioGel P-2 gel filtration column and eluted with water to obtain sialoside mixtures. The fractions containing the product were collected and then purified by silica gel column (EtOAc:MeOH: $\mathrm{H}_{2} \mathrm{O}, 5: 3: 2$ ). The compound was further purified by a reverse-phase $\mathrm{C} 18$ column $(10 \mu \mathrm{m}, 21.2 \times 250 \mathrm{~mm})$ with a flow rate of $10 \mathrm{~mL} / \mathrm{min}$ using a gradient elution of $0-100 \%$ acetonitrile in water containing $0.05 \%$ formic acid over 20 minutes [Mobile phase A: $0.05 \%$ formic acid in water (v/v); Mobile phase B: acetonitrile (v/v); Gradient: $0 \%$ B for 3 minutes, $0 \%$ to $100 \%$ B over 12 minutes, $100 \%$ B for 2 minutes, then $100 \%$ to $0 \%$ B over 3 minutes]. HPLC purification was monitored by absorption at $210 \mathrm{~nm}$, and glycancontaining fractions were analyzed by TLC and MS. The fractions containing the pure product were collected and concentrated to obtain the final pure GD3 glycans (yields 78$86 \%)$.

Neu5Aca2-8Neu5Aca2-3Lac (5): $1.4 \mathrm{~g}$, yield 86\%; white solid. ${ }^{1} \mathrm{H}$ NMR (800 MHz, $\left.\mathrm{D}_{2} \mathrm{O}\right) \delta 5.21(\mathrm{~d}, J=3.2 \mathrm{~Hz}, 0.4 \mathrm{H}), 4.66(\mathrm{~d}, J=8.0 \mathrm{~Hz}, 0.6 \mathrm{H}), 4.52(\mathrm{~d}, J=7.2 \mathrm{~Hz}, 1 \mathrm{H}), 4.16-$ $4.07(\mathrm{~m}, 3 \mathrm{H}), 3.99-3.25(\mathrm{~m}, 23 \mathrm{H}), 2.77(\mathrm{dd}, J=4.8$ and $12.8 \mathrm{~Hz}, 1 \mathrm{H}), 2.67(\mathrm{dd}, J=4.8$ and $12.8 \mathrm{~Hz}, 1 \mathrm{H}), 2.06$ (s, 3H), 2.02 (s, 3H), $1.73(\mathrm{t}, J=12.0 \mathrm{~Hz}, 2 \mathrm{H}) .{ }^{13} \mathrm{C}$ NMR $(200 \mathrm{MHz}$, $\left.\mathrm{D}_{2} \mathrm{O}\right) \delta 174.88,174.86,174.81,173.39,173.24,102.57,102.54,100.41,100.08,100.07$, 95.70, 95.66, 91.75, 91.70, 78.08, 77.97, 77.83, 75.33, 75.10, 74.71, 74.14, 73.89, 73.76, $73.71,72.53,71.69,71.59,71.24,71.07,70.06,69.25,69.18,69.16,68.36,68.27,68.02$, $67.99,67.80,67.39,67.30,62.41,61.49,61.46,61.43,60.99,59.96,59.89,59.81,59.74$, $52.24,52.18,52.15,52.10,51.66,51.63,51.58,40.39,40.35,39.62,39.53,22.23,21.96$. HRMS (ESI) $\mathrm{m} / \mathrm{z}$ calculated for $\mathrm{C}_{34} \mathrm{H}_{55} \mathrm{~N}_{2} \mathrm{O}_{27}(\mathrm{M}-\mathrm{H})$ 923.2992, found 923.2983. NMR data were consistent with those reported in the literature. ${ }^{52}$

Neu5Gca2-8Neu5Aca2-3Lac (6): $52 \mathrm{mg}$, yield 84\%; white solid. ${ }^{1} \mathrm{H}$ NMR (800 MHz, $\left.\mathrm{D}_{2} \mathrm{O}\right) \delta 5.19(\mathrm{~d}, J=4.0 \mathrm{~Hz}, 0.4 \mathrm{H}), 4.64(\mathrm{~d}, J=8.0 \mathrm{~Hz}, 0.6 \mathrm{H}), 4.50(\mathrm{~d}, J=8.0 \mathrm{~Hz}, 1 \mathrm{H}), 4.16$ $(\mathrm{m}, 1 \mathrm{H}), 4.12(\mathrm{~m}, 1 \mathrm{H}), 4.10(\mathrm{~s}, 2 \mathrm{H}), 4.10(\mathrm{~s}, 2 \mathrm{H}), 4.06(\mathrm{~m}, 1 \mathrm{H}), 3.97-3.25(\mathrm{~m}, 23 \mathrm{H}), 2.77$ (dd, $J=12.0$ and $4.8 \mathrm{~Hz}, 1 \mathrm{H}), 2.66(\mathrm{dd}, J=12.0$ and $4.8 \mathrm{~Hz}, 1 \mathrm{H}), 2.05(\mathrm{~s}, 3 \mathrm{H}), 1.73(\mathrm{t}, J=$ $12.0 \mathrm{~Hz}, 1 \mathrm{H}), 1.723(\mathrm{t}, J=12.0 \mathrm{~Hz}, 1 \mathrm{H}) ;{ }^{13} \mathrm{C}$ NMR $\left(200 \mathrm{MHz}, \mathrm{D}_{2} \mathrm{O}\right) \delta 175.61,174.85$, 173.37, 173.26, 102.55, 102.53, 100.38, 100.05, 100.03, 95.67, 91.71, 78.10, 77.94, 77.78, $75.33,75.10,74.71,74.14,73.89,73.71,72.24,71.68,71.20,71.06,70.00,69.16,68.11$, 
67.91, 67.80, 67.32, 62.38, 61.44, 60.99, 60.84, 59.86, 52.14, 51.31, 40.42, 39.57, 22.19. HRMS (ESI) $\mathrm{m} / \mathrm{z}$ calculated for $\mathrm{C}_{34} \mathrm{H}_{55} \mathrm{~N}_{2} \mathrm{O}_{28}$ (M-H) 939.2941, found 939.2920.

Kdna2-8Neu5Aca2-3Lac (7): $39 \mathrm{mg}$, yield 83\%; white solid. ${ }^{1} \mathrm{H}$ NMR (800 MHz, $\mathrm{D}_{2} \mathrm{O}$ ) $\delta 5.20(\mathrm{~d}, J=4.0 \mathrm{~Hz}, 0.4 \mathrm{H}), 4.64(\mathrm{~d}, J=8.0 \mathrm{~Hz}, 0.6 \mathrm{H}), 4.51(\mathrm{~d}, J=8.0 \mathrm{~Hz}, 0.4 \mathrm{H}), 4.50(\mathrm{~d}, J$ $=8.0 \mathrm{~Hz}, 0.6 \mathrm{H}), 4.16-4.06(\mathrm{~m}, 3 \mathrm{H}), 3.97-3.26(\mathrm{~m}, 23 \mathrm{H}), 2.70(\mathrm{dd}, J=12.0$ and $4.8 \mathrm{~Hz}, 1 \mathrm{H})$, $2.66(\mathrm{dd}, J=12.0$ and $4.8 \mathrm{~Hz}, 1 \mathrm{H}), 2.05(\mathrm{~s}, 3 \mathrm{H}), 1.72(\mathrm{t}, J=12.0 \mathrm{~Hz}, 1 \mathrm{H}), 1.69(\mathrm{t}, J=12.0$ $\mathrm{Hz}, 1 \mathrm{H}) ;{ }^{13} \mathrm{C}$ NMR $\left(200 \mathrm{MHz}, \mathrm{D}_{2} \mathrm{O}\right) \delta 174.85,173.45,173.36,143.29,102.54,100.90$, 100.37, 100.06, 95.66, 91.71, 78.02, 77.96, 77.80, 75.33, 75.10, 74.70, 74.14, 73.88, 73.70, $73.52,71.91,71.20,71.06,70.27,70.00,69.69,69.19,69.15,67.80,67.63,67.33,62.49$, $61.42,60.98,59.87,59.72,59.29,52.14,39.92,39.55,22.19$. HRMS (ESI) $\mathrm{m} / \mathrm{z}$ calculated for $\mathrm{C}_{32} \mathrm{H}_{52} \mathrm{NO}_{27}$ (M-H) 882.2727, found 882.2719.

Neu5Aca2-8Neu5Gca2-3Lac (8): $121 \mathrm{mg}$, yield 86\%; white solid. ${ }^{1} \mathrm{H}$ NMR (800 MHz, $\left.\mathrm{D}_{2} \mathrm{O}\right) \delta 5.19(\mathrm{~d}, J=4.0 \mathrm{~Hz}, 0.3 \mathrm{H}), 4.63(\mathrm{~d}, J=8.0 \mathrm{~Hz}, 0.7 \mathrm{H}), 4.49(\mathrm{~d}, J=8.0 \mathrm{~Hz}, 1 \mathrm{H}), 4.17-$ $3.24(\mathrm{~m}, 28 \mathrm{H}), 2.73(\mathrm{dd}, J=4.8$ and $12.8 \mathrm{~Hz}, 1 \mathrm{H}), 2.67(\mathrm{dd}, J=4.8$ and $12.8 \mathrm{~Hz}, 1 \mathrm{H}), 1.99$ (s, 3H), 1.71 (t, $J=12.0 \mathrm{~Hz}, 2 \mathrm{H}) .{ }^{13} \mathrm{C}$ NMR $\left(200 \mathrm{MHz}, \mathrm{D}_{2} \mathrm{O}\right) \delta 175.94,174.86,174.84$, 174.60, 173.50, 173.29, 172.49, 170.61, 170.59, 102.60, 102.52, 101.94, 100.11, 100.04, $95.68,95.65,78.28,75.37,75.32,75.08,74.69,74.12,73.77,73.69,73.59,72.68,72.49$, $71.77,71.60,71.06,69.16,68.98,68.91,68.28,68.22,67.98,67.82,67.46,67.28,62.50$, $61.34,61.30,60.98,59.18,52.01,51.88,51.65,40.42,39.51,39.10,21.95,21.91$. HRMS (ESI) $\mathrm{m} / \mathrm{z}$ calculated for $\mathrm{C}_{34} \mathrm{H}_{55} \mathrm{~N}_{2} \mathrm{O}_{28}(\mathrm{M}-\mathrm{H})$ 939.2941, found 939.2935.

Neu5Gca2-8Neu5Gca2-3Lac (9): $76 \mathrm{mg}$, yield 83\%; white solid. ${ }^{1} \mathrm{H}$ NMR (800 MHz, $\left.\mathrm{D}_{2} \mathrm{O}\right) \delta 5.21(\mathrm{~d}, J=4.0 \mathrm{~Hz}, 0.4 \mathrm{H}), 4.64(\mathrm{~d}, J=8.0 \mathrm{~Hz}, 0.6 \mathrm{H}), 4.50(\mathrm{~d}, J=8.0 \mathrm{~Hz}, 0.4 \mathrm{H})$, 4.49 (d, $J=8.0 \mathrm{~Hz}, 0.6 \mathrm{H}), 4.18(\mathrm{~d}, J=16.8 \mathrm{~Hz}, 1 \mathrm{H}), 4.16(\mathrm{~m}, 1 \mathrm{H}), 4.13(\mathrm{~m}, 1 \mathrm{H}), 4.10$ (s, $2 \mathrm{H}), 4.09(\mathrm{~d}, J=16.8 \mathrm{~Hz}, 1 \mathrm{H}), 4.07(\mathrm{~m}, 1 \mathrm{H}), 3.98-3.25(\mathrm{~m}, 23 \mathrm{H}), 2.76(\mathrm{dd}, J=12.0$ and 4.8 $\mathrm{Hz}, 1 \mathrm{H}), 2.68(\mathrm{dd}, J=12.0$ and $4.8 \mathrm{~Hz}, 1 \mathrm{H}), 1.73(\mathrm{t}, J=12.0 \mathrm{~Hz}, 2 \mathrm{H}) ;{ }^{13} \mathrm{C} \mathrm{NMR}(200 \mathrm{MHz}$, $\left.\mathrm{D}_{2} \mathrm{O}\right) \delta$ 175.61, 174.85, 173.37, 173.26, 102.55, 102.53, 100.38, 100.05, 100.03, 95.67, $91.71,78.10,77.94,77.78,75.33,75.10,74.71,74.14,73.89,73.71,72.24,71.68,71.20$, 71.06, 70.00, 69.16, 68.11, 67.91, 67.80, 67.32, 62.38, 61.44, 60.99, 60.84, 59.86, 52.14, 51.31, 40.42, 39.57, 22.19. HRMS (ESI) $\mathrm{m} / \mathrm{z}$ calculated for $\mathrm{C}_{34} \mathrm{H}_{55} \mathrm{~N}_{2} \mathrm{O}_{29}(\mathrm{M}-\mathrm{H}) 955.2890$, found 955.2900 .

Kdna2-8Neu5Gca2-3Lac (10): $62 \mathrm{mg}$, yield 81\%; white solid. ${ }^{1} \mathrm{H}$ NMR (800 MHz, $\left.\mathrm{D}_{2} \mathrm{O}\right)$ $\delta 5.20(\mathrm{~d}, J=4.0 \mathrm{~Hz}, 0.4 \mathrm{H}), 4.64(\mathrm{~d}, J=8.0 \mathrm{~Hz}, 0.6 \mathrm{H}), 4.50(\mathrm{~d}, J=8.0 \mathrm{~Hz}, 0.4 \mathrm{H}), 4.49(\mathrm{~d}, J$ $=8.0 \mathrm{~Hz}, 0.6 \mathrm{H}), 4.18(\mathrm{~d}, J=16.8 \mathrm{~Hz}, 1 \mathrm{H}), 4.15(\mathrm{~m}, 1 \mathrm{H}), 4.12(\mathrm{~m}, 1 \mathrm{H}), 4.08(\mathrm{~d}, J=16.8 \mathrm{~Hz}$, $1 \mathrm{H}), 4.07(\mathrm{~m}, 1 \mathrm{H}), 3.97-3.26(\mathrm{~m}, 23 \mathrm{H}), 2.68(\mathrm{~m}, 2 \mathrm{H}), 1.73(\mathrm{t}, J=12.0 \mathrm{~Hz}, 1 \mathrm{H}), 1.67(\mathrm{t}, J=$ $12.0 \mathrm{~Hz}, 1 \mathrm{H}) ;{ }^{13} \mathrm{C}$ NMR $\left(200 \mathrm{MHz}, \mathrm{D}_{2} \mathrm{O}\right) \delta 176.06,173.83,173.38,102.66,100.10,95.74$, $91.79,78.36,78.04,77.89,75.45,75.21,74.79,74.21,73.79,73.69,73.58,72.02,71.27$, $71.14,70.27,70.09,69.76,69.23,69.01,67.74,67.41,62.59,61.42,61.08,59.97,59.82$, 52.06, 48.64, 40.16, 39.70. HRMS (ESI) m/z calculated for $\mathrm{C}_{32} \mathrm{H}_{52} \mathrm{NO}_{28}(\mathrm{M}-\mathrm{H})$ 898.2676, found 898.2668.

Neu5Aca2-8Kdna2-3Lac (11): $24 \mathrm{mg}$, yield 82\%; white solid. ${ }^{1} \mathrm{H}$ NMR (800 MHz, $\mathrm{D}_{2} \mathrm{O}$ ) $\delta 5.20(\mathrm{~d}, J=4.0 \mathrm{~Hz}, 0.4 \mathrm{H}), 4.64(\mathrm{~d}, J=8.0 \mathrm{~Hz}, 0.6 \mathrm{H}), 4.50(\mathrm{~d}, J=8.0 \mathrm{~Hz}, 0.4 \mathrm{H}), 4.49(\mathrm{~d}, J$ 
$=8.0 \mathrm{~Hz}, 0.6 \mathrm{H}), 4.18-3.25(\mathrm{~m}, 26 \mathrm{H}), 2.76-2.61(\mathrm{~m}, 2 \mathrm{H}), 2.01(\mathrm{~s}, 3 \mathrm{H}), 1.80-1.70(\mathrm{~m}, 2 \mathrm{H})$;

${ }^{13} \mathrm{C}$ NMR $\left(200 \mathrm{MHz}, \mathrm{D}_{2} \mathrm{O}\right) \delta 174.83,169.88,102.54,95.66,91.71,77.93,77.83,77.69$, $75.38,75.10,74.90,74.71,74.15,73.71,73.54,72.60,71.59,71.20,71.06,70.59,70.40$, $70.00,69.46,69.35,69.17,69.13,68.77,68.37,68.31,68.04,67.86,67.47,67.38,67.32$, $62.46,61.23,61.03,60.97,59.90,52.20,51.60,40.35,39.78,39.05,22.19,22.09$. HRMS (ESI) $\mathrm{m} / \mathrm{z}$ calculated for $\mathrm{C}_{32} \mathrm{H}_{52} \mathrm{NO}_{27}(\mathrm{M}-\mathrm{H})$ 882.2727, found 882.2715.

Neu5Gca2-8Kdna2-3Lac (12): $28 \mathrm{mg}$, yield 78\%; white solid. ${ }^{1} \mathrm{H}$ NMR (800 MHz, $\mathrm{D}_{2} \mathrm{O}$ ) $\delta 5.20(\mathrm{~d}, J=4.0 \mathrm{~Hz}, 0.4 \mathrm{H}), 4.64(\mathrm{~d}, J=8.0 \mathrm{~Hz}, 0.6 \mathrm{H}), 4.50(\mathrm{~d}, J=8.0 \mathrm{~Hz}, 0.4 \mathrm{H}), 4.49(\mathrm{~d}, J$ $=8.0 \mathrm{~Hz}, 0.6 \mathrm{H}), 4.21-3.26(\mathrm{~m}, 28 \mathrm{H}), 2.76-2.61(\mathrm{~m}, 2 \mathrm{H}), 1.78-1.66(\mathrm{~m}, 2 \mathrm{H}) ;{ }^{13} \mathrm{C} \mathrm{NMR}(200$ $\left.\mathrm{MHz}, \mathrm{D}_{2} \mathrm{O}\right) \delta 176.01,175.64,173.78,173.57,173.44,102.61,101.11,100.09,99.99,95.75$, $91.79,78.51,78.03,77.86,77.42,75.51,75.22,74.80,74.67,74.22,73.79,73.59,72.37$, $72.27,71.75,71.28,71.14,70.70,70.08,69.48,69.45,69.24,69.17,68.24,68.16,68.11$, 67.69, 67.41, 62.50, 61.38, 61.25, 61.09, 61.07, 60.93, 59.99, 52.12, 51.39, 40.60, 39.60 . HRMS (ESI) m/z calculated for $\mathrm{C}_{32} \mathrm{H}_{52} \mathrm{NO}_{28}(\mathrm{M}-\mathrm{H})$ 898.2676, found 898.2663.

Kdna2-8Kdna2-3Lac (13): $24 \mathrm{mg}$, yield 81\%; white solid. ${ }^{1} \mathrm{H}$ NMR (800 MHz, $\left.\mathrm{D}_{2} \mathrm{O}\right) \delta$ $5.19(\mathrm{~d}, J=4.0 \mathrm{~Hz}, 0.4 \mathrm{H}), 4.63(\mathrm{~d}, J=8.0 \mathrm{~Hz}, 0.6 \mathrm{H}), 4.49$ (d, $J=8.0 \mathrm{~Hz}, 0.4 \mathrm{H}), 4.48$ (d, $J=$ $8.0 \mathrm{~Hz}, 0.6 \mathrm{H}), 4.18-3.24(\mathrm{~m}, 26 \mathrm{H}), 2.67(\mathrm{dd}, J=12.0$ and $4.8 \mathrm{~Hz}, 1 \mathrm{H}), 2.61(\mathrm{dd}, J=12.0$ and $4.8 \mathrm{~Hz}, 1 \mathrm{H}), 1.76(\mathrm{t}, J=12.0 \mathrm{~Hz}, 1 \mathrm{H}), 1.68(\mathrm{t}, J=12.0 \mathrm{~Hz}, 1 \mathrm{H}) ;{ }^{13} \mathrm{C} \mathrm{NMR}(200 \mathrm{MHz}$, $\left.\mathrm{D}_{2} \mathrm{O}\right) \delta 173.88,173.45,102.55,95.66,91.70,77.97,77.82,77.70,75.36,75.11,74.95$, 74.70, 74.14, 73.70, 73.59, 71.84, 71.19, 71.05, 70.41, 70.31, 70.00, 69.66, 69.39, 69.34, $69.15,67.70,67.34,62.50,61.26,60.96,59.90,59.75,39.12$. HRMS (ESI) m/z calculated for $\mathrm{C}_{30} \mathrm{H}_{49} \mathrm{O}_{27}(\mathrm{M}-\mathrm{H})$ 841.2461, found 841.2464.

\section{General procedures for OPME synthesis of GM2 (4 compounds, 14-17) and} GD2 glycans (8 compounds, 18-25) - A GM3 or GD3 glycan (10 mM, 1 eq.) as an acceptor substrate, GalNAc (1.5 eq.), ATP (1.5 eq.), UTP (1.5 eq.), and $\mathrm{MgCl}_{2}(20 \mathrm{mM})$ were incubated at $37^{\circ} \mathrm{C}$ in Tris- $\mathrm{HCl}$ buffer $(100 \mathrm{mM}$, pH 7.5) containing BLNahK (3 mg/ $\mathrm{mL}$ ), PmGlmU (3 mg/mL), CjCgtA (lysate, $4.0 \mathrm{mg} / \mathrm{mL})$, and PmPpA ( $2 \mathrm{mg} / \mathrm{mL})$. The reaction was carried out by incubating the solution in an incubator shaker at $37^{\circ} \mathrm{C}$ for 2 days with agitation at $100 \mathrm{rpm}$. The product formation was monitored by LC-MS. When an optimal yield was achieved, alkaline phosphatase $(10-20 \mathrm{mg})$ was added to the reaction mixture which was incubated in an incubator shaker at $37{ }^{\circ} \mathrm{C}$ for overnight with agitation at $100 \mathrm{rpm}$. The reaction was then quenched by adding the same volume of ice-cold ethanol and incubated at $4{ }^{\circ} \mathrm{C}$ for $30 \mathrm{~min}$. The mixture was centrifuged and the precipitates were removed. The supernatant was concentrated, passed through a BioGel P-2 gel filtration column, and eluted with water to obtain crude sialosides. The fractions containing the product were collected, concentrated, and further purified by HPLC over a XBridge BEH Amide Column (130 ̊, $5 \mu \mathrm{m}, 4.6 \mathrm{~mm} \times 250 \mathrm{~mm})$. Mobile phase A: $100 \mathrm{mM}$ ammonium formate, $\mathrm{pH}$ 3.46; Mobile phase B: acetonitrile; Gradient: $65 \%$ to $50 \%$ B over 25 minutes, $50 \%$ to $0 \%$ B over 1 minute, $0 \%$ B for 2 minutes, $0 \%$ to $65 \%$ B over 2 minutes, $65 \%$ B for 5 minutes. HPLC purification was monitored by absorption at $210 \mathrm{~nm}$, and glycan-containing fractions were analyzed by TLC and MS. The fractions containing pure product were collected and lyophilized to obtain the desired GM2 and GD2 glycans (yields 90-99\%). 
Neu5Aca2-3(GalNAcß1-4)Lac (14): $211 \mathrm{mg}$, yield 99\%; white solid. ${ }^{1} \mathrm{H}$ NMR (800 MHz, $\left.\mathrm{D}_{2} \mathrm{O}\right) \delta 5.21(\mathrm{~d}, J=4.0 \mathrm{~Hz}, 0.4 \mathrm{H}), 4.73(\mathrm{~d}, J=8.0 \mathrm{~Hz}, 1 \mathrm{H}), 4.65(\mathrm{~d}, J=8.0 \mathrm{~Hz}, 0.6 \mathrm{H}), 4.52$ $(\mathrm{d}, J=8.0 \mathrm{~Hz}, 1 \mathrm{H}), 4.16-3.25(\mathrm{~m}, 25 \mathrm{H}), 2.65(\mathrm{dd}, J=12.0$ and $4.8 \mathrm{~Hz}, 1 \mathrm{H}), 2.02(\mathrm{~s}, 3 \mathrm{H})$, 2.01 (s, 3H), 1.91 (t, $J=12.0 \mathrm{~Hz}, 1 \mathrm{H}) ;{ }^{13} \mathrm{C}$ NMR $\left(200 \mathrm{MHz}, \mathrm{D}_{2} \mathrm{O}\right) \delta 174.89,174.71,173.97$, 102.63, 102.45, 102.41, 101.50, 95.63, 91.68, 78.45, 78.37, 77.05, 74.65, 74.59, 74.23, 74.20, 73.89, 73.61, 72.94, 72.16, 71.27, 71.14, 70.96, 69.94, 69.90, 68.58, 67.87, 67.65, $62.70,61.04,60.45,59.98,59.84,52.21,51.47,36.82,22.49,21.94$. HRMS (ESI) $\mathrm{m} / \mathrm{z}$ calcd for $\mathrm{C}_{31} \mathrm{H}_{51} \mathrm{~N}_{2} \mathrm{O}_{24}(\mathrm{M}-\mathrm{H})$ 835.2832, found 835.2821. NMR data were consistent with those reported in the literature. ${ }^{82}$

Neu5Gca2-3(GalNAc $\boldsymbol{\beta 1 - 4 ) L a c ~ ( 1 5 ) : ~} 114 \mathrm{mg}$, yield 99\%; white solid. ${ }^{1} \mathrm{H}$ NMR (800 $\left.\mathrm{MHz}, \mathrm{D}_{2} \mathrm{O}\right) \delta 5.21(\mathrm{~d}, J=4.0 \mathrm{~Hz}, 0.5 \mathrm{H}), 4.74(\mathrm{~d}, J=8.0 \mathrm{~Hz}, 1 \mathrm{H}), 4.65(\mathrm{~d}, J=8.0 \mathrm{~Hz}, 0.5 \mathrm{H})$, $4.52(\mathrm{~d}, J=8.0 \mathrm{~Hz}, 1 \mathrm{H}), 4.15(\mathrm{~m}, 1 \mathrm{H}), 4.11(\mathrm{~s}, 2 \mathrm{H}), 3.96-3.25(\mathrm{~m}, 25 \mathrm{H}), 2.67(\mathrm{dd}, J=12.0$ and $4.8 \mathrm{~Hz}, 1 \mathrm{H}), 2.01(\mathrm{~s}, 3 \mathrm{H}), 1.93(\mathrm{t}, J=12.0 \mathrm{~Hz}, 1 \mathrm{H}) ;{ }^{13} \mathrm{C} \mathrm{NMR}\left(200 \mathrm{MHz}, \mathrm{D}_{2} \mathrm{O}\right) \delta$ 175.64, 174.71, 173.99, 102.63, 102.45, 102.41, 101.51, 95.63, 78.45, 78.37, 77.03, 74.65, $74.59,74.23,74.21,74.20,73.90,73.61,72.66,72.23,71.27,71.14,70.96,69.95,69.90$, $68.33,67.79,67.65,62.66,61.04,60.87,60.45,59.98,52.22,51.18,36.89,22.50$. HRMS (ESI) $\mathrm{m} / z$ calcd for $\mathrm{C}_{31} \mathrm{H}_{51} \mathrm{~N}_{2} \mathrm{O}_{25}(\mathrm{M}-\mathrm{H}) 851.2781$, found 851.2770.

Kdna2-3(GalNAcß1-4)Lac (16): $27 \mathrm{mg}$, yield 99\%; white solid. ${ }^{1} \mathrm{H}$ NMR (800 MHz, $\left.\mathrm{D}_{2} \mathrm{O}\right) \delta 5.19(\mathrm{~d}, J=4.0 \mathrm{~Hz}, 0.4 \mathrm{H}), 4.72(\mathrm{~d}, J=8.0 \mathrm{~Hz}, 1 \mathrm{H}), 4.63(\mathrm{~d}, J=8.0 \mathrm{~Hz}, 0.6 \mathrm{H}), 4.49$ $(\mathrm{d}, J=8.0 \mathrm{~Hz}, 1 \mathrm{H}), 4.01-3.23(\mathrm{~m}, 25 \mathrm{H}), 2.59(\mathrm{dd}, J=12.0$ and $4.8 \mathrm{~Hz}, 1 \mathrm{H}), 1.99(\mathrm{~s}, 3 \mathrm{H})$, 1.85 (t, $J=12.0 \mathrm{~Hz}, 1 \mathrm{H}) ;{ }^{13} \mathrm{C}$ NMR $\left(200 \mathrm{MHz}, \mathrm{D}_{2} \mathrm{O}\right) \delta 174.70,174.12,170.54,102.60$, $102.43,102.39,101.50,95.62,91.67,78.38,78.30,76.95,74.63,74.58,74.21,74.14,73.91$, $73.85,73.60,72.41,71.25,71.09,70.96,70.45,69.93,69.87,69.51,67.64,67.44,62.76$, $61.05,60.38,59.95,52.20,36.39,22.47$. HRMS (ESI) $\mathrm{m} / z$ calcd for $\mathrm{C}_{29} \mathrm{H}_{48} \mathrm{NO}_{24}(\mathrm{M}-\mathrm{H})$ 794.2566 , found 794.2571 .

Neu5Ac8OMea2-3(GalNAcß1-4)Lac (17): 6 mg, yield 95\%; white solid. ${ }^{1} \mathrm{H}$ NMR (800 $\left.\mathrm{MHz}, \mathrm{D}_{2} \mathrm{O}\right) \delta 5.20(\mathrm{~d}, J=4.0 \mathrm{~Hz}, 1 \mathrm{H}), 4.65(\mathrm{~d}, J=8.0 \mathrm{~Hz}, 1 \mathrm{H}), 4.47$ (d, $\left.J=8.0 \mathrm{~Hz}, 1 \mathrm{H}\right)$, 4.15-3.24 (m, 25H), 3.47 (s, 3H), $2.62(\mathrm{dd}, J=12.0$ and $4.8 \mathrm{~Hz}, 1 \mathrm{H}), 2.03(\mathrm{~s}, 3 \mathrm{H}), 2.01$ (s, $3 \mathrm{H}), 1.79(\mathrm{t}, J=12.0 \mathrm{~Hz}, 1 \mathrm{H}) ;{ }^{13} \mathrm{C}$ NMR $\left(200 \mathrm{MHz}, \mathrm{D}_{2} \mathrm{O}\right) \delta 174.84,174.75,173.43$, 102.61, 102.55, 100.51, 95.63, 80.33, 78.23, 76.23, 74.73, 74.69, 74.43, 74.16, 74.13, 73.61, $72.43,70.99,69.74,68.19,67.59,66.93,60.87,60.51,59.34,57.57,52.37,51.96,38.76$, 22.42, 21.96. HRMS (ESI) $\mathrm{m} / \mathrm{z}$ calcd for $\mathrm{C}_{32} \mathrm{H}_{53} \mathrm{~N}_{2} \mathrm{O}_{24}(\mathrm{M}-\mathrm{H})$ 849.2988, found 849.2975.

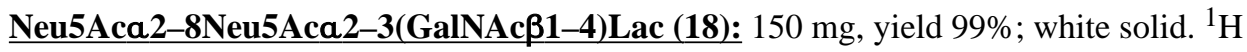
NMR $\left(800 \mathrm{MHz}, \mathrm{D}_{2} \mathrm{O}\right) \delta 5.21(\mathrm{~d}, J=4.0 \mathrm{~Hz}, 0.4 \mathrm{H}), 4.69(\mathrm{~d}, J=8.0 \mathrm{~Hz}, 0.4 \mathrm{H}), 4.68(\mathrm{~d}, J=$ $8.0 \mathrm{~Hz}, 0.6 \mathrm{H}), 4.65(\mathrm{~d}, J=8.0 \mathrm{~Hz}, 0.6 \mathrm{H}), 4.50(\mathrm{~d}, J=8.0 \mathrm{~Hz}, 0.4 \mathrm{H}), 4.49(\mathrm{~d}, J=8.0 \mathrm{~Hz}$, $0.6 \mathrm{H}), 4.18-3.25(\mathrm{~m}, 32 \mathrm{H}), 2.75(\mathrm{dd}, J=12.0$ and $4.8 \mathrm{~Hz}, 1 \mathrm{H}), 2.66(\mathrm{dd}, J=12.0$ and 4.8 $\mathrm{Hz}, 1 \mathrm{H}), 2.05$ (s, 3H), 2.03 (s, 3H), $2.02(\mathrm{~s}, 3 \mathrm{H}), 1.76(\mathrm{t}, J=12.0 \mathrm{~Hz}, 1 \mathrm{H}), 1.72(\mathrm{t}, J=12.0$ $\mathrm{Hz}, 1 \mathrm{H}) ;{ }^{13} \mathrm{C}$ NMR $\left(200 \mathrm{MHz}, \mathrm{D}_{2} \mathrm{O}\right) \delta 174.95,174.90,174.82,173.35,173.28,102.68$, $100.50,95.75,95.73,91.79,91.76,78.27,78.23,78.15,75.87,74.79,74.48,74.42,74.21$, $73.73,73.68,72.61,71.73,71.26,71.08,70.81,70.09,69.65,69.27,69.23,68.44,68.07$, $67.70,67.66,62.52,61.45,60.91,60.61,59.97,59.82,59.30,52.44,52.33,51.72,40.41$, 
39.15, 22.53, 22.33, 22.03. HRMS (ESI) $\mathrm{m} / \mathrm{z}$ calcd for $\mathrm{C}_{42} \mathrm{H}_{68} \mathrm{~N}_{3} \mathrm{O}_{32}(\mathrm{M}-\mathrm{H}) 1126.3786$, found 1126.3770 .

Neu5Gca2-8Neu5Aca2-3(GalNAcß1-4)Lac (19): $32 \mathrm{mg}$, yield 97\%; white solid. ${ }^{1} \mathrm{H}$ NMR $\left(800 \mathrm{MHz}, \mathrm{D}_{2} \mathrm{O}\right) \delta 5.20(\mathrm{~d}, J=4.0 \mathrm{~Hz}, 0.4 \mathrm{H}), 4.69(\mathrm{~d}, J=8.0 \mathrm{~Hz}, 0.4 \mathrm{H}), 4.68(\mathrm{~d}, J=$ $8.0 \mathrm{~Hz}, 0.6 \mathrm{H}), 4.65(\mathrm{~d}, J=8.0 \mathrm{~Hz}, 0.6 \mathrm{H}), 4.50(\mathrm{~d}, J=8.0 \mathrm{~Hz}, 0.4 \mathrm{H}), 4.49$ (d, $J=8.0 \mathrm{~Hz}$, $0.6 \mathrm{H}), 4.19-4.12(\mathrm{~m}, 3 \mathrm{H}), 4.10(\mathrm{~s}, 2 \mathrm{H}), 4.03-3.24(\mathrm{~m}, 29 \mathrm{H}), 2.76(\mathrm{dd}, J=12.0$ and $4.8 \mathrm{~Hz}$, $1 \mathrm{H}), 2.66(\mathrm{dd}, J=12.0$ and $4.8 \mathrm{~Hz}, 1 \mathrm{H}), 2.05(\mathrm{~s}, 3 \mathrm{H}), 2.04(\mathrm{~s}, 3 \mathrm{H}), 1.76(\mathrm{t}, J=12.0 \mathrm{~Hz}, 1 \mathrm{H})$, $1.74(\mathrm{t}, J=12.0 \mathrm{~Hz}, 1 \mathrm{H}) ;{ }^{13} \mathrm{C}$ NMR $\left(200 \mathrm{MHz}, \mathrm{D}_{2} \mathrm{O}\right) \delta 175.62,174.83,174.75,173.31$, 173.22, 102.62, 102.60, 100.43, 95.66, 93.47, 93.44, 78.19, 78.16, 78.08, 75.82, 75.80, $74.71,74.40,74.34,74.14,73.65,73.61,72.25,71.70,71.57,71.19,71.01,70.74,70.02$, 69.59, 69.16, 68.33, 68.12, 68.01, 67.92, 67.60, 67.29, 62.40, 61.37, 61.07, 60.86, 60.83, $60.53,59.90,52.36,52.25,51.33,49.85,49.81,40.40,22.44,22.24,21.94$. HRMS (ESI) $\mathrm{m} / \mathrm{z}$ calcd for $\mathrm{C}_{42} \mathrm{H}_{68} \mathrm{~N}_{3} \mathrm{O}_{33}(\mathrm{M}-\mathrm{H}) 1142.3735$, found 1142.3749 .

Kdna2-8Neu5Aca2-3(GalNAcß1-4)Lac (20): $16 \mathrm{mg}$, yield 96\%; white solid. ${ }^{1} \mathrm{H}$ NMR $\left(800 \mathrm{MHz}, \mathrm{D}_{2} \mathrm{O}\right) \delta 5.20(\mathrm{~d}, J=4.0 \mathrm{~Hz}, 0.4 \mathrm{H}), 4.68(\mathrm{~d}, J=8.0 \mathrm{~Hz}, 0.4 \mathrm{H}), 4.67(\mathrm{~d}, J=8.0 \mathrm{~Hz}$, $0.6 \mathrm{H}), 4.64(\mathrm{~d}, J=8.0 \mathrm{~Hz}, 0.6 \mathrm{H}), 4.48(\mathrm{~d}, J=8.0 \mathrm{~Hz}, 0.4 \mathrm{H}), 4.47(\mathrm{~d}, J=8.0 \mathrm{~Hz}, 0.6 \mathrm{H})$, 4.17-4.01 (m, 4H), 3.96-3.24 (m, 28H), 2.70-2.65 (m, 2H), 2.05 (s, 3H), 2.03 (s, 3H), 1.75 (t, $J=12.0 \mathrm{~Hz}, 1 \mathrm{H}), 1.68(\mathrm{t}, J=12.0 \mathrm{~Hz}, 1 \mathrm{H}) ;{ }^{13} \mathrm{C} \mathrm{NMR}\left(200 \mathrm{MHz}, \mathrm{D}_{2} \mathrm{O}\right) \delta 174.89,174.81$, 173.57, 173.29, 160.99, 102.67, 100.49, 100.48, 95.74, 95.72, 78.19, 78.13, 75.84, 74.77, $74.47,74.40,74.19,73.67,73.60,71.99,71.06,70.79,70.35,69.76,69.63,69.27,69.22$, 68.07, 67.67, 62.42, 61.42, 60.90, 60.58, 52.31, 39.98, 39.94, 34.17, 22.51, 22.31. HRMS (ESI) $\mathrm{m} / \mathrm{z}$ calcd for $\mathrm{C}_{40} \mathrm{H}_{65} \mathrm{~N}_{2} \mathrm{O}_{32}(\mathrm{M}-\mathrm{H}) 1085.3520$, found 1085.3508 .

Neu5Aca2-8Neu5Gca2-3(GalNAcß1-4)Lac (21): $51 \mathrm{mg}$, yield 94\%; white solid. ${ }^{1} \mathrm{H}$ NMR $\left(800 \mathrm{MHz}, \mathrm{D}_{2} \mathrm{O}\right) \delta 5.19(\mathrm{~d}, J=4.0 \mathrm{~Hz}, 0.4 \mathrm{H}), 4.68(\mathrm{~d}, J=8.0 \mathrm{~Hz}, 0.4 \mathrm{H}), 4.67(\mathrm{~d}, J=$ $8.0 \mathrm{~Hz}, 0.6 \mathrm{H}), 4.64(\mathrm{~d}, J=8.0 \mathrm{~Hz}, 0.6 \mathrm{H}), 4.48(\mathrm{~d}, J=8.0 \mathrm{~Hz}, 0.4 \mathrm{H}), 4.47(\mathrm{~d}, J=8.0 \mathrm{~Hz}$, $0.6 \mathrm{H}), 4.18(\mathrm{~d}, J=16.8 \mathrm{~Hz}, 1 \mathrm{H}), 4.17-4.09(\mathrm{~m}, 3 \mathrm{H}), 4.08(\mathrm{~d}, J=16.8 \mathrm{~Hz}, 1 \mathrm{H}), 4.03-3.24$ (m, 29H), 2.73 (dd, $J=12.0$ and $4.8 \mathrm{~Hz}, 1 \mathrm{H}), 2.68(\mathrm{dd}, J=12.0$ and $4.8 \mathrm{~Hz}, 1 \mathrm{H}), 2.02$ (s, $3 \mathrm{H}), 2.00(\mathrm{~s}, 3 \mathrm{H}), 1.77(\mathrm{t}, J=12.0 \mathrm{~Hz}, 1 \mathrm{H}), 1.70(\mathrm{t}, J=12.0 \mathrm{~Hz}, 1 \mathrm{H}) ;{ }^{13} \mathrm{C}$ NMR $(200 \mathrm{MHz}$, $\left.\mathrm{D}_{2} \mathrm{O}\right) \delta 177.01,175.95,174.87,174.84,174.73,174.58,173.58,173.19,172.49,102.63$, $102.61,101.89,100.44,100.42,100.05,96.46,95.65,91.68,78.40,78.15,78.06,75.85$, $75.82,75.05,74.70,74.41,74.32,74.14,74.13,73.63,73.33,72.68,72.48,71.98,71.64$, $71.17,70.98,70.72,70.12,69.99,69.57,69.46,68.88,68.29,68.28,68.00,67.84,67.58$, 67.52, 67.44, 66.81, 62.43, 61.27, 61.00, 60.81, 60.69, 60.50, 60.11, 59.88, 59.73, 52.34, 52.20, 52.06, 51.61, 51.53, 40.89, 40.46, 39.11, 39.02, 22.43, 22.04, 21.92, 21.91. HRMS (ESI) $\mathrm{m} / z$ calcd for $\mathrm{C}_{42} \mathrm{H}_{68} \mathrm{~N}_{3} \mathrm{O}_{33}(\mathrm{M}-\mathrm{H}) 1142.3735$, found 1142.3755 .

Neu5Gca2-8Neu5Gca2-3(GalNAcß1-4)Lac (22): $36 \mathrm{mg}$, yield 96\%; white solid. ${ }^{1} \mathrm{H}$ NMR $\left(800 \mathrm{MHz}, \mathrm{D}_{2} \mathrm{O}\right) \delta 5.19(\mathrm{~d}, J=4.0 \mathrm{~Hz}, 0.4 \mathrm{H}), 4.69(\mathrm{~d}, J=8.0 \mathrm{~Hz}, 0.4 \mathrm{H}), 4.68(\mathrm{~d}, J=$ $8.0 \mathrm{~Hz}, 0.6 \mathrm{H}), 4.64(\mathrm{~d}, J=8.0 \mathrm{~Hz}, 0.6 \mathrm{H}), 4.49(\mathrm{~d}, J=8.0 \mathrm{~Hz}, 0.4 \mathrm{H}), 4.48(\mathrm{~d}, J=8.0 \mathrm{~Hz}$, $0.6 \mathrm{H}), 4.18(\mathrm{~d}, J=16.8 \mathrm{~Hz}, 1 \mathrm{H}), 4.17-4.14(\mathrm{~m}, 2 \mathrm{H}), 4.11(\mathrm{~m}, 1 \mathrm{H}), 4.09(\mathrm{~s}, 2 \mathrm{H}), 4.08(\mathrm{~d}, J=$ $16.8 \mathrm{~Hz}, 1 \mathrm{H}), 4.03-3.24(\mathrm{~m}, 29 \mathrm{H}), 2.75(\mathrm{dd}, J=12.0$ and $4.8 \mathrm{~Hz}, 1 \mathrm{H}), 2.68(\mathrm{dd}, J=12.0$ and $4.8 \mathrm{~Hz}, 1 \mathrm{H}), 2.02(\mathrm{~s}, 3 \mathrm{H}), 1.77(\mathrm{t}, J=12.0 \mathrm{~Hz}, 1 \mathrm{H}), 1.72(\mathrm{t}, J=12.0 \mathrm{~Hz}, 1 \mathrm{H}) ;{ }^{13} \mathrm{C}$ NMR $(200$ 
$\left.\mathrm{MHz}, \mathrm{D}_{2} \mathrm{O}\right) \delta 175.96,175.61,174.74,173.62,173.19,102.63,102.61,100.45,100.06$, $95.65,91.69,78.40,78.15,78.07,75.86,74.70,74.42,74.32,74.13,73.63,73.34,72.20$, $71.70,70.99,70.73,70.00,69.58,69.46,68.87,68.03,67.93,67.59,67.53,62.40,61.28$, $61.01,60.84,60.81,60.51,59.89,52.35,52.07,51.32,40.53,22.43$. HRMS (ESI) $\mathrm{m} / z$ calcd for $\mathrm{C}_{42} \mathrm{H}_{68} \mathrm{~N}_{3} \mathrm{O}_{34}(\mathrm{M}-\mathrm{H}) 1158.3684$, found 1158.3690 .

Kdna2-8Neu5Gca2-3(GalNAcß1-4)Lac (23): $46 \mathrm{mg}$, yield 94\%; white solid. ${ }^{1} \mathrm{H}$ NMR $\left(800 \mathrm{MHz}, \mathrm{D}_{2} \mathrm{O}\right) \delta 5.19(\mathrm{~d}, J=4.0 \mathrm{~Hz}, 0.4 \mathrm{H}), 4.68(\mathrm{~d}, J=8.0 \mathrm{~Hz}, 0.4 \mathrm{H}), 4.67$ (d, $J=8.0 \mathrm{~Hz}$, $0.6 \mathrm{H}), 4.64(\mathrm{~d}, J=8.0 \mathrm{~Hz}, 0.6 \mathrm{H}), 4.48(\mathrm{~d}, J=8.0 \mathrm{~Hz}, 0.4 \mathrm{H}), 4.47(\mathrm{~d}, J=8.0 \mathrm{~Hz}, 0.6 \mathrm{H}), 4.17$ $(\mathrm{d}, J=16.8 \mathrm{~Hz}, 1 \mathrm{H}), 4.16-4.13(\mathrm{~m}, 2 \mathrm{H}), 4.08(\mathrm{~d}, J=16.8 \mathrm{~Hz}, 1 \mathrm{H}), 4.07(\mathrm{~m}, 1 \mathrm{H}), 4.01(\mathrm{~m}$, $1 \mathrm{H}), 3.95-3.23(\mathrm{~m}, 28 \mathrm{H}), 2.70-2.66(\mathrm{~m}, 2 \mathrm{H}), 2.02(\mathrm{~s}, 3 \mathrm{H}), 1.76(\mathrm{t}, J=12.0 \mathrm{~Hz}, 1 \mathrm{H}), 1.66(\mathrm{t}$, $J=12.0 \mathrm{~Hz}, 1 \mathrm{H}) ;{ }^{13} \mathrm{C}$ NMR $\left(200 \mathrm{MHz}, \mathrm{D}_{2} \mathrm{O}\right) \delta 175.97,174.73,173.79,173.18,102.62$, $100.42,100.41,100.05,95.65,78.35,78.15,78.07,75.81,74.70,74.42,74.32,74.14,74.12$, $73.63,73.50,73.35,71.94,70.99,70.72,70.19,69.68,69.56,69.46,68.88,67.64,67.58$, 67.52, 62.50, 61.27, 61.00, 60.83, 60.50, 52.35, 52.06, 48.58, 40.07, 25.99, 22.44. HRMS (ESI) $\mathrm{m} / \mathrm{z}$ calcd for $\mathrm{C}_{40} \mathrm{H}_{65} \mathrm{~N}_{2} \mathrm{O}_{33}(\mathrm{M}-\mathrm{H}) 1101.3470$, found 1101.3478 .

Neu5Gca2-8Kdna2-3(GalNAcß1-4)Lac (24): $12 \mathrm{mg}$, yield 90\%; white solid. ${ }^{1} \mathrm{H}$ NMR $\left(800 \mathrm{MHz}, \mathrm{D}_{2} \mathrm{O}\right) \delta 5.19(\mathrm{~d}, J=3.2 \mathrm{~Hz}, 0.4 \mathrm{H}), 4.69(\mathrm{~d}, J=8.0 \mathrm{~Hz}, 0.4 \mathrm{H}), 4.68(\mathrm{~d}, J=8.0 \mathrm{~Hz}$, $0.6 \mathrm{H}), 4.64(\mathrm{~d}, J=8.0 \mathrm{~Hz}, 0.6 \mathrm{H}), 4.49(\mathrm{~d}, J=8.0 \mathrm{~Hz}, 0.4 \mathrm{H}), 4.48(\mathrm{~d}, J=8.0 \mathrm{~Hz}, 0.6 \mathrm{H})$, $4.28-3.24(\mathrm{~m}, 34 \mathrm{H}), 2.75(\mathrm{dd}, J=12.0$ and $4.8 \mathrm{~Hz}, 1 \mathrm{H}), 2.68(\mathrm{dd}, J=12.0$ and $4.8 \mathrm{~Hz}, 1 \mathrm{H})$, 2.03 (s, 3H), 1.74-1.69 (m, 2H); ${ }^{13} \mathrm{C}$ NMR (200 MHz, $\left.\mathrm{D}_{2} \mathrm{O}\right) \delta$ 175.57, 175.66, 174.44, 173.60, 103.61, 102.49, 102.43, 95.67, 91.72, 79.92, 78.29, 78.16, 77.81, 77.71, 75.73, $75.64,75.17,75.08,74.75,74.72,74.59,74.17,73.71,73.24,72.23,71.69,71.31,71.23$, 71.06, 70.52, 70.10, 70.03, 69.37, 69.17, 69.11, 68.69, 68.02, 67.76, 67.64, 67.44, 62.45, $61.51,61.07,61.00,60.84,59.92,59.83,52.41,51.96,51.31,51.22,40.49,38.96,22.30$. HRMS (ESI) $\mathrm{m} / \mathrm{z}$ calcd for $\mathrm{C}_{40} \mathrm{H}_{65} \mathrm{~N}_{2} \mathrm{O}_{33}$ (M-H) 1101.3470, found 1101.3455 .

Kdna2-8Kdna2-3(GalNAcß1-4)Lac (25): 8 mg, yield 95\%; white solid. ${ }^{1} \mathrm{H}$ NMR (800 $\left.\mathrm{MHz}, \mathrm{D}_{2} \mathrm{O}\right) \delta 5.20(\mathrm{~d}, J=4.0 \mathrm{~Hz}, 0.4 \mathrm{H}), 4.69(\mathrm{~d}, J=8.0 \mathrm{~Hz}, 0.4 \mathrm{H}), 4.68(\mathrm{~d}, J=8.0 \mathrm{~Hz}$, $0.6 \mathrm{H}), 4.64(\mathrm{~d}, J=8.0 \mathrm{~Hz}, 0.6 \mathrm{H}), 4.47(\mathrm{~d}, J=8.0 \mathrm{~Hz}, 1 \mathrm{H}), 4.18-3.24(\mathrm{~m}, 32 \mathrm{H}), 2.67(\mathrm{dd}, J=$ 12.0 and $4.8 \mathrm{~Hz}, 1 \mathrm{H}), 2.61(\mathrm{dd}, J=12.0$ and $4.8 \mathrm{~Hz}, 1 \mathrm{H}), 2.01(\mathrm{~s}, 3 \mathrm{H}), 1.75(\mathrm{t}, J=12.0 \mathrm{~Hz}$, $1 \mathrm{H}), 1.72(\mathrm{t}, J=12.0 \mathrm{~Hz}, 1 \mathrm{H}) ;{ }^{13} \mathrm{C}$ NMR $\left(200 \mathrm{MHz}, \mathrm{D}_{2} \mathrm{O}\right) \delta 174.73,173.96,173.41$, 135.18, 102.59, 100.68, 100.49, 95.64, 91.68, 78.10, 77.78, 75.96, 74.72, 74.69, 74.36, $74.32,74.13,73.62,73.57,71.86,71.18,70.98,70.76,70.50,70.32,70.24,69.99,69.67$, $69.59,69.46,69.37,67.70,67.58,63.44,62.50,61.21,60.80,60.55,59.91,52.34,42.51$, 39.15, 38.42, 34.11, 22.42. HRMS (ESI) $\mathrm{m} / \mathrm{z}$ calcd for $\mathrm{C}_{38} \mathrm{H}_{62} \mathrm{NO}_{32}(\mathrm{M}-\mathrm{H})$ 1044.3255, found 1044.3186 .

\section{General procedures for OPME synthesis of GM1 (4 compounds, 26-29) and} GD1 glycans (5 compounds, 30-34)-A GM2 or GD2 glycan (10 mM, 1 eq.) as an acceptor and Gal (1.1 eq.) were incubated at $37{ }^{\circ} \mathrm{C}$ in Tris- $\mathrm{HCl}$ buffer ( $100 \mathrm{mM}$, pH 7.5) containing ATP (1.2 eq.), UTP (1.2 eq.), $\mathrm{MgCl}_{2}(10 \mathrm{mM})$, EcGalK ( $\left.3 \mathrm{mg} / \mathrm{mL}\right)$, BLUSP (3 $\mathrm{mg} / \mathrm{mL}), \mathrm{CjCgtB}(2.5 \mathrm{mg} / \mathrm{mL})$, and PmPpA $(2 \mathrm{mg} / \mathrm{mL})$. The reaction was carried out by incubating the solution in an incubator shaker at $37^{\circ} \mathrm{C}$ for overnight with agitation at 100 
rpm. The product formation was monitored by LC-MS. When an optimal yield was achieved, alkaline phosphatase (10-20 mg) was added to the reaction mixture and the mixture was incubated in an incubator shaker at $37^{\circ} \mathrm{C}$ for overnight with agitation at 100 $\mathrm{rpm}$. The reaction was then quenched by adding the same volume of ice-cold ethanol and incubated at $4{ }^{\circ} \mathrm{C}$ for $30 \mathrm{~min}$. The mixture was then centrifuged and the precipitates were removed. The supernatant was concentrated, passed through a BioGel P-2 gel filtration column, and eluted with water to obtain sialoside mixtures. The fractions containing the product were collected, concentrated, and further purified by HPLC with a XBridge BEH

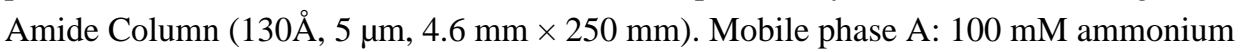
formate, $\mathrm{pH}$ 3.46; Mobile phase B: acetonitrile; Gradient: $65 \%$ to $50 \%$ B over 25 minutes, $50 \%$ to $0 \%$ B over 1 minute, $0 \%$ B for 2 minutes, $0 \%$ to $65 \%$ B over 2 minutes, $65 \%$ B for 5 minutes. HPLC purification was monitored by absorption at $210 \mathrm{~nm}$, and glycan-containing fractions were analyzed by TLC and MS. The fractions containing the pure product were collected and lyophilized to produce the desired GM1 and GD1b glycans (yields 80-90\%).

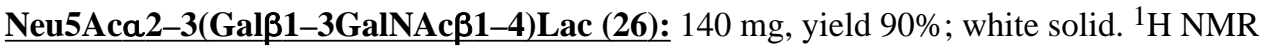
$\left(800 \mathrm{MHz}, \mathrm{D}_{2} \mathrm{O}\right) \delta 5.21(\mathrm{~d}, J=4.0 \mathrm{~Hz}, 0.4 \mathrm{H}), 4.76(\mathrm{~d}, J=8.0 \mathrm{~Hz}, 1 \mathrm{H}), 4.65(\mathrm{~d}, J=8.0 \mathrm{~Hz}$, $0.6 \mathrm{H}), 4.52(\mathrm{~d}, J=8.0 \mathrm{~Hz}, 1 \mathrm{H}), 4.51(\mathrm{~d}, J=8.0 \mathrm{~Hz}, 1 \mathrm{H}), 4.10(\mathrm{~s}, 2 \mathrm{H}), 4.15-3.24(\mathrm{~m}, 31 \mathrm{H})$, $2.66(\mathrm{dd}, J=12.0$ and $4.8 \mathrm{~Hz}, 1 \mathrm{H}), 2.00(\mathrm{~s}, 3 \mathrm{H}), 1.92(\mathrm{t}, J=12.0 \mathrm{~Hz}, 1 \mathrm{H}) ;{ }^{13} \mathrm{C}$ NMR $(200$ $\left.\mathrm{MHz}, \mathrm{D}_{2} \mathrm{O}\right) \delta 174.97,174.72,174.07,104.68,102.51,102.47,101.58,95.72,91.77,80.28$, $78.51,78.44,77.10,74.84,74.72,74.38,74.31,74.28,74.03,73.69,73.02,72.45,72.23$, $71.36,71.04,70.64,70.02,69.97,68.65,68.56,68.53,67.96,67.85,62.78,61.07,60.90$, 60.60, 60.07, 59.92, 51.57, 51.14, 36.91, 22.56, 22.05.HRMS (ESI) $\mathrm{m} / \mathrm{z}$ calcd for $\mathrm{C}_{37} \mathrm{H}_{61} \mathrm{~N}_{2} \mathrm{O}_{29}(\mathrm{M}-\mathrm{H}) 997.3360$, found 997.3349 .

Neu5Gca2-3(Galß1-3GalNAcß1-4)Lac (27): $51 \mathrm{mg}$, yield 86\%; white solid. ${ }^{1} \mathrm{H}$ NMR $\left(800 \mathrm{MHz}, \mathrm{D}_{2} \mathrm{O}\right) \delta 5.20(\mathrm{~d}, J=4.0 \mathrm{~Hz}, 0.4 \mathrm{H}), 4.76(\mathrm{~d}, J=8.0 \mathrm{~Hz}, 1 \mathrm{H}), 4.65(\mathrm{~d}, J=8.0 \mathrm{~Hz}$, $0.6 \mathrm{H}), 4.52(\mathrm{~d}, J=8.0 \mathrm{~Hz}, 1 \mathrm{H}), 4.51(\mathrm{~d}, J=8.0 \mathrm{~Hz}, 1 \mathrm{H}), 4.51(\mathrm{~d}, J=8.0 \mathrm{~Hz}, 0.6 \mathrm{H}), 4.16-$ $3.25(\mathrm{~m}, 31 \mathrm{H}), 2.65(\mathrm{dd}, J=12.0$ and $4.8 \mathrm{~Hz}, 1 \mathrm{H}), 2.02(\mathrm{~s}, 3 \mathrm{H}), 1.99(\mathrm{~s}, 3 \mathrm{H}), 1.92(\mathrm{t}, J=$ $12.0 \mathrm{~Hz}, 1 \mathrm{H}) ;{ }^{13} \mathrm{C}$ NMR $\left(200 \mathrm{MHz}, \mathrm{D}_{2} \mathrm{O}\right) \delta 175.71,174.72,174.09,104.67,102.49,102.45$, 102.41, 101.58, 95.71, 91.76, 80.28, 78.50, 78.42, 77.06, 74.83, 74.71, 74.29, 74.03, 74.02, $73.69,73.66,72.73,72.43,72.28,71.02,70.62,69.97,69.95,68.56,68.49,68.41,68.37$, $67.85,67.82,62.73,62.69,61.05,60.94,60.89,60.87,60.58,60.05,59.91,51.28,51.24$, 51.14, 36.98, 36.93, 22.56. HRMS (ESI) $\mathrm{m} / z$ calcd for $\mathrm{C}_{37} \mathrm{H}_{61} \mathrm{~N}_{2} \mathrm{O}_{30}$ (M-H) 1013.3309, found 1013.3318 .

Kdna2-3(Galß1-3GalNAc $\boldsymbol{\beta 1 - 4 ) L a c ~ ( 2 8 ) : ~} 5$ mg, yield 87\%; white solid. ${ }^{1} \mathrm{H}$ NMR (800 $\left.\mathrm{MHz}, \mathrm{D}_{2} \mathrm{O}\right) \delta 5.20(\mathrm{~d}, J=4.0 \mathrm{~Hz}, 0.4 \mathrm{H}), 4.76(\mathrm{~d}, J=8.0 \mathrm{~Hz}, 1 \mathrm{H}), 4.64(\mathrm{~d}, J=8.0 \mathrm{~Hz}, 0.6 \mathrm{H})$, $4.52(\mathrm{~d}, J=8.0 \mathrm{~Hz}, 1 \mathrm{H}), 4.50(\mathrm{~d}, J=8.0 \mathrm{~Hz}, 1 \mathrm{H}), 4.17-3.23(\mathrm{~m}, 31 \mathrm{H}), 2.59(\mathrm{dd}, J=12.0$ and $4.8 \mathrm{~Hz}, 1 \mathrm{H}), 1.98(\mathrm{~s}, 3 \mathrm{H}), 1.86(\mathrm{t}, J=12.0 \mathrm{~Hz}, 1 \mathrm{H}) ;{ }^{13} \mathrm{C} \mathrm{NMR}\left(200 \mathrm{MHz}, \mathrm{D}_{2} \mathrm{O}\right) \delta 174.73$, 174.15, 104.61, 104.15, 102.42, 102.36, 95.62, 78.31, 76.93, 74.90, 74.74, 74.63, 74.22, $74.15,73.93,73.59,72.40,72.35,71.25,70.95,70.90,70.54,70.46,69.92,69.87,69.52$, 68.44, 67.77, 67.45, 62.75, 60.99, 60.79, 60.44, 59.96, 36.37, 22.45. HRMS (ESI) $\mathrm{m} / \mathrm{z}$ calcd for $\mathrm{C}_{35} \mathrm{H}_{58} \mathrm{NO}_{29}(\mathrm{M}-\mathrm{H}) 956.3094$, found 956.3088 . 
Neu5Ac80Mea2-3(Galß1-3GalNAc $\boldsymbol{\beta 1 - 4 ) L a c ~ ( 2 9 ) : ~} 2 \mathrm{mg}$, yield 80\%; white solid. ${ }^{1} \mathrm{H}$ NMR $\left(800 \mathrm{MHz}, \mathrm{D}_{2} \mathrm{O}\right) \delta 5.20(\mathrm{~d}, J=4.0 \mathrm{~Hz}, 1 \mathrm{H}), 4.65(\mathrm{~d}, J=8.0 \mathrm{~Hz}, 1 \mathrm{H}), 4.47(\mathrm{~d}, J=8.0$ $\mathrm{Hz}, 1 \mathrm{H})$ ), $4.42(\mathrm{~d}, J=8.0 \mathrm{~Hz}, 2 \mathrm{H}), 4.20-3.24(\mathrm{~m}, 31 \mathrm{H}), 3.41$ (s, 3H), $2.54(\mathrm{dd}, J=12.0$ and $4.8 \mathrm{~Hz}, 1 \mathrm{H}), 1.95(\mathrm{~s}, 3 \mathrm{H}), 1.94(\mathrm{~s}, 3 \mathrm{H}), 1.74(\mathrm{t}, J=12.0 \mathrm{~Hz}, 1 \mathrm{H})$; HRMS (ESI) $\mathrm{m} / z$ calcd for $\mathrm{C}_{38} \mathrm{H}_{63} \mathrm{~N}_{2} \mathrm{O}_{29}(\mathrm{M}-\mathrm{H})$ 1011.3516, found 1011.3521.

Neu5Aca2-8Neu5Aca2-3(Galß1-3GalNAcß1-4)Lac (30): $12 \mathrm{mg}$, yield 88\%; white solid. ${ }^{1} \mathrm{H}$ NMR $\left(800 \mathrm{MHz}, \mathrm{D}_{2} \mathrm{O}\right) \delta 5.19(\mathrm{~d}, J=4.0 \mathrm{~Hz}, 0.4 \mathrm{H}), 4.73(\mathrm{~d}, J=8.0 \mathrm{~Hz}, 0.4 \mathrm{H})$, $4.48(\mathrm{~d}, J=8.0 \mathrm{~Hz}, 0.6 \mathrm{H}), 4.64(\mathrm{~d}, J=8.0 \mathrm{~Hz}, 0.6 \mathrm{H}), 4.50(\mathrm{~d}, J=8.0 \mathrm{~Hz}, 1 \mathrm{H}), 4.49$ (d, $J=$ $8.0 \mathrm{~Hz}, 0.4 \mathrm{H}), 4.49$ (d, $J=8.0 \mathrm{~Hz}, 0.6 \mathrm{H}), 4.17-3.24(\mathrm{~m}, 38 \mathrm{H}), 2.74(\mathrm{dd}, J=12.0$ and $4.8 \mathrm{~Hz}$, $1 \mathrm{H}), 2.66(\mathrm{dd}, J=12.0$ and $4.8 \mathrm{~Hz}, 1 \mathrm{H}), 2.05(\mathrm{~s}, 3 \mathrm{H}), 2.01(\mathrm{~s}, 3 \mathrm{H}), 2.00(\mathrm{~s}, 3 \mathrm{H}), 1.77$ (t, $J=$ $12.0 \mathrm{~Hz}, 1 \mathrm{H}), 1.71(\mathrm{t}, J=12.0 \mathrm{~Hz}, 1 \mathrm{H}) ;{ }^{13} \mathrm{C} \mathrm{NMR}\left(200 \mathrm{MHz}, \mathrm{D}_{2} \mathrm{O}\right) \delta 174.86,174.81$, $174.71,173.29,173.28,104.52,102.58,102.29,95.65,79.70,78.17,78.05,75.85,74.80$, $74.70,74.38,74.14,73.98,73.59,72.52,72.33,71.65,71.20,71.00,70.54,69.60,69.14$, 69.11, 68.47, 68.44, 68.36, 68.01, 67.98, 67.68, 62.43, 61.32, 60.81, 60.76, 60.55, 59.87, $52.23,51.62,51.21,40.32,22.41,22.22,21.91$. HRMS (ESI) $\mathrm{m} / \mathrm{z}$ calcd for $\mathrm{C}_{48} \mathrm{H}_{78} \mathrm{~N}_{3} \mathrm{O}_{37}$ (M-H) 1288.4314 , found 1288.4320 .

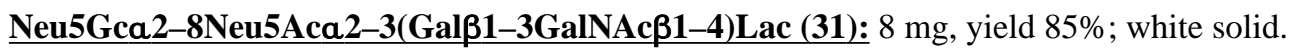
${ }^{1} \mathrm{H}$ NMR $\left(800 \mathrm{MHz}, \mathrm{D}_{2} \mathrm{O}\right) \delta 5.19(\mathrm{~d}, J=4.0 \mathrm{~Hz}, 0.4 \mathrm{H}), 4.74(\mathrm{~d}, J=8.0 \mathrm{~Hz}, 1 \mathrm{H}), 4.64(\mathrm{~d}, J=$ $8.0 \mathrm{~Hz}, 0.6 \mathrm{H}), 4.49(\mathrm{~d}, J=8.0 \mathrm{~Hz}, 1 \mathrm{H}), 4.48(\mathrm{~d}, J=8.0 \mathrm{~Hz}, 1 \mathrm{H}), 4.16-3.25(\mathrm{~m}, 40 \mathrm{H}), 2.76$ (dd, $J=12.0$ and $4.8 \mathrm{~Hz}, 1 \mathrm{H}), 2.66(\mathrm{dd}, J=12.0$ and $4.8 \mathrm{~Hz}, 1 \mathrm{H}), 2.05(\mathrm{~s}, 3 \mathrm{H}), 2.01(\mathrm{~s}, 3 \mathrm{H})$, $1.76(\mathrm{t}, J=12.0 \mathrm{~Hz}, 1 \mathrm{H}), 1.73(\mathrm{t}, J=12.0 \mathrm{~Hz}, 1 \mathrm{H}) ;{ }^{13} \mathrm{C} \mathrm{NMR}\left(200 \mathrm{MHz}, \mathrm{D}_{2} \mathrm{O}\right) \delta 175.61$, 174.81, 174.71, 173.29, 173.28, 104.53, 102.58, 102.29, 95.65, 79.71, 78.15, 78.06, 75.85, $74.80,74.70,74.39,74.15,73.99,73.60,72.34,72.24,71.71,71.19,71.00,70.54,69.61$, 69.12, 68.46, 68.10, 68.02, 67.91, 67.69, 62.40, 61.32, 60.84, 60.56, 52.23, 51.33, 51.22, 40.38, 22.41, 22.22. HRMS (ESI) $\mathrm{m} / \mathrm{z}$ calcd for $\mathrm{C}_{48} \mathrm{H}_{78} \mathrm{~N}_{3} \mathrm{O}_{38}$ (M-H) 1304.4263 , found 1304.4241 .

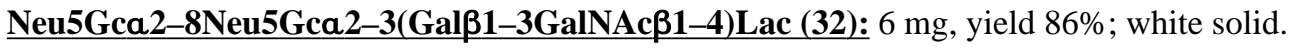
${ }^{1} \mathrm{H}$ NMR $\left(800 \mathrm{MHz}, \mathrm{D}_{2} \mathrm{O}\right) \delta 5.20(\mathrm{~d}, J=4.0 \mathrm{~Hz}, 0.4 \mathrm{H}), 4.74(\mathrm{~d}, J=8.0 \mathrm{~Hz}, 1 \mathrm{H}), 4.64(\mathrm{~d}, J=$ $8.0 \mathrm{~Hz}, 0.6 \mathrm{H}), 4.51(\mathrm{~d}, J=8.0 \mathrm{~Hz}, 1 \mathrm{H}), 4.49(\mathrm{~d}, J=8.0 \mathrm{~Hz}, 1 \mathrm{H}), 4.21-3.24(\mathrm{~m}, 42 \mathrm{H}), 2.76$ (dd, $J=12.0$ and $4.8 \mathrm{~Hz}, 1 \mathrm{H}), 2.68(\mathrm{dd}, J=12.0$ and $4.8 \mathrm{~Hz}, 1 \mathrm{H}), 2.03$ (s, 3H), 1.78 (t, $J=$ $12.0 \mathrm{~Hz}, 1 \mathrm{H}), 1.71(\mathrm{t}, J=12.0 \mathrm{~Hz}, 1 \mathrm{H}) ;{ }^{13} \mathrm{C} \mathrm{NMR}\left(200 \mathrm{MHz}, \mathrm{D}_{2} \mathrm{O}\right){ }^{\text {тм }} 175.97,175.63$, 174.71, 173.63, 173.27, 104.53, 104.15, 102.60, 102.31, 95.65, 79.71, 78.37, 78.08, 75.92, $74.80,74.70,74.42,74.15,73.99,73.64,73.34,72.34,72.21,71.73,71.20,71.00,70.54$, $70.00,69.61,68.87,68.46,68.02,67.95,67.69,67.55,62.42,61.26,61.01,60.84,60.81$, $60.76,60.55,52.07,51.33,51.22,40.52,22.42$. HRMS (ESI) $\mathrm{m} / \mathrm{z}$ calcd for $\mathrm{C}_{48} \mathrm{H}_{78} \mathrm{~N}_{3} \mathrm{O}_{39}$ (M-H) 1320.4212, found 1320.4232 .

Kdna2-8Neu5Gca2-3(Gal $\boldsymbol{1} 1$-3GalNAc $\boldsymbol{\beta} 1-4)$ Lac (33): $3 \mathrm{mg}$, yield 85\%; white solid. ${ }^{1} \mathrm{H}$ NMR $\left(800 \mathrm{MHz}, \mathrm{D}_{2} \mathrm{O}\right) \delta 5.20(\mathrm{~d}, J=4.0 \mathrm{~Hz}, 0.4 \mathrm{H}), 4.74(\mathrm{~d}, J=8.0 \mathrm{~Hz}, 1 \mathrm{H}), 4.65(\mathrm{~d}, J=$ $8.0 \mathrm{~Hz}, 0.6 \mathrm{H}), 4.51(\mathrm{~d}, J=8.0 \mathrm{~Hz}, 1 \mathrm{H}), 4.49$ (d, $J=8.0 \mathrm{~Hz}, 1 \mathrm{H}), 4.20-3.24(\mathrm{~m}, 40 \mathrm{H}), 2.68$ (dd, $J=12.0$ and $4.8 \mathrm{~Hz}, 2 \mathrm{H}), 2.01(\mathrm{~s}, 3 \mathrm{H}), 1.78(\mathrm{t}, J=12.0 \mathrm{~Hz}, 1 \mathrm{H}), 1.67$ (t, $J=12.0 \mathrm{~Hz}$, $1 \mathrm{H}) ;{ }^{13} \mathrm{C}$ NMR (200 MHz, $\left.\mathrm{D}_{2} \mathrm{O}\right) \delta 175.99,174.71,173.80,173.26,104.53,102.61,102.31$, 
$95.65,79.72,78.34,78.10,74.79,74.70,74.42,74.14,73.98,73.63,73.49,73.35,72.33$, $71.96,71.19,70.54,70.19,70.00,69.69,69.60,68.85,68.46,67.66,67.55,62.52,61.24$, 61.00, 60.81, 60.76, 52.07, 40.08, 22.41. HRMS (ESI) $\mathrm{m} / \mathrm{z}$ calcd for $\mathrm{C}_{46} \mathrm{H}_{75} \mathrm{~N}_{2} \mathrm{O}_{38}(\mathrm{M}-\mathrm{H}$ ) 1263.3998, found 1263.4009 .

Kdna2-8Kdna2-3(Galß1-3GalNAcß1-4)Lac (34): $3 \mathrm{mg}$, yield 83\%; white solid. ${ }^{1} \mathrm{H}$ NMR $\left(800 \mathrm{MHz}, \mathrm{D}_{2} \mathrm{O}\right) \delta 5.19(\mathrm{~d}, J=4.0 \mathrm{~Hz}, 0.4 \mathrm{H}), 4.74(\mathrm{~d}, J=8.0 \mathrm{~Hz}, 1 \mathrm{H}), 4.65(\mathrm{~d}, J=$ $8.0 \mathrm{~Hz}, 0.6 \mathrm{H}), 4.51(\mathrm{~d}, J=8.0 \mathrm{~Hz}, 1 \mathrm{H}), 4.49(\mathrm{~d}, J=8.0 \mathrm{~Hz}, 1 \mathrm{H}), 4.18-3.24(\mathrm{~m}, 38 \mathrm{H}), 2.65$ $(\mathrm{dd}, J=12.0$ and $4.8 \mathrm{~Hz}, 2 \mathrm{H}), 2.01(\mathrm{~s}, 3 \mathrm{H}), 1.75(\mathrm{t}, J=12.0 \mathrm{~Hz}, 1 \mathrm{H}), 1.74(\mathrm{t}, J=12.0 \mathrm{~Hz}$, 1H). ${ }^{13} \mathrm{C}$ NMR (200 MHz, $\left.\mathrm{D}_{2} \mathrm{O}\right) \delta 174.70,174.69,173.98,173.48,104.56,102.59,102.30$, 100.69, 95.65, 91.69, 79.78, 78.22, 78.15, 77.76, 76.06, 74.78, 74.73, 74.70, 74.36, 74.16, $73.99,73.62,73.57,72.35,71.87,71.20,70.98,70.55,70.52,70.34,69.99,69.69,69.63$, 69.39, 68.47, 67.73, 62.53, 61.20, 60.81, 60.75, 60.54, 59.93, 51.20, 39.16, 38.35, 22.42. HRMS (ESI) $\mathrm{m} / \mathrm{z}$ calcd for $\mathrm{C}_{44} \mathrm{H}_{72} \mathrm{NO}_{37}$ (M-H) 1206.3783, found 1206.3774 .

\section{One-pot four-enzyme preparative-scale synthesis of GIcNAc $\beta 1-3$ Lac (35)-}

Lactose (0.90 g, $2.63 \mathrm{mmol}, 40.5 \mathrm{mM})$, GlcNAc (0.756 g, $3.42 \mathrm{mmol})$, ATP (1.88 g, 3.42 $\mathrm{mmol}$ ), and UTP (1.99 g, $3.42 \mathrm{mmol})$ were dissolved in Tris-HCl buffer ( $65 \mathrm{~mL}, \mathrm{pH}$ 8.0) containing $\mathrm{MgCl}_{2}$ (20 mM). BLNahK (19.0 mg), PmGlmU (8.0 mg), NmLgtA (6.0 mg), and PmPpA (4-5 mg) were added. The reactions were carried out by incubating the reaction mixture in an incubator shaker at $37^{\circ} \mathrm{C}$ for $48 \mathrm{~h}$. The product formation was monitored by TLC (EtOAc:MeOH: $\mathrm{H}_{2} \mathrm{O}: \mathrm{HOAc}=4: 2: 1: 0.2$ and detected by $p$-anisaldehyde sugar stain) and mass spectrometry (MS). Upon completion, to the reaction was added the same volume $(65 \mathrm{~mL})$ of ethanol and the mixture was incubated at $4{ }^{\circ} \mathrm{C}$ for $30 \mathrm{~min}$. After centrifugation, the supernatant was concentrated and passed through a Bio Gel P-2 gel filtration column (water was used as an eluant). The fractions containing the product were collected, concentrated, and further purified by silica gel column (EtOAc: $\left.\mathrm{MeOH}: \mathrm{H}_{2} \mathrm{O}, 5: 2: 1\right)$ to obtain trisaccharide GlcNAc $\beta 1-3 \mathrm{Lac}(35)(1.35 \mathrm{~g}, 94 \%) .{ }^{1} \mathrm{H}$ NMR $\left(800 \mathrm{MHz}, \mathrm{D}_{2} \mathrm{O}\right) \delta 5.19$ (d, $J=$ $4.0 \mathrm{~Hz}, 0.4 \mathrm{H}), 4.66(\mathrm{~d}, J=8.0 \mathrm{~Hz}, 0.4 \mathrm{H}), 4.65(\mathrm{~d}, J=8.0 \mathrm{~Hz}, 0.6 \mathrm{H}), 4.64(\mathrm{~d}, J=8.0 \mathrm{~Hz}$, $0.6 \mathrm{H}), 4.41(\mathrm{~d}, J=8.0 \mathrm{~Hz}, 1 \mathrm{H}), 4.12(\mathrm{~d}, J=3.2 \mathrm{~Hz}, 1 \mathrm{H}), 3.93-3.24(\mathrm{~m}, 17 \mathrm{H}), 2.01(\mathrm{~s}, 3 \mathrm{H})$. ${ }^{13} \mathrm{C}$ NMR $\left(200 \mathrm{MHz}, \mathrm{D}_{2} \mathrm{O}\right) \beta$-isomer: $\delta 174.87,102.84,102.75,95.66,81.87,78.21,75.57$, 74.80, 74.71, 74.20, 73.71, 73.49, 70.03, 69.92, 68.26, 60.88, 60.41, 60.01, 56.58, 22.09. HRMS (ESI) $\mathrm{m} / \mathrm{z}$ calculated for $\mathrm{C}_{20} \mathrm{H}_{36} \mathrm{NO}_{16}(\mathrm{M}+\mathrm{H})$ 546.2034, found 546.2050. NMR data were consistent with those reported in the literature. ${ }^{64}$

\section{One-pot four-enzyme preparative-scale synthesis of Gal $\beta 1-4$ GIcNAc $\beta 1-3 L a c$}

(36)-Trisaccharide GlcNAc $\beta 1-3 \mathrm{Lac}(1.0 \mathrm{~g}, 1.83 \mathrm{mmol}, 22.9 \mathrm{mM})$, galactose $(0.43 \mathrm{~g}, 2.38$ $\mathrm{mmol})$, ATP (1.40 g, $2.38 \mathrm{mmol})$, and UTP (1.58 g, $2.38 \mathrm{mmol})$ were dissolved in Tris- $\mathrm{HCl}$ buffer ( $80 \mathrm{~mL}, 100 \mathrm{mM}, \mathrm{pH} 8.0)$ containing $\mathrm{MgCl}_{2}$ (20 mM), EcGalK (20.0 mg), BLUSP (20 mg), NmLgtB (15 mg), and PpA (20 mg). The reactions were carried out by incubating the reaction mixture in an incubator shaker at $37^{\circ} \mathrm{C}$ for $30 \mathrm{~h}$. The product formation was monitored by TLC ( $n-\mathrm{PrOH}: \mathrm{H}_{2} \mathrm{O}: \mathrm{NH}_{4} \mathrm{OH}=5: 2: 1$ and detected by $p$-anisaldehyde sugar stain) and mass spectrometry (MS). When an optimal yield was achieved, to the reaction mixture was added the same volume $(80 \mathrm{~mL})$ of ethanol and the mixture was incubated at $4{ }^{\circ} \mathrm{C}$ for $30 \mathrm{~min}$. The precipitates were removed by centrifugation and the supernatant was 
concentrated and purified by a Bio Gel P-2 gel column (water as eluent). Further purification was achieved by silica gel chromatography (EtOAc: $\mathrm{MeOH}: \mathrm{H}_{2} \mathrm{O}=5: 3: 1.5$, by volume) to obtain Gal $\beta 1-4 \mathrm{GlcNAc} \beta 1-3 \mathrm{Lac}(\mathbf{3 6})(1.28 \mathrm{~g}, 99 \%) .{ }^{1} \mathrm{H}$ NMR $\left(800 \mathrm{MHz}, \mathrm{D}_{2} \mathrm{O}\right) \delta 5.17$ (d, $J$ $=4.0 \mathrm{~Hz}, 0.4 \mathrm{H}), 4.66(\mathrm{~d}, J=8.0 \mathrm{~Hz}, 0.4 \mathrm{H}), 4.65(\mathrm{~d}, J=8.0 \mathrm{~Hz}, 0.6 \mathrm{H}), 4.61(\mathrm{~d}, J=8.0 \mathrm{~Hz}$, $0.6 \mathrm{H}), 4.43(\mathrm{~d}, J=7.2 \mathrm{~Hz}, 1 \mathrm{H}), 4.38(\mathrm{~d}, J=8.0 \mathrm{~Hz}, 1 \mathrm{H}), 4.11(\mathrm{~d}, J=3.2 \mathrm{~Hz}, 1 \mathrm{H}), 3.91-3.87$ (m, 2H), 3.84-3.22 (m, 21H), 1.98 (s, 3H). ${ }^{13} \mathrm{C}$ NMR (200 MHz, $\left.\mathrm{D}_{2} \mathrm{O}\right) \beta$-isomer: $\delta 174.83$, 102.79, 102.76, 102.73, 95.61, 81.82, 78.21, 78.11, 75.52 (2C), 74.76, 74.66, 74.22, 73.65, 73.42 (2C), 70.99, 69.88, 68.24, 68.22, 60.85, 60.84, 60.34, 59.93, 56.52, 22.03. HRMS (ESI) $\mathrm{m} / \mathrm{z}$ calculated for $\mathrm{C}_{26} \mathrm{H}_{46} \mathrm{NO}_{21}(\mathrm{M}+\mathrm{H}) 708.2562$, found 708.2586. NMR data were consistent with those reported in the literature. ${ }^{64}$

\section{One-pot three-enzyme preparative-scale synthesis of Gal $\beta 1-4$ (Fuca1- 3)GICNAcß1-3Lac (46)—LNnT (160 mg, $0.23 \mathrm{mmol}, 23 \mathrm{mM}$ ), L-fucose (74 mg, 0.45} $\mathrm{mmol})$, ATP (250 mg, $0.45 \mathrm{mmol})$, and GTP (240 mg, $0.45 \mathrm{mmol})$ were dissolved in Tris$\mathrm{HCl}$ buffer (10 mL, $100 \mathrm{mM}, \mathrm{pH} 7.5)$ containing $\mathrm{MgCl}_{2}$ (20 mM), FKP (3.0 mg), Hpa 13FT (2.5 mg), and PmPpA ( $2 \mathrm{mg}$ ). The reactions were carried out by incubating the reaction mixture in an incubator shaker at $37^{\circ} \mathrm{C}$ for $48 \mathrm{~h}$. The product formation was monitored by TLC ( $n$-PrOH: $\mathrm{H}_{2} \mathrm{O}: \mathrm{NH}_{4} \mathrm{OH}=4: 2: 1$ and detected by $p$-anisaldehyde sugar stain) and mass spectrometry (MS). When an optimal yield was achieved, to the reaction mixture was added the same volume $(10 \mathrm{~mL})$ of ethanol and the mixture was incubated at $4{ }^{\circ} \mathrm{C}$ for $30 \mathrm{~min}$. The precipitates were removed by the centrifuge and the supernatant was concentrated and purified by a Bio Gel P-2 gel column (water was used as an eluant). Further purification was achieved by silica gel chromatography (EtOAc: $\mathrm{MeOH}: \mathrm{H}_{2} \mathrm{O}=5: 3: 2$, by volume) to obtain Gal $\beta 1-4$ (Fuca 1-3)GlcNAc $\beta 1-3 \operatorname{Lac}(\mathbf{4 6})$ (181 mg, 94\%). ${ }^{1} \mathrm{H}$ NMR $\left(800 \mathrm{MHz}, \mathrm{D}_{2} \mathrm{O}\right) \delta 5.17$ $(\mathrm{d}, J=4.0 \mathrm{~Hz}, 0.3 \mathrm{H}), 5.08(\mathrm{~d}, J=4.0 \mathrm{~Hz}, 1 \mathrm{H}), 4.66(\mathrm{~d}, J=7.2 \mathrm{~Hz}, 1 \mathrm{H}), 4.61(\mathrm{~d}, J=8.0 \mathrm{~Hz}$, $0.7 \mathrm{H}), 4.42(\mathrm{~d}, J=8.0 \mathrm{~Hz}, 1 \mathrm{H}), 4.39(\mathrm{~d}, J=8.0 \mathrm{~Hz}, 1 \mathrm{H}), 4.11(\mathrm{~d}, J=3.2 \mathrm{~Hz}, 1 \mathrm{H}), 3.92-3.22$ (m, 27H), 1.98 (s, 3H), 1.13 (d, $J=6.4 \mathrm{~Hz}, 3 \mathrm{H}) .{ }^{13} \mathrm{C}$ NMR $\left(200 \mathrm{MHz}, \mathrm{D}_{2} \mathrm{O}\right) \beta$-isomer: $\delta$ 174.57, 102.77, 102.43, 101.62, 98.48, 95.59, 81.91, 78.04, 74.95, 74.77, 74.65, 74.59, $74.19,73.62,72.87,72.30,71.75,71.24,70.88,69.96,69.81,69.03,68.20,67.53,66.55$, $62.22,61.37,60.82,59.45,56.80,22.08,15.16$. HRMS (ESI) $\mathrm{m} / \mathrm{z}$ calculated for $\mathrm{C}_{32} \mathrm{H}_{55} \mathrm{NO}_{25} \mathrm{Na}(\mathrm{M}+\mathrm{Na})$ 876.2961, found 876.2965.

\section{General procedures for OPME synthesis of sialylated LNnT, LNT, and Le pentasaccharides (37-50)—LNnT, LNT, or Le ${ }^{\mathrm{x}}$ pentasaccharide $(20 \mathrm{mM}, 1$ eq.),} Neu5Ac or a sialic acid precursor (ManNGc, mannose, or ManNAc5OMe, 1.5 eq.) with sodium pyruvate ( 7.5 eq.) were incubated at $37{ }^{\circ} \mathrm{C}$ in a Tris- $\mathrm{HCl}$ buffer $(100 \mathrm{mM}, \mathrm{pH} 8.5)$ containing CTP (1.5 eq.), $\mathrm{MgCl}_{2}$ (20 mM), NmCSS (1.5 mg/mL), PmST1 M144D (3 mg/ $\mathrm{mL}$ ), with or without PmNanA (0.2 mg/mL, omit if Neu5Ac was used). The reactions were carried out by incubating the solution in an incubator shaker at $37^{\circ} \mathrm{C}$ for 1 or 2 days with agitation at $100 \mathrm{rpm}$. The product formation was monitored by LC-MS. When an optimal yield was achieved, alkaline phosphatase (10-20 mg) was added to the reaction and the mixture was incubated in an incubator shaker at $37^{\circ} \mathrm{C}$ for overnight with agitation at 100 $\mathrm{rpm}$. The reaction was then quenched by adding the same volume of ice-cold ethanol and the mixture was incubated at $4{ }^{\circ} \mathrm{C}$ for $30 \mathrm{~min}$. The precipitates were removed by centrifugation and the supernatant was concentrated, passed through a BioGel P-2 gel filtration column, 
and eluted with water to obtain sialoside mixtures. The fractions containing the product were collected, concentrated, and further purified by HPLC using a reverse-phase C18 column (10 $\mu \mathrm{m}, 21.2 \times 250 \mathrm{~mm}$ ) with a flow rate of $10 \mathrm{~mL} / \mathrm{min}$ using a gradient elution of $0-100 \%$ acetonitrile in water containing $0.05 \%$ formic acid over 20 minutes. Mobile phase A: $0.05 \%$ formic acid in water (v/v); Mobile phase B: acetonitrile (v/v); Gradient: 0\% B for 3 minutes, $0 \%$ to $100 \%$ B over 12 minutes, $100 \%$ B for 2 minutes, then $100 \%$ to $0 \%$ B over 3 minutes. HPLC purification was monitored by absorption at $210 \mathrm{~nm}$, and glycan-containing fractions were analyzed by TLC and MS. The fractions containing the pure product were collected and concentrated to obtain the desired sialylated lacto- and neolacto-series glycosphingolipid glycans (yields 80-94\%).

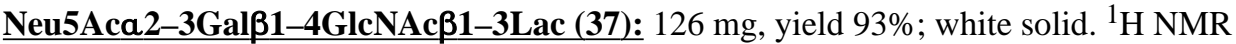
$\left(800 \mathrm{MHz}, \mathrm{D}_{2} \mathrm{O}\right) \delta 5.16(\mathrm{~d}, J=3.2 \mathrm{~Hz}, 0.4 \mathrm{H}), 4.65(\mathrm{~d}, J=8.0 \mathrm{~Hz}, 0.4 \mathrm{H}), 4.64(\mathrm{~d}, J=8.0 \mathrm{~Hz}$, $0.6 \mathrm{H}), 4.60(\mathrm{~d}, J=8.0 \mathrm{~Hz}, 0.6 \mathrm{H}), 4.50(\mathrm{~d}, J=8.0 \mathrm{~Hz}, 1 \mathrm{H}), 4.38(\mathrm{~d}, J=8.0 \mathrm{~Hz}, 1 \mathrm{H}), 4.10(\mathrm{~d}$, $J=3.2 \mathrm{~Hz}, 1 \mathrm{H}), 4.06(\mathrm{dd}, J=3.2$ and $9.6 \mathrm{~Hz}, 1 \mathrm{H}), 3.91-3.21(\mathrm{~m}, 29 \mathrm{H}), 2.70(\mathrm{dd}, J=4.8$ and $12.8 \mathrm{~Hz}, 1 \mathrm{H}), 1.97(\mathrm{~s}, 6 \mathrm{H}), 1.74(\mathrm{t}, J=12.0 \mathrm{~Hz}, 1 \mathrm{H}) .{ }^{13} \mathrm{C}$ NMR $\left(200 \mathrm{MHz}, \mathrm{D}_{2} \mathrm{O}\right) \beta$-isomer: $\delta$ 174.86, 174.77, 173.76, 102.78, 102.69, 102.38, 99.65, 95,59, 81.90, 78.08, 77.77, 75.29, $75.00,74.73,74.37,74.17,73.59,72.70,71.96,71.60,71.22,70.93,69.81,69.21,68.20$, $67.88,67.28,62.37,60.87,59.85,59.72,59.61,56.03,51.58,39.92,22.02,21.89$. HRMS (ESI) $\mathrm{m} / \mathrm{z}$ calculated for $\mathrm{C}_{37} \mathrm{H}_{61} \mathrm{~N}_{2} \mathrm{O}_{29}(\mathrm{M}-\mathrm{H})$ 997.3360, found 997.3364. NMR data were consistent with those reported in the literature. ${ }^{64}$

Neu5Gca2-3Galß1-4GlcNAcß1-3Lac (38): 28 yield 91\%; white solid. ${ }^{1} \mathrm{H}$ NMR (800 $\left.\mathrm{MHz}, \mathrm{D}_{2} \mathrm{O}\right) \delta 5.21(\mathrm{~d}, J=4.0 \mathrm{~Hz}, 0.4 \mathrm{H}), 4.70(\mathrm{~d}, J=8.0 \mathrm{~Hz}, 1 \mathrm{H}), 4.66(\mathrm{~d}, J=8.0 \mathrm{~Hz}, 1 \mathrm{H})$, $4.55(\mathrm{~d}, J=8.0 \mathrm{~Hz}, 1 \mathrm{H}), 4.43(\mathrm{~d}, J=8.0 \mathrm{~Hz}, 1 \mathrm{H}), 4.15(\mathrm{~d}, J=3.2 \mathrm{~Hz}, 1 \mathrm{H}), 4.12(\mathrm{dd}, J=3.2$ and $9.6 \mathrm{~Hz}, 1 \mathrm{H}), 4.11(\mathrm{~s}, 2 \mathrm{H}), 3.97-3.28(\mathrm{~m}, 29 \mathrm{H}), 2.77(\mathrm{dd}, J=4.8$ and $12.8 \mathrm{~Hz}, 1 \mathrm{H}), 2.02$ $(\mathrm{s}, 3 \mathrm{H}), 1.81(\mathrm{t}, J=12.0 \mathrm{~Hz}, 1 \mathrm{H}) .{ }^{13} \mathrm{C}$ NMR $\left(200 \mathrm{MHz}, \mathrm{D}_{2} \mathrm{O}\right) \delta 175.75,174.88,173.87$, 102.87, 102.74, 102.51, 99.79, 95.71, 82.02, 78.23, 77.94, 75.43, 75.14, 74.86, 74.76, 74.51, 74.31, 72.56, 72.10, 71.08, 69.93, 69.35, 68.30, 68.03, 67.96, 61.00, 60.94, 39.64, 22.15. HRMS (ESI) $\mathrm{m} / \mathrm{z}$ calculated for $\mathrm{C}_{37} \mathrm{H}_{61} \mathrm{~N}_{2} \mathrm{O}_{30}(\mathrm{M}-\mathrm{H})$ 1013.3309, found 1013.3292.

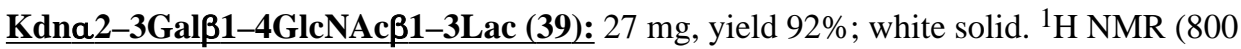
$\left.\mathrm{MHz}, \mathrm{D}_{2} \mathrm{O}\right) \delta 5.20(\mathrm{~d}, J=4.0 \mathrm{~Hz}, 0.4 \mathrm{H}), 4.69(\mathrm{~d}, J=8.0 \mathrm{~Hz}, 0.4 \mathrm{H}), 4.68(\mathrm{~d}, J=8.0 \mathrm{~Hz}$, $0.6 \mathrm{H}), 4.64(\mathrm{~d}, J=8.0 \mathrm{~Hz}, 0.6 \mathrm{H}), 4.52(\mathrm{~d}, J=8.0 \mathrm{~Hz}, 1 \mathrm{H}), 4.42(\mathrm{~d}, J=8.0 \mathrm{~Hz}, 1 \mathrm{H}), 4.13(\mathrm{~d}$, $J=3.2 \mathrm{~Hz}, 1 \mathrm{H}), 4.07(\mathrm{dd}, J=3.2$ and $9.6 \mathrm{~Hz}, 1 \mathrm{H}), 3.95-3.25(\mathrm{~m}, 29 \mathrm{H}), 2.68(\mathrm{dd}, J=4.8$ and $12.8 \mathrm{~Hz}, 1 \mathrm{H}), 2.01(\mathrm{~s}, 3 \mathrm{H}), 1.73(\mathrm{t}, J=12.0 \mathrm{~Hz}, 1 \mathrm{H}) .{ }^{13} \mathrm{C} \mathrm{NMR}\left(200 \mathrm{MHz}, \mathrm{D}_{2} \mathrm{O}\right) \delta 174.85$, $173.99,102.75,102.50,99.75,95.68,82.00,78.20,77.90,75.39,75.13,74.84,74.75,74.49$, $74.29,73.87,73.73,72.08,72.01,71.07,70.20,69.92,69.68,69.31,68.28,67.64,62.57$, $60.99,60.93,55.13,39.22,22.14$. HRMS (ESI) $\mathrm{m} / \mathrm{z}$ calculated for $\mathrm{C}_{35} \mathrm{H}_{58} \mathrm{NO}_{29}(\mathrm{M}-\mathrm{H})$ 956.3094, found 956.3105 .

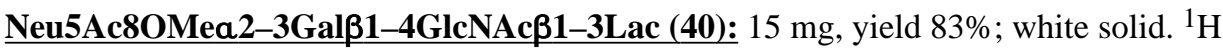
NMR $\left(800 \mathrm{MHz}, \mathrm{D}_{2} \mathrm{O}\right) \delta 5.21(\mathrm{~d}, J=4.0 \mathrm{~Hz}, 0.4 \mathrm{H}), 4.69(\mathrm{~d}, J=8.0 \mathrm{~Hz}, 0.4 \mathrm{H}), 4.68(\mathrm{~d}, J=$ $8.0 \mathrm{~Hz}, 0.6 \mathrm{H}), 4.65(\mathrm{~d}, J=8.0 \mathrm{~Hz}, 0.6 \mathrm{H}), 4.51(\mathrm{~d}, J=8.0 \mathrm{~Hz}, 1 \mathrm{H}), 4.43(\mathrm{~d}, J=8.0 \mathrm{~Hz}, 1 \mathrm{H})$, $4.21-3.25(\mathrm{~m}, 31 \mathrm{H}), 3.49$ (s, 3H), $2.68(\mathrm{dd}, J=4.8$ and $12.8 \mathrm{~Hz}, 1 \mathrm{H}), 2.01(\mathrm{~s}, 3 \mathrm{H}), 1.74(\mathrm{t}, J$ 
$=12.0 \mathrm{~Hz}, 1 \mathrm{H}) .{ }^{13} \mathrm{C}$ NMR $\left(200 \mathrm{MHz}, \mathrm{D}_{2} \mathrm{O}\right) \delta 174.86,174.80,173.52,102.79,102.70$, $102.67,102.59,100.09,95.63,81.96,80.20,78.25,78.14,77.86,76.26,75.62,75.12,74.77$, $74.68,74.47,74.23,71.98,71.00,70.57,69.85,69.27,69.07,68.22,67.88,66.84,60.91$, 59.22, 57.40, 55.10, 43.72, 42.92, 39.71, 26.15, 25.70, 22.07, 21.98. HRMS (ESI) m/z calculated for $\mathrm{C}_{38} \mathrm{H}_{63} \mathrm{~N}_{2} \mathrm{O}_{29}(\mathrm{M}-\mathrm{H})$ 1011.3516, found 1011.3514.

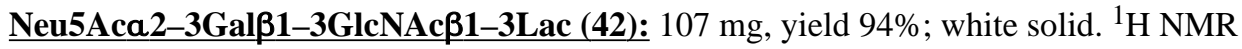
$\left(800 \mathrm{MHz}, \mathrm{D}_{2} \mathrm{O}\right) \delta 5.35(\mathrm{~d}, J=3.2 \mathrm{~Hz}, 0.4 \mathrm{H}), 4.87(\mathrm{~d}, J=8.8 \mathrm{~Hz}, 1 \mathrm{H}), 4.63(\mathrm{~d}, J=8.0 \mathrm{~Hz}$, $1 \mathrm{H}), 4.57(\mathrm{~d}, J=8.0 \mathrm{~Hz}, 1 \mathrm{H}), 4.26(\mathrm{~d}, J=3.2 \mathrm{~Hz}, 1 \mathrm{H}), 4.20(\mathrm{dd}, J=3.2$ and $9.6 \mathrm{~Hz}, 1 \mathrm{H})$, 4.09-3.39 (m, 29H), 2.89 (dd, $J=4.8$ and $12.8 \mathrm{~Hz}, 1 \mathrm{H}), 2.15(\mathrm{~s}, 6 \mathrm{H}), 1.90(\mathrm{t}, J=12.0 \mathrm{~Hz}$, 1H). ${ }^{13} \mathrm{C}$ NMR (200 MHz, $\left.\mathrm{D}_{2} \mathrm{O}\right) \beta$-isomer: $\delta$ 175.07, 174.99, 173.88, 103.42, 102.99, 102.95, 99.76, 95,79, 82.29, 81.98, 78.53, 75.30, 74.73, 74.37, 74.17, 73.59, 72.70, 71.96, $71.60,71.22,70.93,69.81,69.21,68.20,67.88,67.28,61.07,60.65,60.21,60.09,54.66$, $51.78,39.87,22.40,22.11$. HRMS (ESI) m/z calculated for $\mathrm{C}_{37} \mathrm{H}_{61} \mathrm{~N}_{2} \mathrm{O}_{29}$ (M-H) 997.3360, found 997.3368 . NMR data were consistent with those reported in the literature. ${ }^{83}$

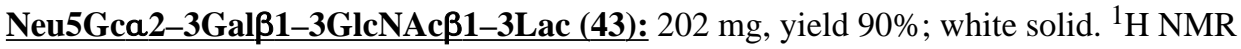
$\left(800 \mathrm{MHz}, \mathrm{D}_{2} \mathrm{O}\right) \delta 5.35(\mathrm{~d}, J=3.2 \mathrm{~Hz}, 0.4 \mathrm{H}), 4.88(\mathrm{~d}, J=8.8 \mathrm{~Hz}, 1 \mathrm{H}), 4.64(\mathrm{~d}, J=8.0 \mathrm{~Hz}$, $2 \mathrm{H}), 4.58(\mathrm{~d}, J=8.0 \mathrm{~Hz}, 0.6 \mathrm{H}), 4.27(\mathrm{~d}, J=3.2 \mathrm{~Hz}, 1 \mathrm{H}), 4.24(\mathrm{~s}, 2 \mathrm{H}), 4.21(\mathrm{dd}, J=3.2$ and $9.6 \mathrm{~Hz}, 1 \mathrm{H}), 4.08-3.39(\mathrm{~m}, 29 \mathrm{H}), 2.89(\mathrm{dd}, J=4.8$ and $12.8 \mathrm{~Hz}, 1 \mathrm{H}), 2.15(\mathrm{~s}, 6 \mathrm{H}), 1.92(\mathrm{t}, J$ $=12.0 \mathrm{~Hz}, 1 \mathrm{H}) .{ }^{13} \mathrm{C}$ NMR $\left(200 \mathrm{MHz}, \mathrm{D}_{2} \mathrm{O}\right) \beta$-isomer: $\delta$ 175.80, 174.94, 173.90, 103.44, 102.97, 102.52, 99.78, 95,74, 82.04, 81.92, 78.54, 75.36, 74.81, 74.50, 74.25, 73.88, 71.98, $71.55,71.54,70.19,69.15,69.10,68.33,67.35,67.10,61.09,61.01,60.62,60.08,54.62$, 51.49, 39.96, 22.41. HRMS (ESI) $\mathrm{m} / \mathrm{z}$ calculated for $\mathrm{C}_{37} \mathrm{H}_{61} \mathrm{~N}_{2} \mathrm{O}_{30}(\mathrm{M}-\mathrm{H}) 1013.3309$, found 1013.3318.

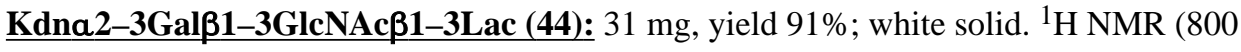
$\left.\mathrm{MHz}, \mathrm{D}_{2} \mathrm{O}\right) \delta 5.20(\mathrm{~d}, J=4.0 \mathrm{~Hz}, 0.4 \mathrm{H}), 4.71(\mathrm{~d}, J=8.0 \mathrm{~Hz}, 0.4 \mathrm{H}), 4.70(\mathrm{~d}, J=8.0 \mathrm{~Hz}$, $0.6 \mathrm{H}), 4.67(\mathrm{~d}, J=8.0 \mathrm{~Hz}, 0.6 \mathrm{H}), 4.47(\mathrm{~d}, J=8.0 \mathrm{~Hz}, 1 \mathrm{H}), 4.42(\mathrm{~d}, J=8.0 \mathrm{~Hz}, 1 \mathrm{H}), 4.12(\mathrm{~d}$, $J=4.0 \mathrm{~Hz}, 1 \mathrm{H}), 4.04(\mathrm{dd}, J=3.2$ and $9.6 \mathrm{~Hz}, 1 \mathrm{H}), 3.94-3.24(\mathrm{~m}, 29 \mathrm{H}), 2.68(\mathrm{dd}, J=4.8$ and $12.8 \mathrm{~Hz}, 1 \mathrm{H}), 2.00(\mathrm{~s}, 3 \mathrm{H}), 1.70$ (t, $J=12.0 \mathrm{~Hz}, 1 \mathrm{H}) .{ }^{13} \mathrm{C}$ NMR $\left(200 \mathrm{MHz}, \mathrm{D}_{2} \mathrm{O}\right) \delta 174.85$, 174.00, 103.37, 103.34, 102.88, 102.84, 102.49, 102.43, 99.52, 95.70, 95.67, 91.78, 91.73, 82.01, 81.89, 81.87, 78.34, 78.22, 75.50, 75.48, 75.15, 75.04, 74.84, 74.74, 74.30, 73.78, 73.72, 72.11, 71.07, 70.20, 69.96, 69.66, 69.01, 69.00, 68.37, 68.27, 68.25, 67.61, 67.16, $67.09,62.47,62.41,60.98,60.92,39.44,39.38,22.26$. HRMS (ESI) $\mathrm{m} / \mathrm{z}$ calculated for $\mathrm{C}_{35} \mathrm{H}_{58} \mathrm{NO}_{29}(\mathrm{M}-\mathrm{H})$ 956.3094, found 956.3106 .

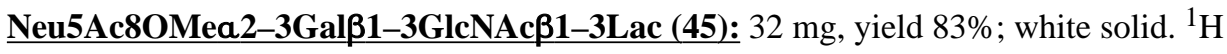
NMR $\left(800 \mathrm{MHz}, \mathrm{D}_{2} \mathrm{O}\right) \delta 5.21(\mathrm{~d}, J=4.0 \mathrm{~Hz}, 0.4 \mathrm{H}), 4.73(\mathrm{~d}, J=8.0 \mathrm{~Hz}, 0.4 \mathrm{H}), 4.72(\mathrm{~d}, J=$ $8.0 \mathrm{~Hz}, 0.6 \mathrm{H}), 4.65(\mathrm{~d}, J=8.0 \mathrm{~Hz}, 0.6 \mathrm{H}), 4.48(\mathrm{~d}, J=8.0 \mathrm{~Hz}, 1 \mathrm{H}), 4.43(\mathrm{~d}, J=8.0 \mathrm{~Hz}, 1 \mathrm{H})$, $4.15-3.25(\mathrm{~m}, 31 \mathrm{H}), 3.48(\mathrm{~s}, 3 \mathrm{H}), 2.67(\mathrm{dd}, J=4.8$ and $12.8 \mathrm{~Hz}, 1 \mathrm{H}), 2.02(\mathrm{~s}, 3 \mathrm{H}), 2.01$ (s, $3 \mathrm{H}), 1.74(\mathrm{t}, J=12.0 \mathrm{~Hz}, 1 \mathrm{H}) .{ }^{13} \mathrm{C}$ NMR $\left(200 \mathrm{MHz}, \mathrm{D}_{2} \mathrm{O}\right) \delta 181.39,174.82,174.74,173.62$, $161.98,103.08,102.82,102.78,102.43,100.01,95.65,95.62,81.82,80.35,78.17,75.56$, 75.06, 74.92, 74.78, 74.68, 74.24, 71.01, 69.89, 69.16, 68.36, 68.21, 67.95, 67.30, 66.82, 
$62.79,62.78,60.87,59.32,57.37,57.36,56.42,51.94,23.15,22.22,21.98$. HRMS (ESI) $\mathrm{m} / \mathrm{z}$ calculated for $\mathrm{C}_{38} \mathrm{H}_{63} \mathrm{~N}_{2} \mathrm{O}_{29}(\mathrm{M}-\mathrm{H})$ 1011.3516, found 1011.3510 .

Neu5Aca2-3Gal $\beta 1$-4(Fuca1-3)GIcNAc $\beta 1$-3Lac (47): $51 \mathrm{mg}$, yield 86\%; white solid. ${ }^{1} \mathrm{H}$ NMR (800 MHz, $\left.\mathrm{D}_{2} \mathrm{O}\right) \delta 5.22(\mathrm{~d}, J=4.0 \mathrm{~Hz}, 0.4 \mathrm{H}), 5.18(\mathrm{~d}, J=3.2 \mathrm{~Hz}, 0.4 \mathrm{H}), 5.12(\mathrm{~d}, J=$ $4.0 \mathrm{~Hz}, 0.6 \mathrm{H}), 4.56(\mathrm{~d}, J=8.0 \mathrm{~Hz}, 0.6 \mathrm{H}), 4.53(\mathrm{~d}, J=8.0 \mathrm{~Hz}, 1 \mathrm{H}), 4.46(\mathrm{~d}, J=8.0 \mathrm{~Hz}$, $0.4 \mathrm{H})$,), 4.44 (d, $J=8.0 \mathrm{~Hz}, 1 \mathrm{H}), 4.42(\mathrm{~d}, J=8.0 \mathrm{~Hz}, 0.6 \mathrm{H}), 4.16(\mathrm{~d}, J=3.2 \mathrm{~Hz}, 1 \mathrm{H}), 4.13-$ $3.27(\mathrm{~m}, 34 \mathrm{H}), 2.77(\mathrm{dd}, J=4.8$ and $12.0 \mathrm{~Hz}, 1 \mathrm{H}), 2.03(\mathrm{~s}, 6 \mathrm{H}), 1.78(\mathrm{~d}, J=12.0 \mathrm{~Hz}, 1 \mathrm{H})$, $1.17(\mathrm{~d}, J=6.4 \mathrm{~Hz}, 3 \mathrm{H}) .{ }^{13} \mathrm{C}$ NMR $\left(200 \mathrm{MHz}, \mathrm{D}_{2} \mathrm{O}\right) \beta$-isomer: $\delta 174.93,174.59,173.77$, 102.83, 102.44, 101.47, 99.56, 98.48, 95.64, 82.00, 78.27, 78.17, 77.92, 75.57, 75.07, 74.82, $74.42,73.68,72.94,72.81,71.81,71.77,71.03,70.02,69.87,69.17,69.08,68.21,68.00$, 67.61, 67.21, 66.56, 62.50, 61.40, 60.89, 59.97, 59.42, 55.17, 51.60, 39.69, 22.13, 21.94, 15.18. HRMS (ESI) $\mathrm{m} / \mathrm{z}$ calculated for $\mathrm{C}_{43} \mathrm{H}_{71} \mathrm{~N}_{2} \mathrm{O}_{33}(\mathrm{M}-\mathrm{H}) 1143.3939$, found 1143.3920 .

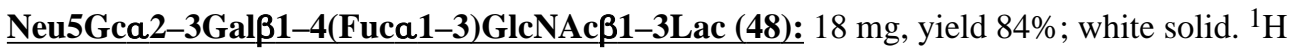
NMR $\left(800 \mathrm{MHz}, \mathrm{D}_{2} \mathrm{O}\right) \delta 5.21(\mathrm{~d}, J=4.0 \mathrm{~Hz}, 0.3 \mathrm{H}), 5.11(\mathrm{~d}, J=4.8 \mathrm{~Hz}, 0.7 \mathrm{H}), 5.09$ (d, $J=$ $4.8 \mathrm{~Hz}, 0.3 \mathrm{H}), 4.69(\mathrm{~d}, J=8.0 \mathrm{~Hz}, 1 \mathrm{H}), 4.65(\mathrm{~d}, J=8.0 \mathrm{~Hz}, 0.7 \mathrm{H}), 4.52(\mathrm{~d}, J=8.0 \mathrm{~Hz}, 1 \mathrm{H})$, $4.44(\mathrm{~d}, J=8.0 \mathrm{~Hz}, 0.3 \mathrm{H}),), 4.42(\mathrm{~d}, J=8.0 \mathrm{~Hz}, 0.7 \mathrm{H}), 4.42(\mathrm{~d}, J=8.0 \mathrm{~Hz}, 1 \mathrm{H}), 4.15(\mathrm{~d}, J=$ $3.2 \mathrm{~Hz}, 1 \mathrm{H}), 4.11(\mathrm{~s}, 2 \mathrm{H}), 4.08(\mathrm{dd}, J=3.2$ and $9.6 \mathrm{~Hz}, 1 \mathrm{H}), 3.98-3.25(\mathrm{~m}, 33 \mathrm{H}), 2.77(\mathrm{dd}, J$ $=4.8$ and $12.0 \mathrm{~Hz}, 1 \mathrm{H}), 2.00(\mathrm{~s}, 3 \mathrm{H}), 1.80(\mathrm{t}, J=12.0 \mathrm{~Hz}, 1 \mathrm{H}), 1.15(\mathrm{~d}, J=6.4 \mathrm{~Hz}, 3 \mathrm{H}) .{ }^{13} \mathrm{C}$ NMR $\left(200 \mathrm{MHz}, \mathrm{D}_{2} \mathrm{O}\right) \delta 175.66,174.56,173.78,102.79,102.46,101.42,99.54,98.46$, 95.60, 91.67, 81.97, 81.94, 78.21, 78.11, 75.52, 74.89, 74.79, 74.76, 74.67, 74.51, 74.22, $73.64,72.89,72.50,72.12,71.78,71.26,70.98,69.98,69.83,69.14,69.04,68.16,67.92$, 67.88, 67.67, 67.57, 67.16, 66.53, 62.41, 61.37, 60.83, 59.93, 59.38, 51.40, 51.26, 48.72, 39.71, 22.11, 15.26, 15.15. HRMS (ESI) m/z calculated for $\mathrm{C}_{43} \mathrm{H}_{71} \mathrm{~N}_{2} \mathrm{O}_{34}(\mathrm{M}-\mathrm{H})$ 1159.3888 , found 1159.3898 .

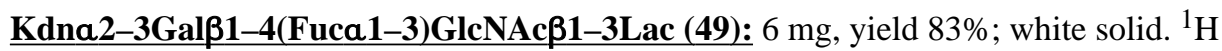
NMR $\left(800 \mathrm{MHz}, \mathrm{D}_{2} \mathrm{O}\right) \delta 5.21(\mathrm{~d}, J=4.0 \mathrm{~Hz}, 0.3 \mathrm{H}), 5.10(\mathrm{~d}, J=4.0 \mathrm{~Hz}, 0.7 \mathrm{H}), 5.09(\mathrm{~d}, J=$ $4.0 \mathrm{~Hz}, 0.3 \mathrm{H}), 4.69(\mathrm{~d}, J=8.0 \mathrm{~Hz}, 1 \mathrm{H}), 4.65(\mathrm{~d}, J=8.0 \mathrm{~Hz}, 0.7 \mathrm{H}), 4.50(\mathrm{~d}, J=8.0 \mathrm{~Hz}, 1 \mathrm{H})$, $4.44(\mathrm{~d}, J=8.0 \mathrm{~Hz}, 0.3 \mathrm{H}),), 4.43(\mathrm{~d}, J=8.0 \mathrm{~Hz}, 0.7 \mathrm{H}), 4.42(\mathrm{~d}, J=8.0 \mathrm{~Hz}, 1 \mathrm{H}), 4.14(\mathrm{~d}, J=$ $3.2 \mathrm{~Hz}, 1 \mathrm{H}), 4.04(\mathrm{dd}, J=3.2$ and $9.6 \mathrm{~Hz}, 1 \mathrm{H}), 3.97-3.25(\mathrm{~m}, 33 \mathrm{H}), 2.69$ (dd, $J=4.8$ and $12.0 \mathrm{~Hz}, 1 \mathrm{H}), 2.01(\mathrm{~s}, 3 \mathrm{H}), 1.72(\mathrm{t}, J=12.0 \mathrm{~Hz}, 1 \mathrm{H}), 1.15(\mathrm{~d}, J=6.4 \mathrm{~Hz}, 3 \mathrm{H}) .{ }^{13} \mathrm{C} \mathrm{NMR}$ (200 MHz, $\left.\mathrm{D}_{2} \mathrm{O}\right) \delta 174.56,173.91,102.80,102.77,102.46,101.45,98.46,95.60,91.68$, 81.97, 78.21, 78.11, 75.50, 74.90, 74.79, 74.76, 74.67, 74.51, 74.22, 73.81, 73.65, 72.91, $72.04,71.77,71.27,70.99,70.09,69.99,69.83,69.73,69.62,69.12,69.04,68.17,67.57$, $67.14,66.53,62.51,61.37,60.85,59.93,59.39,39.29,22.11,15.26,15.15$. HRMS (ESI) $\mathrm{m} / \mathrm{z}$ calculated for $\mathrm{C}_{41} \mathrm{H}_{68} \mathrm{NO}_{33}(\mathrm{M}-\mathrm{H}) 1102.3674$, found 1102.3686 .

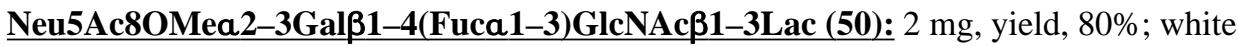
solid. ${ }^{1} \mathrm{H}$ NMR (800 MHz, $\left.\mathrm{D}_{2} \mathrm{O}\right) \delta 5.20(\mathrm{~d}, J=4.0 \mathrm{~Hz}, 0.4 \mathrm{H}), 5.10(\mathrm{~d}, J=4.0 \mathrm{~Hz}, 1 \mathrm{H}), 4.70$ (d, $J=8.0 \mathrm{~Hz}, 1 \mathrm{H}), 4.65(\mathrm{~d}, J=8.0 \mathrm{~Hz}, 0.6 \mathrm{H}), 4.45(\mathrm{~d}, J=8.0 \mathrm{~Hz}, 1 \mathrm{H}), 4.43(\mathrm{~d}, J=8.0 \mathrm{~Hz}$, 1H) $4.41(\mathrm{~d}, J=8.0 \mathrm{~Hz}, 1 \mathrm{H}), 4.14-3.25(\mathrm{~m}, 35 \mathrm{H}), 2.65(\mathrm{~m}, 1 \mathrm{H}), 2.01(\mathrm{~s}, 6 \mathrm{H}), 1.68(\mathrm{~m}, 1 \mathrm{H})$, $1.15(\mathrm{~d}, J=6.4 \mathrm{~Hz}, 3 \mathrm{H}) .{ }^{13} \mathrm{C}$ NMR $\left(200 \mathrm{MHz}, \mathrm{D}_{2} \mathrm{O}\right) \delta 174.86,174.84,174.62,173.70$, $173.54,102.81,102.78,101.68,101.66,100.91,99.90,98.53,98.49,95.61,91.69,81.98$, 
$81.95,80.44,80.34,78.24,78.14,75.81,75.05,74.97,74.86,74.77,74.68,74.23,73.65$, $73.21,72.77,72.74,72.56,72.13,71.92,71.79,71.28,71.00,70.89,70.00,69.84,69.13$, 69.06, 69.00, 68.21, 68.18, 67.87, 67.83, 67.67, 67.58, 67.38, 67.03, 66.80, 66.54, 62.41, $61.36,60.86,59.94,59.81,59.65,59.57,59.23,57.61,57.45,52.06,51.89,39.89,22.12$, 21.95, 15.25, 15.17. HRMS (ESI) $\mathrm{m} / \mathrm{z}$ calculated for $\mathrm{C}_{44} \mathrm{H}_{73} \mathrm{~N}_{2} \mathrm{O}_{33}(\mathrm{M}-\mathrm{H}) 1157.4096$, found 1157.4084 .

General procedures for OPME synthesis of $\mathbf{G b}_{3}$ and $\mathbf{i G b}_{3}$ glycans-Lac $(20 \mathrm{mM}$, 1 eq.), Gal (1.5 eq.) were incubated at $37{ }^{\circ} \mathrm{C}$ in $100 \mathrm{mM}$ of Tris- $\mathrm{HCl}$ buffer (pH 7.5) containing ATP (1.5 eq.), UTP (1.5 eq.), $\mathrm{MgCl}_{2}(10 \mathrm{mM}), \mathrm{MnCl}_{2}$ (10 mM), EcGalK (4 mg/ $\mathrm{mL})$, BLUSP $(4 \mathrm{mg} / \mathrm{mL}), \mathrm{Ba} 1-3 \mathrm{GalT}\left(6 \mathrm{mg} / \mathrm{mL}\right.$, for preparing $\left.\mathrm{iGb}_{3}\right)$ or NmLgtC $(5$ $\mathrm{mg} / \mathrm{mL}$, for preparing $\left.\mathrm{Gb}_{3}\right)$, and PmPpA $(3 \mathrm{mg} / \mathrm{mL})$. The reaction was carried out by incubating the solution in an incubator shaker at $37^{\circ} \mathrm{C}$ for overnight with agitation at 100 $\mathrm{rpm}$. The product formation was monitored by LC-MS. When an optimal yield was achieved, the reaction was quenched by adding the same volume of ice-cold ethanol and the mixture was incubated at $4{ }^{\circ} \mathrm{C}$ for $30 \mathrm{~min}$. The precipitates were removed by centrifugation and the supernatant was concentrated and purified by silica gel column (EtOAc: $\mathrm{MeOH}: \mathrm{H}_{2} \mathrm{O}$, 4:2:1) followed by a Bio-gel P2 gel filtration column to obtain the desired $\mathrm{Gb}_{3}$ or $\mathrm{iGb}_{3}$.

Gala1-4Lac (51): $850 \mathrm{mg}$, yield 95\%; white solid. ${ }^{1} \mathrm{H}$ NMR (800 MHz, $\left.\mathrm{D}_{2} \mathrm{O}\right): \delta 5.18$ (d, $J$ $=4.0 \mathrm{~Hz}, 0.4 \mathrm{H}), 4.90(\mathrm{~d}, J=4.0 \mathrm{~Hz}, 1 \mathrm{H}), 4.63(\mathrm{~d}, J=8.0 \mathrm{~Hz}, 0.6 \mathrm{H}), 4.47(\mathrm{~d}, J=7.2 \mathrm{~Hz}$, $1 \mathrm{H}), 4.31(\mathrm{~m}, 1 \mathrm{H}), 4.00(\mathrm{~m}, 2 \mathrm{H}), 3.92-3.23(\mathrm{~m}, 15 \mathrm{H}) ;{ }^{13} \mathrm{C} \mathrm{NMR}\left(200 \mathrm{MHz}, \mathrm{D}_{2} \mathrm{O}\right): \delta 103.41$, 103.37, 100.46, 95.86, 91.94, 78.82, 78.71, 77.51, 75.58, 74.99, 74.56, 74.04, 72.30, 71.59, 71.35, 71.06, 70.96, 70.30, 69.28, 69.08, 68.71, 60.65, 60.53, 60.18, 60.06; HRMS:

calculated for $\mathrm{C}_{18} \mathrm{H}_{32} \mathrm{O}_{16} \mathrm{Na}(\mathrm{M}+\mathrm{Na}) 527.1588$, found 527.1613. NMR data were consistent with those reported in the literature. ${ }^{84}$

Gala1-3Lac (52): $790 \mathrm{mg}$, yield 99\%; white solid. ${ }^{1} \mathrm{H}$ NMR (800 MHz, $\left.\mathrm{D}_{2} \mathrm{O}\right): \delta 5.21$ (d, $J$ $=3.2 \mathrm{~Hz}, 0.4 \mathrm{H}), 5.13(\mathrm{~d}, J=3.2 \mathrm{~Hz}, 1 \mathrm{H}), 4.65(\mathrm{~d}, J=8.0 \mathrm{~Hz}, 0.6 \mathrm{H}), 4.51(\mathrm{~d}, J=8.0 \mathrm{~Hz}$, $1 \mathrm{H}), 4.17(\mathrm{~m}, 2 \mathrm{H}), 4.00-3.27(\mathrm{~m}, 16 \mathrm{H}) ;{ }^{13} \mathrm{C} \mathrm{NMR}\left(200 \mathrm{MHz}, \mathrm{D}_{2} \mathrm{O}\right) \delta 102.71,102.68$, 95.65, 95.31, 95.30, 91.70, 78.53, 78.41, 77.07, 77.05, 74.93, 74.65, 74.31, 73.66, 71.37, 71.00, 70.70, 69.95, 69.46, 69.16, 69.00, 68.09, 64.71, 64.69, 60.90, 60.88, 60.80, 60.03, 59.89. HRMS: calculated for $\mathrm{C}_{18} \mathrm{H}_{32} \mathrm{O}_{16} \mathrm{Na}(\mathrm{M}+\mathrm{Na}), 527.1588$, found 527.1583. NMR data were consistent with those reported in the literature. ${ }^{85}$

General procedures for OPME synthesis of $\mathrm{Gb}_{\mathbf{4}}$ and $\mathrm{iGb}_{\mathbf{4}}$ glycans- $\mathrm{Gb}_{3}$ or $\mathrm{iGb}_{3}$ glycan $\left(20 \mathrm{mM}, 1\right.$ eq.) as an acceptor and GalNAc $(1.5$ eq. $)$ were incubated at $37{ }^{\circ} \mathrm{C}$ in Tris$\mathrm{HCl}$ buffer (100 mM, pH 7.5) containing ATP (1.5 eq.), UTP (1.5 eq.), $\mathrm{MgCl}_{2}(20 \mathrm{mM})$, NahK ( $3 \mathrm{mg} / \mathrm{mL})$, PmGlmU ( $3 \mathrm{mg} / \mathrm{mL})$, HiLgtD (6 mg/mL), and PmPpA (2 mg/mL). The reaction was carried out by incubating the solution in an incubator shaker at $37{ }^{\circ} \mathrm{C}$ for 2 days with agitation at $100 \mathrm{rpm}$. The product formation was monitored by LC-MS. When an optimal yield was achieved, the reaction was quenched by adding the same volume of icecold ethanol and the mixture was incubated at $4{ }^{\circ} \mathrm{C}$ for $30 \mathrm{~min}$. The precipitates were removed by centrifugation and the supernatant was concentrated and purified by silica gel 
column (EtOAc:MeOH: $\mathrm{H}_{2} \mathrm{O}, 5: 3: 2$ ) followed by a Bio-gel P2 gel filtration column to afford the desired $\mathrm{Gb}_{4}$ or $\mathrm{iGb}_{4}$ glycan.

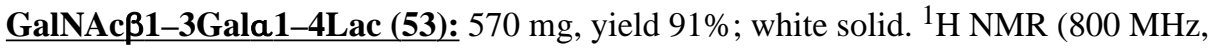
$\left.\mathrm{D}_{2} \mathrm{O}\right): \delta 5.20(\mathrm{~d}, J=3.2 \mathrm{~Hz}, 0.4 \mathrm{H}), 4.89(\mathrm{~d}, J=3.2 \mathrm{~Hz}, 1 \mathrm{H}), 4.64(\mathrm{~d}, J=8.0 \mathrm{~Hz}, 0.6 \mathrm{H}), 4.60$ (d, $J=8.0 \mathrm{~Hz}, 1 \mathrm{H}), 4.49(\mathrm{~d}, J=8.0 \mathrm{~Hz}, 1 \mathrm{H}), 4.37(\mathrm{~m}, 1 \mathrm{H}), 4.23(\mathrm{bs}, 1 \mathrm{H}), 4.01(\mathrm{bs}, 1 \mathrm{H})$, 3.95-3.22 (m, $21 \mathrm{H}), 2.02(\mathrm{~s}, 3 \mathrm{H}) ;{ }^{13} \mathrm{C}$ NMR $\left(200 \mathrm{MHz}, \mathrm{D}_{2} \mathrm{O}\right) \delta$ 175.09, 103.21, 103.15, 100.29, 95.60, 91.64 78.74, 78.55, 77.09, 77.03, 75.34, 75.32, 74.81, 74.72, 74.32, 73.83, $73.78,71.98,71.09,70.77,70.76,70.65,70.16,70.12,68.85,68.81,67.67,67.59,60.88$, 60.26, 60.25, 60.20, 52.61, 22.16. HRMS: calculated for $\mathrm{C}_{26} \mathrm{H}_{46} \mathrm{NO}_{21}(\mathrm{M}+\mathrm{H}), 708.2562$, found 708.2598. NMR data were consistent with those reported in the literature. ${ }^{78}$

GalNAc $\boldsymbol{\beta 1 - 3 G a l a 1 - 3 L a c ~ ( 5 4 ) : ~} 340 \mathrm{mg}$, yield 92\%; white solid. ${ }^{1} \mathrm{H}$ NMR (800 MHz, $\left.\mathrm{D}_{2} \mathrm{O}\right): \delta 5.20(\mathrm{~d}, J=4.0 \mathrm{~Hz}, 0.4 \mathrm{H}), 4.88(\mathrm{~d}, J=4.0 \mathrm{~Hz}, 1 \mathrm{H}), 4.64(\mathrm{~d}, J=8.0 \mathrm{~Hz}, 0.6 \mathrm{H}), 4.60$ $(\mathrm{d}, J=8.8 \mathrm{~Hz}, 1 \mathrm{H}), 4.49(\mathrm{~d}, J=8.8 \mathrm{~Hz}, 0.4 \mathrm{H}), 4.48(\mathrm{~d}, J=8.0 \mathrm{~Hz}, 0.6 \mathrm{H}), 4.35(\mathrm{~m}, 1 \mathrm{H}), 4.23$ (bs, 1H), 4.00-3.24 (m, $22 \mathrm{H}), 2.01$ (s, 3H); ${ }^{13} \mathrm{C}$ NMR (200 MHz, $\left.\mathrm{D}_{2} \mathrm{O}\right) \delta 175.08,103.15$, 100.29, 100.22, 99.91, 95.59, 95.54, 91.69, 91.61, 78.73, 78.55, 77.10, 76.98, 75.33, 74.78, $74.71,74.31,73.83,73.75,71.97,71.35,71.07,70.75,70.62,70.16,70.10,68.86,68.78$, 67.71, 67.59, 67.53, 60.86, 60.31, 60.25, 60.21, 60.05, 59.80, 52.51, 52.34, 22.17, 22.14. HRMS: calculated for $\mathrm{C}_{26} \mathrm{H}_{46} \mathrm{NO}_{21}(\mathrm{M}+\mathrm{H}), 708.2562$, found 708.2596. NMR data were consistent with those reported in the literature. ${ }^{78}$

General procedures for OPME synthesis of $\mathrm{Gb}_{5}$ and $\mathrm{iGb}_{5}$ glycans- $\mathrm{Gb}_{4}$ or $^{\mathrm{iGb}}$ glycan (20 mM, 1 eq.) as an acceptor and $\mathrm{Gal}\left(1.1\right.$ eq.) were incubated at $37^{\circ} \mathrm{C}$ in $\mathrm{Tris}-\mathrm{HCl}$ buffer (100 mM, pH 7.5) containing ATP (1.2 eq.), UTP (1.2 eq.), $\mathrm{MgCl}_{2}$ (10 mM), $\mathrm{MnCl}_{2}$ (10 mM), EcGalK (3 mg/mL), BLUSP ( $3 \mathrm{mg} / \mathrm{mL})$, CjCgtB $(6 \mathrm{mg} / \mathrm{mL})$, and PmPpA ( $2 \mathrm{mg} /$ $\mathrm{mL})$. The reaction was carried out by incubating the solution in an incubator shaker at $37{ }^{\circ} \mathrm{C}$ for overnight with agitation at $100 \mathrm{rpm}$. The product formation was monitored by LC-MS. When an optimal yield was achieved, alkaline phosphatase (10-20 mg) was added to the reaction mixture and incubated in an incubator shaker at $37^{\circ} \mathrm{C}$ for overnight with agitation at $100 \mathrm{rpm}$. The reaction was quenched by adding the same volume of ice-cold ethanol and the mixture was incubated at $4{ }^{\circ} \mathrm{C}$ for $30 \mathrm{~min}$. The precipitates were removed by centrifugation and the supernatant was concentrated, passed through a BioGel P-2 gel filtration column, and eluted with water to obtain sialoside mixtures. The fractions containing the product were collected, concentrated, and further purified by HPLC using a reverse-phase $\mathrm{C} 18$ column $(10 \mu \mathrm{m}, 21.2 \times 250 \mathrm{~mm})$ with a flow rate of $10 \mathrm{~mL} / \mathrm{min}$ and a gradient elution of $0-100 \%$ acetonitrile in water containing $0.05 \%$ formic acid over 20 minutes. Mobile phase A: $0.05 \%$ formic acid in water (v/v); Mobile phase B: acetonitrile (v/v); Gradient: 0\% B for $3 \mathrm{~min}, 0 \%$ to $100 \%$ B over $12 \mathrm{~min}, 100 \%$ B for $2 \mathrm{~min}$, then $100 \%$ to $0 \% \mathrm{~B}$ over $3 \mathrm{~min}$. HPLC purification was monitored by absorption at $210 \mathrm{~nm}$, and glycancontaining fractions were analyzed by TLC and MS. The fractions containing the pure product were collected and concentrated to obtain the desired $\mathrm{Gb}_{5}$ or iGb5 glycan.

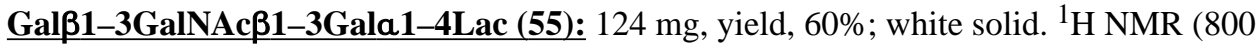
$\left.\mathrm{MHz}, \mathrm{D}_{2} \mathrm{O}\right): \delta 5.20$ (d, $\left.J=3.2 \mathrm{~Hz}, 0.4 \mathrm{H}\right), 4.89(\mathrm{~d}, J=4.0 \mathrm{~Hz}, 1 \mathrm{H}), 4.67(\mathrm{~d}, J=8.0 \mathrm{~Hz}, 1 \mathrm{H})$, 
$4.64(\mathrm{~d}, J=8.0 \mathrm{~Hz}, 0.6 \mathrm{H}), 4.50(\mathrm{~d}, J=8.0 \mathrm{~Hz}, 1 \mathrm{H}), 4.43(\mathrm{~d}, J=8.0 \mathrm{~Hz}, 1 \mathrm{H}), 4.36(\mathrm{~m}, 1 \mathrm{H})$, 4.23 (bs, 1H), 4.16-3.24 (m, $28 \mathrm{H}), 2.00$ (s, 3H); ${ }^{13} \mathrm{C}$ NMR (200 MHz, $\left.\mathrm{D}_{2} \mathrm{O}\right) \delta$ 175.01, 104.69, 103.16, 103.13, 102.87, 102.84, 100.27, 95.60, 91.67, 79.46, 78.67, 78.63, 78.58, 78.52, 77.05, 75.32, 74.87, 74.71, 74.47, 74.32, 73.80, 72.31, 71.97, 71.35, 71.09, 70.74, 70.46, 70.13, 70.01, 68.81, 68.44, 67.86, 67.49, 60.87, 60.82, 60.23, 60.18, 59.92, 59.79, 51.34, 22.14. HRMS: calculated for $\mathrm{C}_{32} \mathrm{H}_{55} \mathrm{NNaO}_{26}(\mathrm{M}+\mathrm{Na}), 892.2910$, found 892.2898.

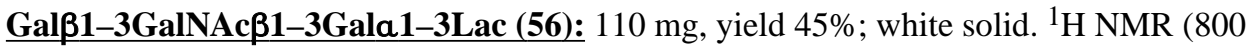
$\left.\mathrm{MHz}, \mathrm{D}_{2} \mathrm{O}\right): \delta 5.20(\mathrm{~d}, J=4.0 \mathrm{~Hz}, 0.4 \mathrm{H}), 5.09(\mathrm{~d}, J=4.0 \mathrm{~Hz}, 1 \mathrm{H}), 4.68(\mathrm{~d}, J=8.0 \mathrm{~Hz}, 1 \mathrm{H})$, $4.64(\mathrm{~d}, J=8.0 \mathrm{~Hz}, 0.6 \mathrm{H}), 4.50(\mathrm{~d}, J=8.0 \mathrm{~Hz}, 1 \mathrm{H}), 4.43(\mathrm{~d}, J=8.8 \mathrm{~Hz}, 1 \mathrm{H}), 4.21-3.26(\mathrm{~m}$, $30 \mathrm{H}), 2.00(\mathrm{~s}, 3 \mathrm{H}) ;{ }^{13} \mathrm{C}$ NMR $\left(200 \mathrm{MHz}, \mathrm{D}_{2} \mathrm{O}\right) \delta 175.01,104.69,102.76,102.65,95.63$, 95.51, 91.68, 79.48, 78.70, 78.43, 78.30, 77.05, 74.90, 74.87, 74.64, 74.50, 74.30, 73.65, 72.31, 71.36, 70.98, 70.46, 70.26, 69.94, 69.49, 68.91, 68.44, 67.85, 67.13, 64.72, 60.87, $60.79,60.66,60.00,59.86,51.39,22.15$. HRMS: calculated for $\mathrm{C}_{32} \mathrm{H}_{55} \mathrm{NNaO}_{26}(\mathrm{M}+\mathrm{Na})$, 892.2910, found 892.2930.

\section{General procedures for OPME synthesis of sialylated $\mathrm{Gb}_{5}$ and $\mathrm{iGb}_{5}$ glycans-} $\mathrm{Gb}_{5}$ or $\mathrm{iGb}_{5}(20 \mathrm{mM}, 1$ eq.) and Neu5Ac or a sialic acid precursor (ManNGc, mannose, or ManNAc5OMe, 1.5 eq.) with sodium pyruvate $(7.5$ eq. $)$ were incubated at $37{ }^{\circ} \mathrm{C}$ in a Tris$\mathrm{HCl}$ buffer (100 mM, pH 8.5) containing CTP (1.5 eq.), $\mathrm{MgCl}_{2}(20 \mathrm{mM}), \mathrm{NmCSS}$ ( $3 \mathrm{mg}$ / $\mathrm{mL})$, PmST1 M144D (4 mg/mL), with or without PmNanA (1.5 mg/mL, omit if Neu5Ac was used). The reactions were carried out by incubating the solution in an incubator shaker at $37^{\circ} \mathrm{C}$ for 1 or 2 days with agitation at $100 \mathrm{rpm}$. The product formation was monitored by LC-MS. When an optimal yield was achieved, alkaline phosphatase (10-20 mg) was added and the reaction mixture was incubated in an incubator shaker at $37{ }^{\circ} \mathrm{C}$ for overnight with agitation at $100 \mathrm{rpm}$. The reaction was then quenched by adding the same volume of icecold ethanol and the mixture was incubated at $4{ }^{\circ} \mathrm{C}$ for $30 \mathrm{~min}$. The precipitates were removed by centrifugation and the supernatant was concentrated, passed through a BioGel P-2 gel filtration column, and eluted with water to obtain sialoside mixtures. The fractions containing product were collected, concentrated, and further purified by HPLC with a reverse-phase C18 column $(10 \mu \mathrm{m}, 21.2 \times 250 \mathrm{~mm})$ with a flow rate of $10 \mathrm{~mL} / \mathrm{min}$ using a gradient elution of $0-100 \%$ acetonitrile in water containing $0.05 \%$ formic acid over $20 \mathrm{~min}$. Mobile phase A: $0.05 \%$ formic acid in water (v/v); Mobile phase B: acetonitrile (v/v); Gradient: 0\% B for $3 \mathrm{~min}, 0 \%$ to $100 \%$ B over $12 \mathrm{~min}, 100 \%$ B for $2 \mathrm{~min}$, then $100 \%$ to $0 \%$ B over $3 \mathrm{~min}$. HPLC purification was monitored by absorption at $210 \mathrm{~nm}$, and glycancontaining fractions were analyzed by TLC and MS. The fractions containing the pure product were collected and concentrated to obtain the desired sialylated lacto- and neolactoseries glycosphingolipid glycans (yields 71-86\%).

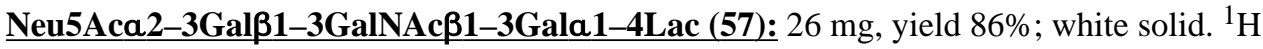
NMR $\left(800 \mathrm{MHz}, \mathrm{D}_{2} \mathrm{O}\right) \delta 5.21(\mathrm{~d}, J=4.0 \mathrm{~Hz}, 0.4 \mathrm{H}), 4.89(\mathrm{~d}, J=4.0 \mathrm{~Hz}, 1 \mathrm{H}), 4.67(\mathrm{~d}, J=$ $8.0 \mathrm{~Hz}, 1 \mathrm{H}), 4.65(\mathrm{~d}, J=8.0 \mathrm{~Hz}, 0.6 \mathrm{H}), 4.51(\mathrm{~d}, J=8.0 \mathrm{~Hz}, 1 \mathrm{H}), 4.50(\mathrm{~d}, J=8.0 \mathrm{~Hz}, 1 \mathrm{H})$, $4.37(\mathrm{~m}, 1 \mathrm{H}), 4.24-3.25(\mathrm{~m}, 36 \mathrm{H}), 2.73(\mathrm{dd}, J=4.8$ and $12.0 \mathrm{~Hz}, 1 \mathrm{H}), 2.01(\mathrm{~s}, 3 \mathrm{H}), 2.00$ (s, $3 \mathrm{H}), 1.77$ (t, $J=12.0 \mathrm{~Hz}, 1 \mathrm{H}) ;{ }^{13} \mathrm{C}$ NMR $\left(200 \mathrm{MHz}, \mathrm{D}_{2} \mathrm{O}\right) \delta 174.99,174.83,173.82$, 104.44, 103.16, 102.84, 100.26, 99.55, 95.57, 79.67, 78.64, 78.58, 78.52, 77.02, 75.42, 
$75.32,74.71,74.65,74.48,74.32,73.80,72.66,71.98,71.71,71.35,71.11,70.75,70.14$, $70.02,68.89,68.81,68.28,67.92,67.72,67.49,67.23,62.35,60.86,60.25,60.18,51.53$, 51.21, 39.59, 22.21, 21.92. HRMS (ESI) $\mathrm{m} / \mathrm{z}$ calculated for $\mathrm{C}_{43} \mathrm{H}_{71} \mathrm{~N}_{2} \mathrm{O}_{34}(\mathrm{M}-\mathrm{H})$ 1159.3888 , found 1159.3907 .

Neu5Gca2-3Galß1-3GalNAcß1-3Gala1-4Lac (58): 9 mg, yield 83\%; white solid. ${ }^{1} \mathrm{H}$ NMR $\left(800 \mathrm{MHz}, \mathrm{D}_{2} \mathrm{O}\right) \delta 5.20(\mathrm{~d}, J=4.0 \mathrm{~Hz}, 0.4 \mathrm{H}), 4.89(\mathrm{~d}, J=4.0 \mathrm{~Hz}, 1 \mathrm{H}), 4.67(\mathrm{~d}, J=$ $8.0 \mathrm{~Hz}, 1 \mathrm{H}), 4.65(\mathrm{~d}, J=8.0 \mathrm{~Hz}, 0.6 \mathrm{H}), 4.50(\mathrm{~d}, J=8.0 \mathrm{~Hz}, 1 \mathrm{H}), 4.49(\mathrm{~d}, J=8.0 \mathrm{~Hz}, 1 \mathrm{H})$, $4.36(\mathrm{~m}, 1 \mathrm{H}), 4.23(\mathrm{bs}, 1 \mathrm{H}), 4.15(\mathrm{~d}, J=3.2 \mathrm{~Hz}, 1 \mathrm{H}), 4.09(\mathrm{~s}, 2 \mathrm{H}), 4.07-3.25(\mathrm{~m}, 34 \mathrm{H}), 2.75$ (dd, $J=4.8$ and $12.0 \mathrm{~Hz}, 1 \mathrm{H}), 2.01(\mathrm{~s}, 3 \mathrm{H}), 1.78(\mathrm{t}, J=12.0 \mathrm{~Hz}, 1 \mathrm{H}) ;{ }^{13} \mathrm{C}$ NMR $(200 \mathrm{MHz}$, $\left.\mathrm{D}_{2} \mathrm{O}\right) \delta 175.60,174.98,173.84,104.45,103.16,103.13,102.84,100.25,99.55,95.57$, $91.65,79.65,78.64,78.58,78.52,77.02,75.41,75.32,74.71,74.66,74.47,74.32,73.80$, $72.37,71.97,71.77,71.35,71.10,70.74,70.14,70.02,68.89,68.80,68.00,67.84,67.73$, $67.49,67.21,62.31,60.84,60.24,60.18,59.92,51.21,39.66,22.21$. HRMS (ESI) m/z calculated for $\mathrm{C}_{43} \mathrm{H}_{71} \mathrm{~N}_{2} \mathrm{O}_{35}(\mathrm{M}-\mathrm{H})$ 1175.3837, found 1175.3874.

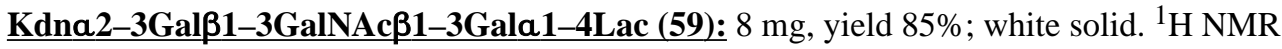
$\left(800 \mathrm{MHz}, \mathrm{D}_{2} \mathrm{O}\right) \delta 5.21(\mathrm{~d}, J=3.2 \mathrm{~Hz}, 0.4 \mathrm{H}), 4.90(\mathrm{~d}, J=4.0 \mathrm{~Hz}, 1 \mathrm{H}), 4.67(\mathrm{~d}, J=8.0 \mathrm{~Hz}$, $1 \mathrm{H}), 4.65(\mathrm{~d}, J=8.0 \mathrm{~Hz}, 0.6 \mathrm{H}), 4.50(\mathrm{~d}, J=8.0 \mathrm{~Hz}, 1 \mathrm{H}), 4.49(\mathrm{~d}, J=8.0 \mathrm{~Hz}, 1 \mathrm{H}), 4.37(\mathrm{~m}$, $1 \mathrm{H}), 4.24(\mathrm{bs}, 1 \mathrm{H}), 4.15(\mathrm{~d}, J=3.2 \mathrm{~Hz}, 1 \mathrm{H}), 4.07-3.26(\mathrm{~m}, 34 \mathrm{H}), 2.68(\mathrm{dd}, J=4.8$ and 12.0 $\mathrm{Hz}, 1 \mathrm{H}), 2.01$ (s, 3H), $1.72(\mathrm{t}, J=12.0 \mathrm{~Hz}, 1 \mathrm{H}) ;{ }^{13} \mathrm{C} \mathrm{NMR}\left(200 \mathrm{MHz}, \mathrm{D}_{2} \mathrm{O}\right) \delta 175.06$, 174.05, 104.56, 103.24, 102.92, 100.33, 99.53, 95.65, 79.66, 78.72, 78.66, 78.60, 77.10, $75.45,75.40,74.79,74.76,74.56,74.39,73.87,73.77,72.08,72.05,71.42,71.17,70.82$, $70.21,70.10,69.66,68.93,68.88,67.82,67.63,67.57,67.20,62.47,61.34,60.91,60.32$, $60.26,60.00,51.30,39.38,24.41,22.29$. HRMS (ESI) m/z calculated for $\mathrm{C}_{41} \mathrm{H}_{68} \mathrm{NO}_{34}(\mathrm{M}-$ H) 1118.3623, found 1118.3629 .

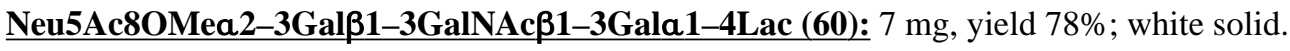
${ }^{1} \mathrm{H} \mathrm{NMR}\left(800 \mathrm{MHz}, \mathrm{D}_{2} \mathrm{O}\right) \delta 5.20(\mathrm{~d}, J=4.0 \mathrm{~Hz}, 0.4 \mathrm{H}), 4.89(\mathrm{~d}, J=4.0 \mathrm{~Hz}, 1 \mathrm{H}), 4.66(\mathrm{~d}, J=$ $8.0 \mathrm{~Hz}, 1 \mathrm{H}), 4.64(\mathrm{~d}, J=8.0 \mathrm{~Hz}, 0.6 \mathrm{H}), 4.49(\mathrm{~d}, J=8.0 \mathrm{~Hz}, 1 \mathrm{H}), 4.48(\mathrm{~d}, J=8.0 \mathrm{~Hz}, 1 \mathrm{H})$, $4.36(\mathrm{~m}, 1 \mathrm{H}), 4.23-3.25(\mathrm{~m}, 36 \mathrm{H}), 3.44(\mathrm{~s}, 3 \mathrm{H}), 2.63(\mathrm{dd}, J=4.8$ and $12.0 \mathrm{~Hz}, 1 \mathrm{H}), 2.01(\mathrm{~s}$, $3 \mathrm{H}), 2.00(\mathrm{~s}, 3 \mathrm{H}), 1.80(\mathrm{t}, J=12.0 \mathrm{~Hz}, 1 \mathrm{H}) ;{ }^{13} \mathrm{C} \mathrm{NMR}\left(200 \mathrm{MHz}, \mathrm{D}_{2} \mathrm{O}\right) \delta 176.36,174.94$, 174.81, 174.64, 173.75, 173.65, 100.48, 100.26, 100.00, 96.19, 95.56, 80.28, 79.89, 78.53, 74.71, 74.60, 74.46, 74.30, 71.96, 70.75, 70.16, 69.75, 69.45, 69.15, 69.03, 67.93, 67.06, 66.81, 64.92, 62.31, 61.70, 60.82, 60.23, 59.78, 57.74, 57.44, 57.35, 39.49, 21.98, 19.94 . HRMS (ESI) m/z calculated for $\mathrm{C}_{44} \mathrm{H}_{73} \mathrm{~N}_{2} \mathrm{O}_{34}(\mathrm{M}-\mathrm{H}) 1173.4045$, found 1173.4046 .

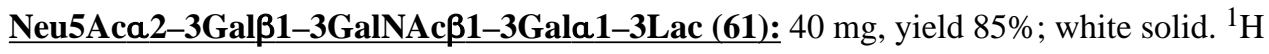
NMR $\left(800 \mathrm{MHz}, \mathrm{D}_{2} \mathrm{O}\right) \delta 5.16(\mathrm{~d}, J=4.0 \mathrm{~Hz}, 0.4 \mathrm{H}), 5.05(\mathrm{~d}, J=4.0 \mathrm{~Hz}, 1 \mathrm{H}), 4.65(\mathrm{~d}, J=$ $8.0 \mathrm{~Hz}, 1 \mathrm{H}), 4.61(\mathrm{~d}, J=8.0 \mathrm{~Hz}, 0.6 \mathrm{H}), 4.47(\mathrm{~d}, J=8.0 \mathrm{~Hz}, 1 \mathrm{H}), 4.46(\mathrm{~d}, J=8.0 \mathrm{~Hz}, 1 \mathrm{H})$, 4.26-3.21 (m, 37 H), 2.68 (dd, $J=4.8$ and $12.0 \mathrm{~Hz}, 1 \mathrm{H}), 1.97$ (s, 3H), 1.96 (s, 3H), 1.72 (t, $J$ $=12.0 \mathrm{~Hz}, 1 \mathrm{H}) ;{ }^{13} \mathrm{C}$ NMR $\left(200 \mathrm{MHz}, \mathrm{D}_{2} \mathrm{O}\right) \delta 175.07,174.92,173.87,104.48,103.20$, $102.88,100.29,99.60,95.61,79.72,78.68,78.63,78.57,77.06,75.47,75.36,74.75,74.69$, $74.52,74.35,73.84,72.66,71.98,71.71,71.35,71.11,70.75,70.14,70.02,68.89,68.81$, 
68.28, 67.92, 67.72, 67.49, 67.23, 62.35, 60.86, 60.25, 60.22, 51.56, 51.24, 39.61, 22.23, 21.94. HRMS (ESI) m/z calculated for $\mathrm{C}_{43} \mathrm{H}_{71} \mathrm{~N}_{2} \mathrm{O}_{34}(\mathrm{M}-\mathrm{H}) 1159.3888$, found 1159.3896 .

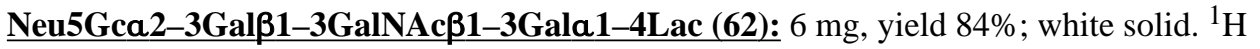
NMR $\left(800 \mathrm{MHz}, \mathrm{D}_{2} \mathrm{O}\right) \delta 5.20(\mathrm{~d}, J=4.0 \mathrm{~Hz}, 0.4 \mathrm{H}), 5.09(\mathrm{~d}, J=4.0 \mathrm{~Hz}, 1 \mathrm{H}), 4.68(\mathrm{~d}, J=$ $8.0 \mathrm{~Hz}, 1 \mathrm{H}), 4.64(\mathrm{~d}, J=8.0 \mathrm{~Hz}, 0.6 \mathrm{H}), 4.50(\mathrm{~d}, J=8.0 \mathrm{~Hz}, 2 \mathrm{H}), 4.21(\mathrm{~d}, J=4.0 \mathrm{~Hz}, 0.4 \mathrm{H})$, $4.18(\mathrm{~m}, 1 \mathrm{H}), 4.15(\mathrm{~d}, J=4.0 \mathrm{~Hz}, 0.6 \mathrm{H}), 4.09$ (s, 2H), 4.07-3.25 (m, $35 \mathrm{H}), 2.75$ (dd, $J=4.8$ and $12.0 \mathrm{~Hz}, 1 \mathrm{H}), 2.00(\mathrm{~s}, 3 \mathrm{H}), 1.78(\mathrm{t}, J=12.0 \mathrm{~Hz}, 1 \mathrm{H}) ;{ }^{13} \mathrm{C} \mathrm{NMR}\left(200 \mathrm{MHz}, \mathrm{D}_{2} \mathrm{O}\right) \delta$ 175.61, 174.99, 173.84, 104.44, 102.75, 102.66, 99.56, 95.63, 95.54, 79.66, 78.68, 78.45, $78.32,77.09,75.41,74.90,74.66,74.64,74.50,74.30,73.65,72.37,71.77,70.99,70.27$, 69.48, 68.89, 68.00, 67.84, 67.72, 67.13, 62.31, 60.87, 60.83, 60.67, 51.25, 39.66, 22.22. HRMS (ESI) m/z calculated for $\mathrm{C}_{43} \mathrm{H}_{71} \mathrm{~N}_{2} \mathrm{O}_{35}$ (M-H) 1175.3837, found 1175.3865.

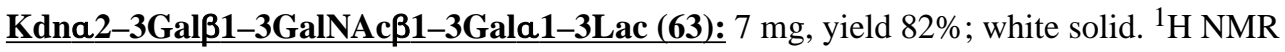
$\left(800 \mathrm{MHz}, \mathrm{D}_{2} \mathrm{O}\right) \delta 5.20(\mathrm{~d}, J=3.2 \mathrm{~Hz}, 0.4 \mathrm{H}), 5.09(\mathrm{~d}, J=4.0 \mathrm{~Hz}, 1 \mathrm{H}), 4.68(\mathrm{~d}, J=8.0 \mathrm{~Hz}$, $1 \mathrm{H}), 4.65(\mathrm{~d}, J=8.0 \mathrm{~Hz}, 0.6 \mathrm{H}), 4.50(\mathrm{~d}, J=8.0 \mathrm{~Hz}, 1 \mathrm{H}), 4.49(\mathrm{~d}, J=8.0 \mathrm{~Hz}, 1 \mathrm{H}), 4.23-3.26$ $(\mathrm{m}, 37 \mathrm{H}), 2.68(\mathrm{dd}, J=4.8$ and $12.0 \mathrm{~Hz}, 1 \mathrm{H}), 2.00(\mathrm{~s}, 3 \mathrm{H}), 1.71(\mathrm{t}, J=12.0 \mathrm{~Hz}, 1 \mathrm{H}) ;{ }^{13} \mathrm{C}$ NMR (200 MHz, D $2 \mathrm{O}) \delta 174.99,173.98,104.48,102.75,102.67,99.48,95.63,95.54$, $79.61,78.68,78.46,78.33,77.09,75.38,74.91,74.69,74.65,74.51,74.30,73.70,73.65$, 73.46, 73.37, 73.06, 72.01, 71.36, 70.99, 70.28, 70.14, 69.94, 69.80, 69.59, 69.48, 68.91, 68.86, 67.74, 67.55, 67.14, 64.74, 62.55, 62.40, 60.88, 60.81, 60.68, 51.28, 39.30, 22.23. HRMS (ESI) $\mathrm{m} / \mathrm{z}$ calculated for $\mathrm{C}_{41} \mathrm{H}_{68} \mathrm{NO}_{34}(\mathrm{M}-\mathrm{H}) 1118.3623$, found 1118.3622 .

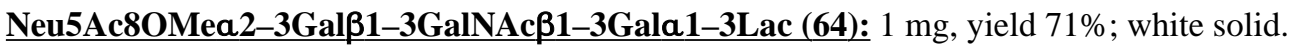
${ }^{1} \mathrm{H} \mathrm{NMR}\left(800 \mathrm{MHz}, \mathrm{D}_{2} \mathrm{O}\right) \delta 5.21(\mathrm{~d}, J=3.2 \mathrm{~Hz}, 0.5 \mathrm{H}), 4.89(\mathrm{~d}, J=4.0 \mathrm{~Hz}, 1 \mathrm{H}), 4.67(\mathrm{~d}, J=$ $8.8 \mathrm{~Hz}, 1 \mathrm{H}), 4.65(\mathrm{~d}, J=8.0 \mathrm{~Hz}, 0.5 \mathrm{H}), 4.50(\mathrm{~d}, J=7.2 \mathrm{~Hz}, 1 \mathrm{H}), 4.49(\mathrm{~d}, J=8.0 \mathrm{~Hz}, 1 \mathrm{H})$, $4.37-3.25(\mathrm{~m}, 37 \mathrm{H}), 3.45(\mathrm{~s}, 3 \mathrm{H}), 2.64(\mathrm{dd}, J=4.8$ and $12.0 \mathrm{~Hz}, 1 \mathrm{H}), 2.02(\mathrm{~s}, 3 \mathrm{H}), 2.00$ (s, $3 \mathrm{H}), 1.81(\mathrm{t}, J=12.0 \mathrm{~Hz}, 1 \mathrm{H})$. HRMS (ESI) $\mathrm{m} / \mathrm{z}$ calculated for $\mathrm{C}_{44} \mathrm{H}_{73} \mathrm{~N}_{2} \mathrm{O}_{34}(\mathrm{M}-\mathrm{H})$ 1173.4045, found 1173.4025 .

\section{Supplementary Material}

Refer to Web version on PubMed Central for supplementary material.

\section{Acknowledgments}

This work was supported by the National Institute of General Medical Sciences and the National Cancer Institute of National Institutes of Health Project Number 261201300041C. The plasmid for expressing HiLgtD was a kind gift from Dr. Peng G. Wang in Georgia State University.

\section{References}

1. Fang Y. J Am Chem Soc. 2006; 128:3158. [PubMed: 16522092]

2. Pukel CS, Lloyd KO, Travassos LR, Dippold WG, Oettgen HF, Old LJ. J Exp Med. 1982; 155:1133. [PubMed: 7061953]

3. Chapman PB, Morrissey DM, Panageas KS, Hamilton WB, Zhan C, Destro AN, Williams L, Israel RJ, Livingston PO. Clin Cancer Res. 2000; 6:874. [PubMed: 10741710] 
4. Heimburg-Molinaro J, Lum M, Vijay G, Jain M, Almogren A, Rittenhouse-Olson K. Vaccine. 2011; 29:8802. [PubMed: 21964054]

5. Padler-Karavani V, Hurtado-Ziola N, Pu M, Yu H, Huang S, Muthana S, Chokhawala HA, Cao H, Secrest P, Friedmann-Morvinski D, Singer O, Ghaderi D, Verma IM, Liu YT, Messer K, Chen X, Varki A, Schwab R. Cancer Res. 2011; 71:3352. [PubMed: 21505105]

6. Hedlund M, Padler-Karavani V, Varki NM, Varki A. Proc Natl Acad Sci U S A. 2008; 105:18936. [PubMed: 19017806]

7. Merrill AH Jr. Chem Rev. 111:6387.

8. Bitton RJ, Guthmann MD, Gabri MR, Carnero AJ, Alonso DF, Fainboim L, Gomez DE. Oncol Rep. 2002; 9:267. [PubMed: 11836591]

9. Fernandez LE, Gabri MR, Guthmann MD, Gomez RE, Gold S, Fainboim L, Gomez DE, Alonso DF. Clin Dev Immunol. 2010; 2010:814397. [PubMed: 21048926]

10. Peguet-Navarro J, Sportouch M, Popa I, Berthier O, Schmitt D, Portoukalian J. J Immunol. 2003; 170:3488. [PubMed: 12646609]

11. Schnaar, RL., Suzuki, A., Stanley, P. Essentials of Glycobiology. 2nd. Varki, A.Cummings, RD.Esko, JD.Freeze, HH.Stanley, P.Bertozzi, CR.Hart, GW., Etzler, ME., editors. Cold Spring Harbor Laboratory Press; 2008. p. 129Chapter 10

12. Samual Tesfay, DS., Hecht, Gail A. Bacterial-Epithelial cell cross-talk. McCormick, BA., editor. Cambridge Press; Cambridge: 2006.

13. Gioannini TL, Weiss JP. Immunol Res. 2007; 39:249. [PubMed: 17917069]

14. Shoaf-Sweeney KD, Hutkins RW. Adv Food Nutr Res. 2009; 55:101. [PubMed: 18772103]

15. Fukuta S, Magnani JL, Twiddy EM, Holmes RK, Ginsburg V. Infect Immun. 1988; 56:1748. [PubMed: 3290106]

16. Jobling MG, Holmes RK. Infect Immun. 2002; 70:1260. [PubMed: 11854209]

17. Iwamori M, Takamizawa K, Momoeda M, Iwamori Y, Taketani Y. Glycoconj J. 2008; 25:675. [PubMed: 18498052]

18. Smit H, Gaastra W, Kamerling JP, Vliegenthart JF, de Graaf FK. Infect Immun. 1984; 46:578. [PubMed: 6150011]

19. Campanero-Rhodes MA, Smith A, Chai W, Sonnino S, Mauri L, Childs RA, Zhang Y, Ewers H, Helenius A, Imberty A, Feizi T. J Virol. 2007; 81:12846. [PubMed: 17855525]

20. Hakomori S. Proc Natl Acad Sci U S A. 2002; 99:225. [PubMed: 11773621]

21. Song X, Lasanajak Y, Xia B, Heimburg-Molinaro J, Rhea JM, Ju H, Zhao C, Molinaro RJ, Cummings RD, Smith DF. Nat Meth. 2011; 8:85.

22. Schnaar RL. Methods Enzymol. 1994; 230:348. [PubMed: 8139508]

23. Song X, Smith DF, Cummings RD. Anal Biochem. 2012; 429:82. [PubMed: 22776091]

24. Arigi E, Blixt O, Buschard K, Clausen H, Levery SB. Glycoconj J. 2012; 29:1. [PubMed: 22102144]

25. Mulloy, B., Hart, DA., Stanley, P. Essentials of Glycobiology. 2nd. Varki, A.Cummings, RD.Esko, JD.Freeze, HH.Stanley, P.Bertozzi, CR.Hart, GW., Etzler, ME., editors. Cold Spring Harbor Laboratory Press; 2008. p. 661Chapter 47

26. Ando H, Ishida H, Kiso M. Methods Enzymol. 2010; 478:521. [PubMed: 20816497]

27. Wang Z, Gilbert M, Eguchi H, Yu H, Cheng J, Muthana S, Zhou L, Wang PG, Chen X, Huang X. Adv Synth Catal. 2008; 350:1717. [PubMed: 20305750]

28. Jeon I, Iyer K, Danishefsky SJ. J Org Chem. 2009; 74:8452. [PubMed: 19874068]

29. Burkhart F, Zhang Z, Wacowich-Sgarbi S, Wong CH. Angew Chem Int Ed Engl. 2001; 40:1274. [PubMed: 11301448]

30. Su DM, Eguchi H, Yi W, Li L, Wang PG, Xia C. Org Lett. 2008; 10:1009. [PubMed: 18254640]

31. Blixt O, Vasiliu D, Allin K, Jacobsen N, Warnock D, Razi N, Paulson JC, Bernatchez S, Gilbert M, Wakarchuk W. Carbohydr Res. 2005; 340:1963. [PubMed: 16005859]

32. Sauerzapfe B, Krenek K, Schmiedel J, Wakarchuk WW, Pelantova H, Kren V, Elling L. Glycoconj J. 2009; 26:141. [PubMed: 18758940]

33. Yu H, Chen X. Org Biomol Chem. 2016; 14:2809. [PubMed: 26881499] 
34. Vyas AA, Schnaar RL. Biochimie. 2001; 83:677. [PubMed: 11522397]

35. Yu, RK., Saito, M. Neurobiology of glycoconjugates. Margolis, RU., Margolis, RK., editors. New York: Plenum Press; 1989. p. 1-42.1989

36. Turton K, Chaddock JA, Acharya KR. Trends Biochem Sci. 2002; 27:552. [PubMed: 12417130]

37. Mocchetti I. Cell Mol Life Sci. 2005; 62:2283. [PubMed: 16158191]

38. Nashar TO, Betteridge ZE, Mitchell RN. Int Immunol. 2001; 13:541. [PubMed: 11282993]

39. Kolter T, Sandhoff K. Biochim Biophys Acta. 2006; 1758:2057. [PubMed: 16854371]

40. Cheresh DA, Varki AP, Varki NM, Stallcup WB, Levine J, Reisfeld RA. J Biol Chem. 1984; 259:7453. [PubMed: 6203895]

41. Hitoshi S, Kusunoki S, Kon K, Chiba A, Waki H, Ando S, Kanazawa I. J Neuroimmunol. 1996; 66:95. [PubMed: 8964919]

42. Song Y, Kitajima K, Inoue S, Inoue Y. J Biol Chem. 1991; 266:21929. [PubMed: 1939215]

43. Song Y, Kitajima K, Inoue S, Muto Y, Kasama T, Handa S, Inoue Y. Biochemistry. 1993; 32:9221. [PubMed: 8369289]

44. Song Y, Kitajima K, Inoue S, Khoo KH, Morris HR, Dell A, Inoue Y. Glycobiology. 1995; 5:207. [PubMed: 7540078]

45. Qu S, Barrett-Wilt G, Fonseca LM, Rankin SA. J Dairy Sci. 2016; 99:5083. [PubMed: 27085416]

46. Jahan M, Wynn PC, Wang B. J Dairy Sci. 2016; 99:8431. [PubMed: 27423948]

47. Smirnova GP, Kochetkov NK, Sadovskaya VL. Biochim Biophys Acta. 1987; 920:47. [PubMed: 3593756]

48. Muralikrishna G, Reuter G, Peter-Katalinic J, Egge H, Hanisch FG, Siebert HC, Schauer R. Carbohydr Res. 1992; 236:321. [PubMed: 1291056]

49. Bulai T, Bratosin D, Pons A, Montreuil J, Zanetta JP. FEBS Lett. 2003; 534:185. [PubMed: 12527384]

50. Furuya S, Irie F, Hashikawa T, Nakazawa K, Kozakai A, Hasegawa A, Sudo K, Hirabayashi Y. J Biol Chem. 1994; 269:32418. [PubMed: 7528216]

51. Yu H, Huang S, Chokhawala H, Sun M, Zheng H, Chen X. Angew Chem Int Ed Engl. 2006; 45:3938. [PubMed: 16721893]

52. Yu H, Cheng J, Ding L, Khedri Z, Chen Y, Chin S, Lau K, Tiwari VK, Chen X. J Am Chem Soc. 2009; 131:18467. [PubMed: 19947630]

53. Yu H, Chokhawala H, Karpel R, Yu H, Wu B, Zhang J, Zhang Y, Jia Q, Chen X. J Am Chem Soc. 2005; 127:17618. [PubMed: 16351087]

54. Yu H, Yu H, Karpel R, Chen X. Bioorg Med Chem. 2004; 12:6427. [PubMed: 15556760]

55. Yu H, Lau K, Li Y, Sugiarto G, Chen X. Curr Protoc Chem Biol. 2012; 4:233. [PubMed: 25000293]

56. Yu H, Cao H, Tiwari VK, Li Y, Chen X. Bioorg Med Chem Lett. 2011; 21:5037. [PubMed: 21592790]

57. Gilbert M, Karwaski MF, Bernatchez S, Young NM, Taboada E, Michniewicz J, Cunningham AM, Wakarchuk WW. J Biol Chem. 2002; 277:327. [PubMed: 11689567]

58. Chen X, Fang J, Zhang J, Liu Z, Shao J, Kowal P, Andreana P, Wang PG. J Am Chem Soc. 2001; 123:2081. [PubMed: 11456841]

59. Sugiarto G, Lau K, Qu J, Li Y, Lim S, Mu S, Ames JB, Fisher AJ, Chen X. ACS Chem Biol. 2012; 7:1232. [PubMed: 22583967]

60. Nojiri H, Kitagawa S, Nakamura M, Kirito K, Enomoto Y, Saito M. J Biol Chem. 1988; 263:7443. [PubMed: 2836383]

61. Mizuguchi S, Nishiyama N, Iwata T, Nishida T, Izumi N, Tsukioka T, Inoue K, Kameyama M, Suehiro S. Ann Thorac Surg. 2007; 83:216. [PubMed: 17184666]

62. Ratei R, Karawajew L, Schabath R, Ehrfeldt A, Grunert F, Ludwig WD. Int J Hematol. 2008; 87:137. [PubMed: 18299959]

63. Julien S, Ivetic A, Grigoriadis A, QiZe D, Burford B, Sproviero D, Picco G, Gillett C, Papp SL, Schaffer L, Tutt A, Taylor-Papadimitriou J, Pinder SE, Burchell JM. Cancer Res. 2011; 71:7683. [PubMed: 22025563] 
64. Yu H, Lau K, Thon V, Autran CA, Jantscher-Krenn E, Xue M, Li Y, Sugiarto G, Qu J, Mu S, Ding L, Bode L, Chen X. Angew Chem Int Ed Engl. 2014; 53:6687. [PubMed: 24848971]

65. Yi W, Liu X, Li Y, Li J, Xia C, Zhou G, Zhang W, Zhao W, Chen X, Wang PG. Proc Natl Acad Sci U S A. 2009; 106:4207. [PubMed: 19251666]

66. Utskarpen A, Massol R, van Deurs B, Lauvrak SU, Kirchhausen T, Sandvig K. PLOS One. $5: \mathrm{e} 10944$.

67. Lingwood CA, Binnington B, Manis A, Branch DR. FEBS Lett. 1879; 584

68. Adlercreutz D, Weadge JT, Petersen BO, Duus JO, Dovichi NJ, Palcic MM. Carbohydr Res. 345:1384.

69. Bekri S, Lidove O, Jaussaud R, Knebelmann B, Barbey F. Cardiovasc Hematol Agents Med Chem. 2006; 4:289. [PubMed: 17073606]

70. Bremer EG, Levery SB, Sonnino S, Ghidoni R, Canevari S, Kannagi R, Hakomori S. J Biol Chem. 1984; 259:14773. [PubMed: 6501317]

71. Slovin SF, Ragupathi G, Adluri S, Ungers G, Terry K, Kim S, Spassova M, Bornmann WG, Fazzari M, Dantis L, Olkiewicz K, Lloyd KO, Livingston PO, Danishefsky SJ, Scher HI. Proc Natl Acad Sci U S A. 1999; 96:5710. [PubMed: 10318949]

72. Gilewski T, Ragupathi G, Bhuta S, Williams LJ, Musselli C, Zhang XF, Bornmann WG, Spassova M, Bencsath KP, Panageas KS, Chin J, Hudis CA, Norton L, Houghton AN, Livingston PO, Danishefsky SJ. Proc Natl Acad Sci U S A. 2001; 98:3270. [PubMed: 11248068]

73. Slovin SF, Ragupathi G, Fernandez C, Jefferson MP, Diani M, Wilton AS, Powell S, Spassova M, Reis C, Clausen H, Danishefsky S, Livingston P, Scher HI. Vaccine. 2005; 23:3114. [PubMed: 15837210]

74. Slovin SF, Ragupathi G, Fernandez C, Diani M, Jefferson MP, Wilton A, Kelly WK, Morris M, Solit D, Clausen H, Livingston P, Scher HI. Cancer Immunol Immunother. 2007; 56:1921. [PubMed: 17619878]

75. Chen X, Zhang J, Kowal P, Liu Z, Andreana PR, Lu Y, Wang PG. J Am Chem Soc. 2001; 123:8866. [PubMed: 11535100]

76. Liu Z, Lu Y, Zhang J, Pardee K, Wang PG. Appl Environ Microbiol. 2003; 69:2110. [PubMed: 12676690]

77. Fang J, Li J, Chen X, Zhang Y, Wang J, Guo Z, Zhang W, Yu L, Brew K, Wang PG. J Am Chem Soc. 1998; 120:6635.

78. Shao J, Zhang J, Kowal P, Wang PG. Appl Environ Microbiol. 2002; 68:5634. [PubMed: 12406759]

79. Shao J, Zhang J, Kowal P, Lu Y, Wang PG. Biochem Biophys Res Commun. 2002; 295:1. [PubMed: 12083757]

80. Muthana MM, Qu J, Li Y, Zhang L, Yu H, Ding L, Malekan H, Chen X. Chem Commun. 2012; 48:2728.

81. Haverkamp J, van Halbeek H, Dorland L, Vliegenthart JF, Pfeil R, Schauer R. Eur J Biochem. 1982; 122:305. [PubMed: 7060578]

82. Soh CP, Donald AS, Feeney J, Morgan WT, Watkins WM. Glycoconj J. 1989; 6:319. [PubMed: 2535492]

83. Sabesan S, Paulson JC. J Am Chem Soc. 1986; 108:2068.

84. Zhang J, Kowal P, Fang J, Andreana P, Wang PG. Carbohydr Res. 2002; 337:969. [PubMed: 12039536]

85. Fang JW, Li J, Chen X, Zhang YN, Wang JQ, Guo ZM, Zhang W, Yu LB, Brew K, Wang PG. J Am Chem Soc. 1998; 120:6635. 


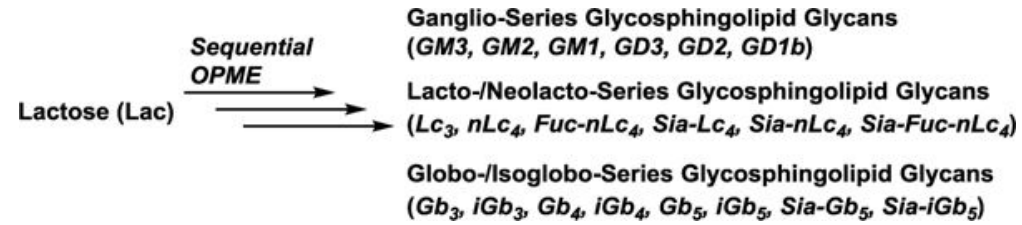

Scheme 1.

Sequential One-Pot Multienzyme (OPME) Synthesis of Ganglio-, Lacto-/Neolacto-, and Globo-/Isoglobo-Series Glycosphingolipid Glycans. 

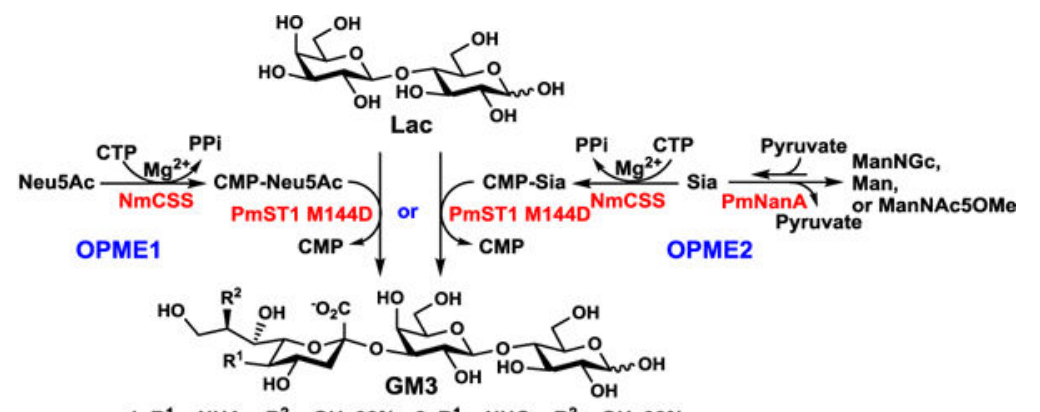

$1, R^{1}=$ NHAC, $R^{2}=\mathrm{OH}, 98 \% ; 2, R^{1}=\mathrm{NHG}, \mathrm{R}^{2}=\mathrm{OH}, 93 \%$; $3, R^{1}=\mathrm{OH}, \mathbf{R}^{2}=\mathrm{OH}, 95 \% ; \quad 4, \mathbf{R}^{1}=\mathrm{NHAC}, \mathrm{R}^{2}=\mathrm{OMe}, 91 \%$
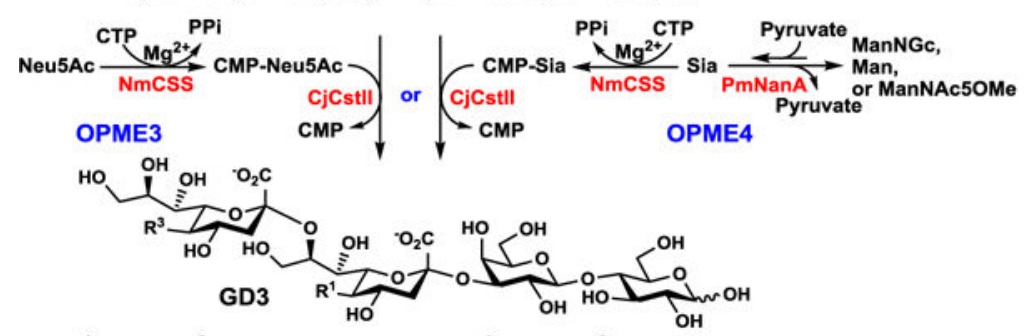

$5, R^{1}=$ NHAc, $R^{3}=$ NHAc, $85 \%$ (from 1); $6, R^{1}=$ NHAc, $R^{3}=$ NHGc, $84 \%$ (from 1); $7, R^{1}=$ NHAc, $R^{3}=O H, 83 \%$ (from 1); $8, R^{1}=N_{H G c} R^{3}=$ NHAc, $86 \%$ (from 2 ); 9, $\mathbf{R}^{1}=\mathrm{NHGc}, \mathbf{R}^{3}=\mathrm{NHGc}, \mathbf{8 3} \%$ (from 2); $10, \mathbf{R}^{1}=\mathrm{NHGc} \mathbf{R}^{3}=\mathrm{OH}, \mathbf{8 1} \%$ (from 2); $11, R^{1}=\mathrm{OH}, \mathrm{R}^{3}=\mathrm{NHAc}, 82 \%$ (from 3); $12, \mathrm{R}^{1}=\mathrm{OH}, \mathrm{R}^{3}=\mathrm{NHGc}, 78 \%$ (from 3 ); $13, R^{1}=O H, R^{3}=O H, 81 \%$ (from 3 )

Scheme 2.

Production of GM3 and GD3 Glycans Using OPME a2-3- and a2-8-Sialylation Systems. 


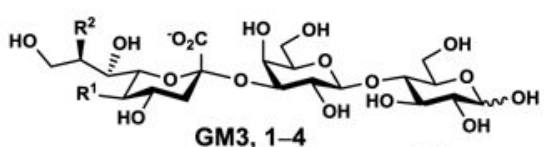

GM3, 1-4

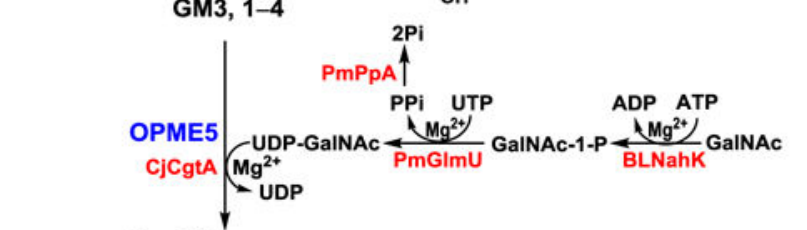

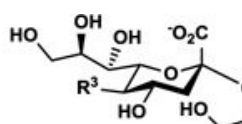

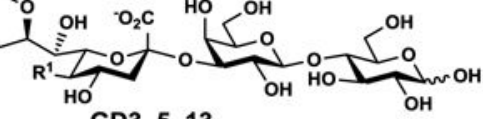

GD3, 5-13
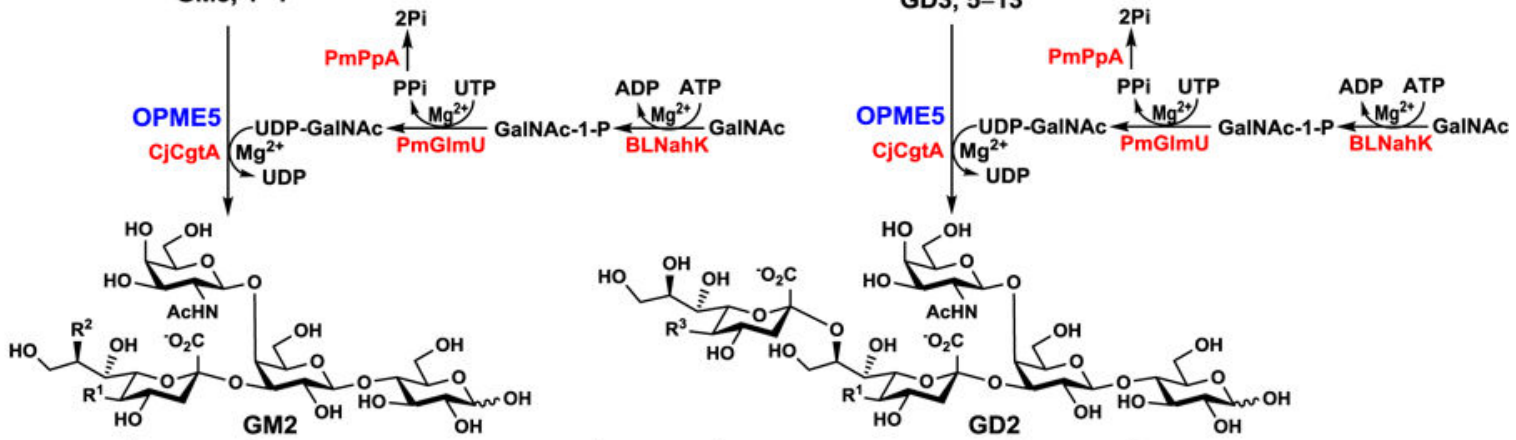

$14, R^{1}=$ NHAC, $R^{2}=$ OH, $99 \%$ (from 1) $15, R^{1}=$ NHGc, $R^{2}=\mathrm{OH}, 99 \%$ (from 2) $16, R^{1}=O H, R^{2}=O H, 99 \%$ (from 3)

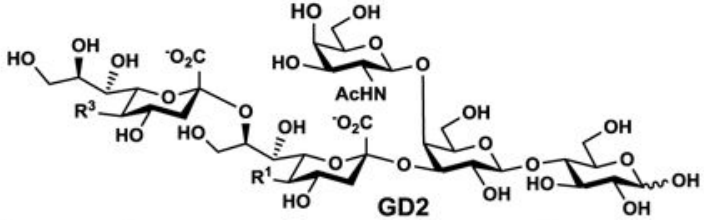

$17, R^{1}=$ NHAC, $R^{2}=$ OMe, $95 \%$ (from 4 )

$18, R^{1}=$ NHAc, $R^{3}=$ NHAc, $99 \%$ (from 5); $19, R^{1}=$ NHAc, $R^{3}=$ NHGc, $97 \%$ (from 6); $20, R^{1}=$ NHAc, $\mathbf{R}^{3}=\mathrm{OH}, 96 \%$ (from 7); $\quad 21, \mathbf{R}^{1}=\mathrm{NHGc}, \mathbf{R}^{3}=\mathrm{NHAc}, 98 \%$ (from 8 ); $24, R^{1}=\mathrm{OH}, \mathbf{R}^{3}=\mathrm{NHGc}, 90 \%$ (from 12); $25, \mathbf{R}^{1}=\mathrm{OH}, \mathbf{R}^{3}=\mathrm{OH}, 95 \%$ (from 13)

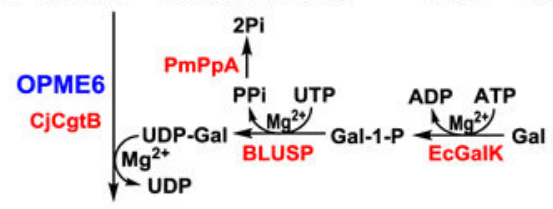

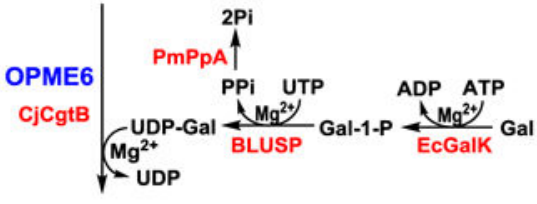

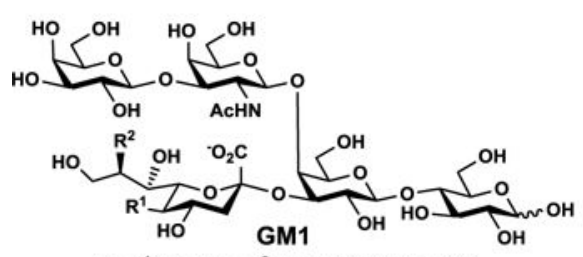

26, $R^{1}=$ NHAc, $R^{2}=\mathrm{OH}, 90 \%$ (from 14)

$27, R^{1}=$ NHGc, $R^{2}=O H, 86 \%$ (from 15)

$28, R^{1}=O H, R^{2}=O H, 87 \%$ (from 16)

$29, R^{1}=$ NHAc, $R^{2}=$ OMe, $80 \%$ (from 17)

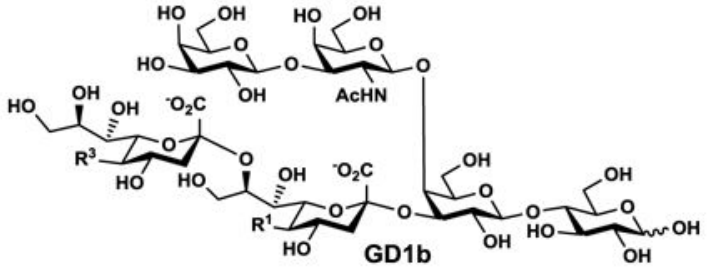

$30, R^{1}=$ NHAc, $\mathbf{R}^{3}=$ NHAc, $88 \%$ (from 18); $31, \mathbf{R}^{1}=$ NHAc, $\mathbf{R}^{3}=$ NHGc, $85 \%$ (from 19); $32, R^{1}=N H G c, R^{3}=N H G c, 86 \%$ (from 22); $33, R^{1}=N H G c, R^{3}=O H, 83 \%$ (from 23); $34, \mathbf{R}^{1}=\mathrm{OH}, \mathbf{R}^{3}=\mathrm{OH}, 85 \%$ (from 25)

Scheme 3.

Synthesis of GM2/GD2 and GM1/GD1b Glycans Containing Neu5Ac, Neu5Gc, Kdn, or Neu5Ac8OMe via One-Pot Multienzyme (OPME) GalNAc and Gal Transfer Systems, Respectively. 


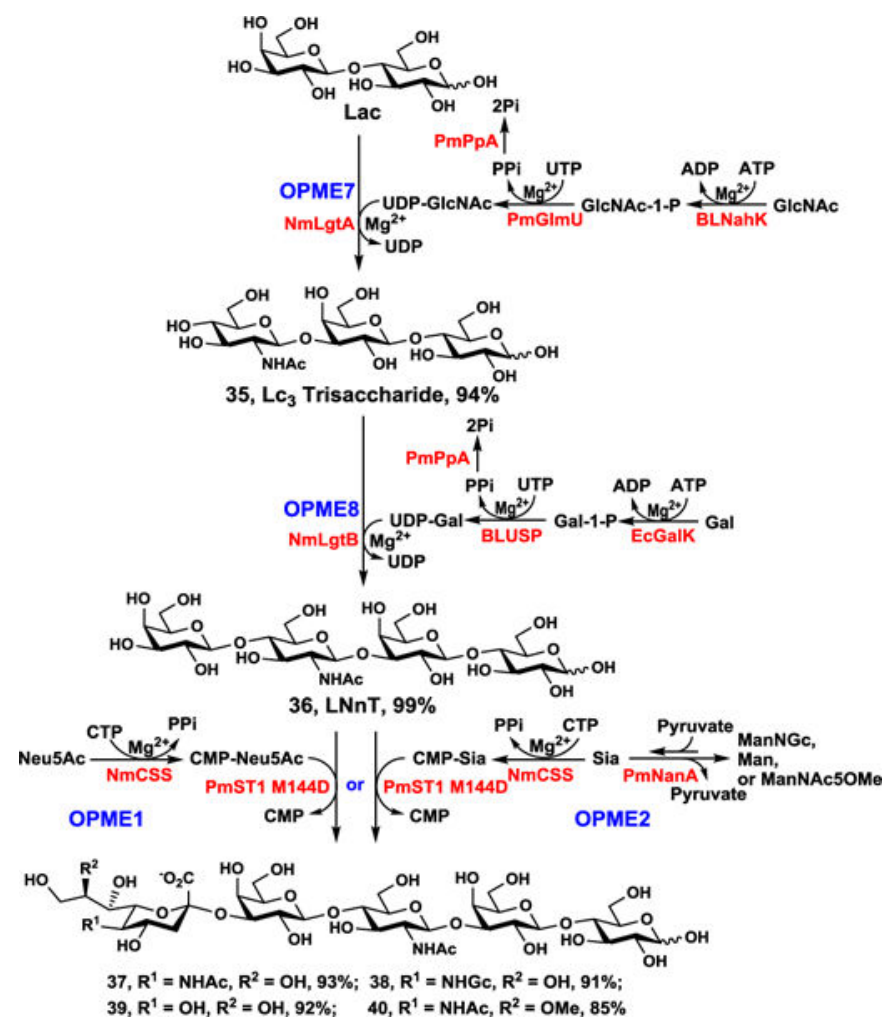

Scheme 4.

Synthesis of $\mathrm{Lc}_{3}$, LNnT, and Sialylated LNnT using OPME Glycosylation Systems. 


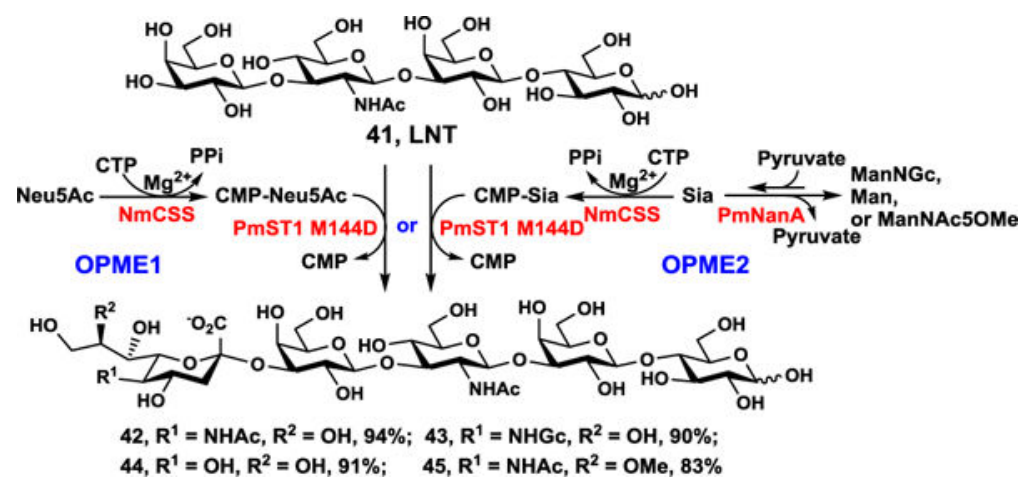

Scheme 5.

Synthesis of Sialylated LNT Using OPME Sialylation Systems. 

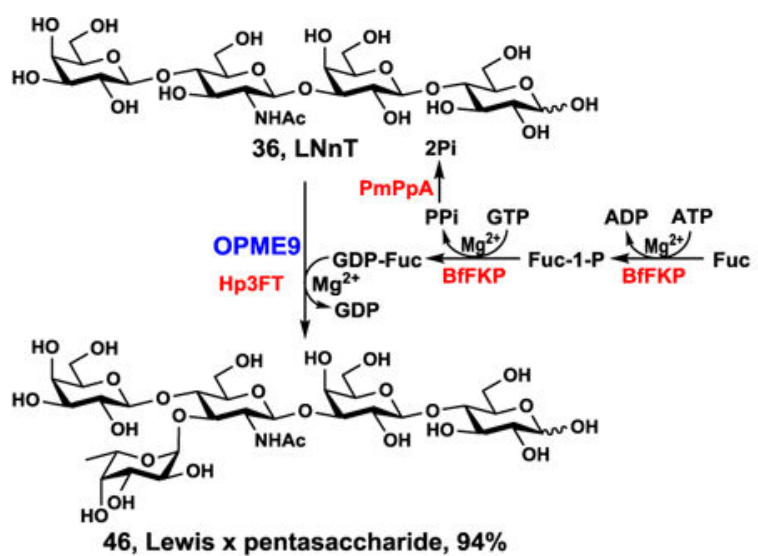

46, Lewis $x$ pentasaccharide, $94 \%$
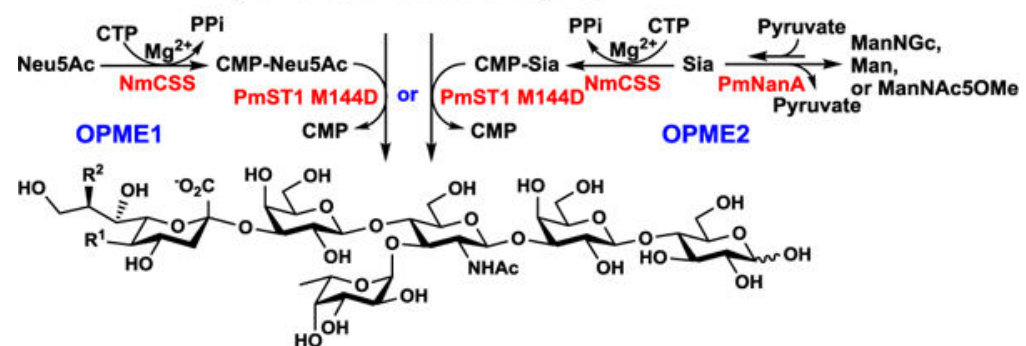

$47, R^{1}=$ NHAc, $R^{2}=$ OH, $86 \% ; 48, R^{1}=$ NHGc, $R^{2}=$ OH, $84 \%$;

$49, \mathbf{R}^{1}=\mathrm{OH}, \mathbf{R}^{2}=\mathrm{OH}, 83 \% ; \quad 50, \mathbf{R}^{1}=\mathrm{NHAC}, \mathrm{R}^{2}=\mathrm{OMe}, 80 \%$

Scheme 6.

Synthesis of Le ${ }^{\mathrm{x}}$ Pentasaccharide and Its Sialylated Forms using OPME Glycosylation Systems. 


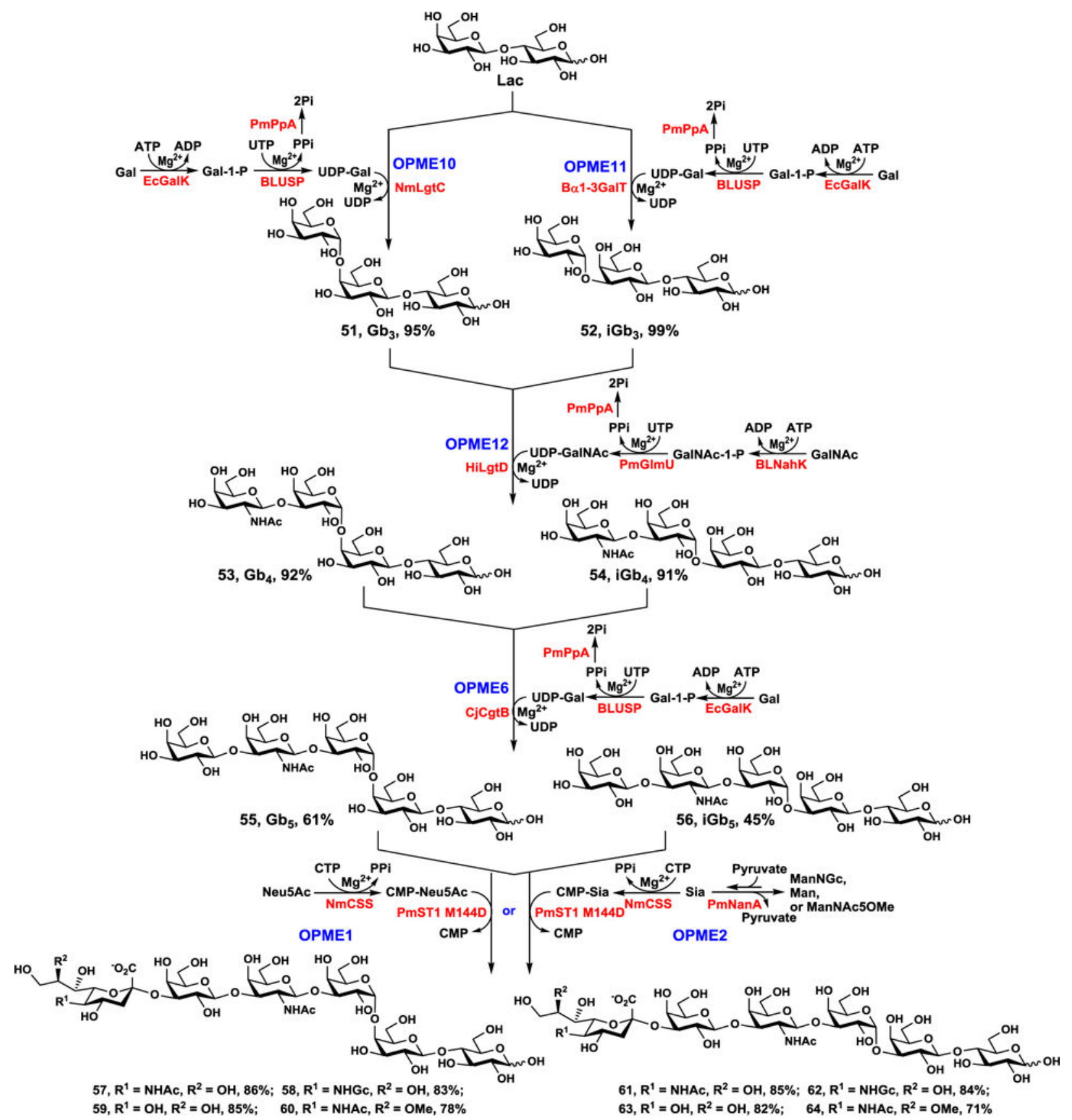

Scheme 7.

OPME Synthesis of Globo and Isoglobo-Series Glycans. 